\title{
Potential of Porous-Media Combustion Technology as Applied to Internal Combustion Engines
}

\author{
Miroslaw Weclas \\ Institute of Vehicle Technology (IFZN), Faculty of Mechanical Engineering, Georg Simon Ohm University of Applied Sciences \\ Nuremberg, Kesselrplatz 12, 90489 Nuremberg, Germany \\ Correspondence should be addressed to Miroslaw Weclas, miroslaw.weclas@ohm-hochschule.de
}

Received 7 April 2010; Revised 27 October 2010; Accepted 18 November 2010

Academic Editor: L. P. H. De Goey

Copyright (C) 2010 Miroslaw Weclas. This is an open access article distributed under the Creative Commons Attribution License, which permits unrestricted use, distribution, and reproduction in any medium, provided the original work is properly cited.

\begin{abstract}
The paper summarizes the knowledge concerning porous media combustion techniques as applied in engines. One of most important reasons of this review is to introduce this still not well known technology to researchers doing with internal combustion engine processes, thermal engines, reactor thermodynamics, combustion, and material science. The paper gives an overview of possible applications of a highly porous open cell structures to in-cylinder processes. This application means utilization of unique features of porous media for supporting engine processes, especially fuel distribution in space, vaporization, mixing with air, heat recuperation, ignition and combustion. There are three ways for applying porous medium technology to engines: support of individual processes, support of homogeneous combustion process (catalytic and non-catalytic) with temperature control, and utilization of the porous structure as a heat capacitor only. In the first type of application, the porous structure may be utilized for fuel vaporization and improved fuel distribution in space making the mixture more homogeneous in the combustion chamber. Extension of these processes to mixture formation and ignition inside a combustion reactor allows the realization of a homogeneous and a nearly zero emissions level combustion characterized by a homogeneous temperature field at reduced temperature level.
\end{abstract}

\section{Introduction}

Internal combustion (IC) engines have achieved a very high level of technical development characterized by high power density (engine power per swept volume), high torque, relatively high cycle efficiency (especially Diesel engines), and reduced exhaust emissions. Further requirements on engines complicate progressing development and systems optimization even more. These requirements concern not only acceptable (preferably high) power density and good dynamic properties, but especially significant reduction of fuel (energy) consumption related to $\mathrm{CO}_{2}$ emissions reduction and simultaneously virtual elimination of the toxic exhaust components (especially $\mathrm{NO}_{\mathrm{x}}$ and particles). Increased legal requirements explain the strong and costly efforts presently carried out in engine research.

The introduction of this paper provides a short summary of ongoing efforts to clean exhaust emissions of internal combustion engines. Two approaches can be taken toward this effort, one which allows the combustion to produce high emissions and then uses systems to clean the exhaust gases prior to passing them onto the environment. This method is presently being chosen by most developers advancing modern combustion engines. For example, a conventional engine may apply a complex exhaust after-treatment system to reduce or almost eliminate particular exhaust components (e.g., Diesel particle filter, lean catalytic converter for $\mathrm{NO}_{\mathrm{x}}$ reduction, oxidation catalyst for $\mathrm{HC}$ and $\mathrm{CO}$, as well as a three-way catalytic converter for gasoline engines operating on a stoichiometric mixture composition). Diesel Particle Filter (DPF) systems principally consist of a filter medium made of porous structure, regeneration strategy (arrangement and procedure), and a control and monitoring system. The type of solution used in a given DPF system significantly depends on vehicle application, for example, passenger cars, heavy-duty vehicles, and off-road application [1-15]. Beside filter medium and filtering efficiency, the regeneration strategy defines the practicability and applicability of DPF 
technology. Only structures rich in surface (large specific surface area of porous medium) and of high thermal stability are suitable as particle trapping materials. This leaves the choice between monolithic porous ceramic cell structures (wall flow) or foams, of highly alloyed porous sintered metals or metal foams and of filament structures-like fleeces, wound yarn or textile webbing (knitted or wicker work) of ceramic or metallic fibres. The pore size or fibre diameter crucial for separation is about $10 \mu \mathrm{m}$ or less. Please note that a typical pore size of the porous structures for application to inengine processes is on the order of 1 to $3 \mathrm{~mm}$ (or more), that is, a hundred times larger than the structures suitable for Diesel particle filters. With time, the particles fill up and clog the filter causing pressure increase in the exhaust system (backpressure). This backpressure reduces the fuel economy of the engine and inhibits engine performance, thus creating the necessity for filter regeneration (filter cleaning process). This regeneration poses the greatest challenge to particulate filters and requires either passively or actively (with additional energy supply) initiating combustion (burning up) of the accumulated soot. Soot normally ignites at around 500 to $650^{\circ} \mathrm{C}$, a temperature rarely achieved in Diesel exhaust gases (depending on the engine load). An active system of fuel regeneration uses burners, electrical heating, microwave systems, or throttling of the exhaust gas downstream of the filter to increase temperature and initiate soot combustion. These exhaust after-treatment systems, however, may require higher fuel consumption and thus increase $\mathrm{CO}_{2}$ emissions (by even more than 15\%). So, for future engine development, it is necessary to resolve this dilemma and to promote high engine-cycle efficiency and clean combustion process. One of the possible solutions could be supporting engine processes by the application of highly porous structures to inengine processes, especially to fuel distribution in space, fuel vaporization, mixture preparation, ignition and combustion, as well as in-cylinder heat recuperation. In this paper, the porous-medium combustion technology means application of highly porous open-cell 3D structures for supporting of these individual engine processes to improve engine-cycle efficiency and to perform clean combustion. Application of porous structures does not automatically guarantee the improvement of engine processes. The utilization of unique features of the porous structures for improving of individual engine processes is a subject of this paper. The paper gives an overview of different possible applications of a porousmedium technology to in-engine (mostly to in-cylinder) processes and indicates the potential of this technology for improving engine-cycle efficiency as reduction of combustion emissions.

Application to in-cylinder processes means the utilization of unique features of highly porous open-cell 3D structures (as described in the next section) to control and to improve individual engine processes performed inside the cylinder, especially fuel distribution in space, fuel vaporization, mixture formation, ignition, combustion process and heat recuperation. As shown in the paper, many of engine processes as supported by application of porous media (e.g., fuel injection in porous structure and vaporization) may perform quite different as it is observed in a free volume.
The goal of application of the porous-media combustion technology to internal combustion engine is to significantly improve individual engine processes to get a clean combustion process.

It must be indicated that the application of this technology to internal combustion engines (in-cylinder processes) is still not a usual way in engine application, but the great potential of this technology makes the technology more and more interesting and attractive for future engine development.

Characterizations of engine processes are presented in Section 2. Here, the combustion mode and different engine combustion processes are shortly described to give an indication what must be improved for achieving a clean engine in the future. Section 3 describes highly porous opencell 3D structures and lists the most important features of this technology. Particularly, a definition of porous-medium technology is given in Section 3.1, a description of different materials and structures available for engine application is presented in Section 3.2 and characterization of porous media for engine applications is described in Section 3.3. In the next section (Section 4), a short introduction to a stationary combustion process in porous reactors is given to outline the unique features of such a process resulting in a high-efficiency and almost-zero emissions level. Selection of in-engine processes to be supported by porous media for increasing of engine cycle efficiency and improving combustion quality is done in Section 5. Characteristic types of applications of porous-medium technology to engine processes are selected in Section 5.1. Especially, attention is paid to the following processes: fuel distribution (homogenization) in space (this mostly concerns interaction of Diesel or gasoline jets with porous structures), fuel vaporization and mixture formation (this mostly concerns liquid-fuel vaporization inside the porous structure volume, interphase heat transfer and mixing of different fluids in the PM reactor volume), catalytic supported ignition and combustion (this concerns porous structures with catalytic coating for controlling ignition conditions and combustion process) noncatalytic ignition and combustion processes (this utilizes the PM volume as a combustion chamber and requires a proper level of the solid-phase temperature and interphase heat transfer), and heat recuperation (the porous medium is considered as a heat capacitor and heat exchanger). A short overview of the most important concepts for fuel distribution and homogenization in space using porous structures is given in Section 5.2. An enumeration of the most important concepts for catalytic supported ignition and combustion is given in Section 5.3. The next section presents a short overview of the most important concepts for (noncatalytic) ignition and combustion in the porousstructure volume. Section 6 consists of a more detailed analysis of selected engine concepts with porous structures for in-cylinder processes, especially for a clean combustion process: Section 6.1. describes an intelligent engine concept (PM reactor for fuel distribution, vaporization, and chemical recombination); Section 6.2 presents liquid-fuel distribution and mixture homogenization by Diesel jet interaction with porous structures; Section 6.3 describes an engine concept 


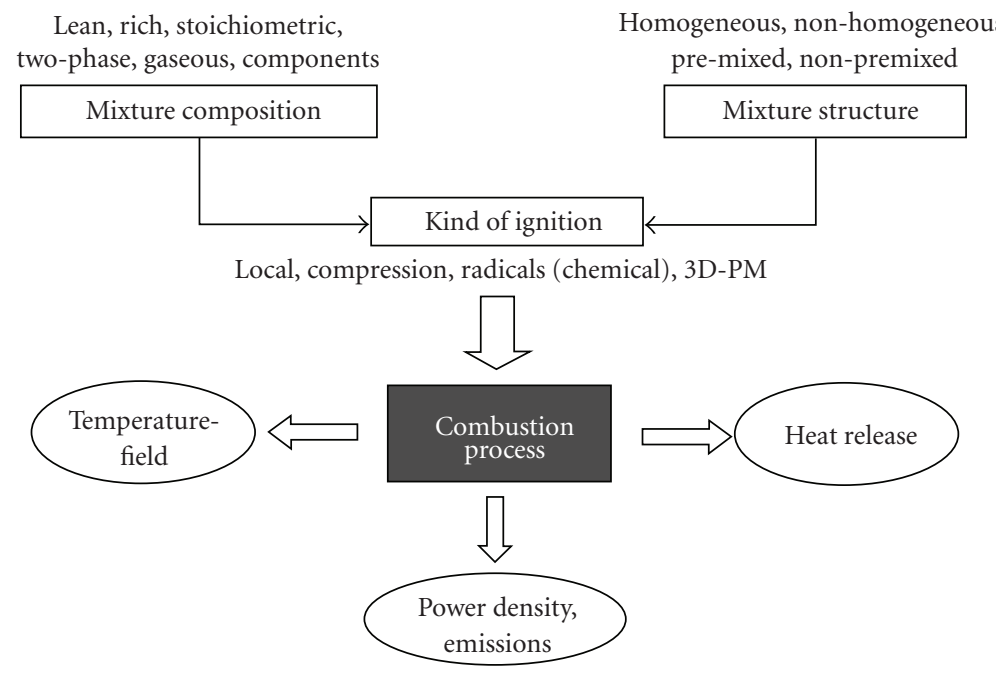

FIGURE 1: Definition of combustion mode in internal combustion engine.

with catalytic porous components (PM reactor with catalytic coating for heat recuperation, supporting of ignition, and combustion); an engine concept with mixture formation and combustion in the PM reactor is described in Section 6.4, and finally an engine cycle with heat recirculation in a porous structure is presented in Section 6.3. Summary, conclusions, final remarks, and outlook on the application of porousmedium combustion technology to in-engine processes are given in Section 7.

\section{Characterization of Engine Combustion Processes}

In order to better understand the great potential of clean combustion in porous reactors as applied to internal combustion engines, it is useful to make a short characterization of conventional combustion process in engines indicating a tradeoff between conditions for low exhaust emissions level (particular exhaust gas components) and for high cycle efficiency $\left(\mathrm{CO}_{2}\right.$ emissions). Finally, the goal would be to develop the engine combustion process allowing combination of both near-zero exhaust emissions level with the highest cycle efficiency. For this target, the combustion technology in porous reactors may open quite new possibilities for development of internal combustion engines, also if renewable and alternative fuels are considered. The engine combustion process is determined by the parameters of a combustible mixture: particularly by the air-to-fuel ratio (chemical mixture composition), homogeneity of the charge (homogeneity of distribution in space), and by the type of ignition. Mixture composition together, with mixture structure and the kind of ignition, defines the combustion process and may be defined as a combustion mode in the internal-combustion engine (Figure 1). The combustion process itself may be considered as a result following the combination of mixture properties (mixture structure and composition characterized by a fuelair ratio) and the ignition source. The resulting combustion mode (as combination of a given mixture with a particular ignition source) defines engine output power, exhaust emissions, combustion temperature field, and temperature level as well as heat-release rate. Current problems in the further development of direct-injection (DI) reciprocating engines are mostly related to the reduction of exhaust emissions (especially $\mathrm{NO}_{\mathrm{x}}, \mathrm{CO}, \mathrm{UHC}$, and soot) and to simultaneous reduction of engine fuel consumption $\left(\mathrm{CO}_{2}\right)$. In conventional engines, different combustion modes would be required for low fuel consumption (e.g., lean operation under part load conditions), maximum engine output power (nearly stoichiometric mixture composition), and homogeneous (possibly lean) mixture for low exhaust emissions with preferably volumetric ignition conditions (e.g., compression ignition). The tradeoff between conditions for low engine exhaust emissions and for reduced $\mathrm{CO}_{2}$ levels is a major limiting factor in engine development and is of different importance in different classes of engines, for example, direct-injection Diesel engine and gasoline direct-injection (GDI) engines. However, in both classes of engines, the main problem is a lack of mechanisms for controlling mixture formation (especially homogenization) and combustion processes under different operational conditions. Combustion control means that the location of ignition sources, heat release rate, temporal and spatial temperature distribution in the combustion chamber volume (i.e., gas temperature in conventional engines), as well as combustion emissions can be predicted and controlled. In order to influence the mixture formation conditions, two typical "controllers" are available in conventional engine combustion systems: "air flow" and "fuel supply" conditions. For air flow processes, three groups of parameters have to be considered: volumetric efficiency, which represents the mass of air supplied to the cylinder and pumping losses, flow structure in the cylinder which represents a macrostructure of the in-cylinder flow field (e.g., swirl, tumble, tipped), and turbulence level and its scales which represents a microstructure of the in-cylinder 
flow field. An intake valve timing and lift, geometry of the port/valve assembly, and valve location in the engine head significantly influence the flow properties of the intake system [16-21]. Especially attractive are throttle-free systems with variable valve timing and variable valve lift. Similar complexity in process optimization is observed in the case of "fuel supply" and spray formation conditions. Here, four main parameters are selected: injection characteristics expressed by instantaneous flow rate and by the volume of fuel injected per cycle (this depends on the injection system) including pilot injection, after injection, multiple injection, and so forth, spray microstructure and the spray penetration length to characterize conditions for air entrainment, fuel vaporisation, and mixing with air, injection timing, which is characterized by the start of injection and the duration of the injection process, and spatial distribution of fuel in the combustion chamber [22-26]. A typical example of different injection strategies depending on the operational mode is shown in a GDI engine. The spray geometry is different for late and for early injection modes according to the actual cylinder pressure conditions. These differences are utilized for charge stratification (light loads) or for charge homogenization (high loads) depending on operational conditions. In the case of a DI Diesel engine, a combination of a multihole nozzle with small nozzle-holes diameter and with a high injection pressure aids in controlling mixture formation and combustion processes under different operational conditions.

Two opposed operational conditions must be satisfied in the DI combustion system: high load at high engine rates (large volume of injected fuel and short time available for mixture formation and combustion) and part load at low engine rates (small volume of injected fuel and relatively long time available for mixture formation and combustion).

New concepts for future engine combustion systems must permit homogenization of the combustion process (not only homogenization of the mixture, according to the definition of combustion process as presented below) in a wide range of operational conditions (loads and speeds). These different conditions require different mixture compositions (mostly with respect to air-to-fuel ratio) characterized by different ignition conditions (e.g., ignitability). In order to attain a clean combustion process, the mixture should be homogeneous in space and gaseous in state. Necessary requirements for the development of future engines are: lowest possible specific fuel consumption, (near-) zero combustion emissions level by application of homogeneous combustion, combustion of homogeneous (nearly) stoichiometric charges (for high power density), combustion of homogeneous lean charges (for low specific fuel consumption), combustion of homogeneous ultra-lean charges (for low specific fuel consumption), engine operation over a wide range of loads and speeds, good dynamic properties (also transient properties), high power density, tolerance regarding fuel and its quality, high durability, and low cost.

A unique potential for solving the tradeoff between low exhaust emissions and low fuel consumption is the realization of a homogeneous combustion process in internal- combustion engines. It will be useful to define the conditions necessary for a homogeneous combustion process in engines. Homogeneous combustion may here be defined as a process in which a $3 \mathrm{D}$ ignition of a homogeneous charge is followed by simultaneous heat release (flameless) in the whole combustion chamber volume characterized by a homogenous temperature field. For future engines, it is required that such conditions be fulfilled over the wide range of engine loads and speeds. First of all, the combustion temperature, especially for close-to-stoichiometric charge compositions, must be reduced and controlled to realize near-zero $\mathrm{NO}_{\mathrm{x}}$ emissions. Another open question is inasmuch the homogeneous combustion system may under consideration operate over a wide range of engine loads, that is, may operate with homogeneous charges from very lean to nearly stoichiometric charge compositions. Additionally, a wide range of engine speed (time scale) must also be considered. In order to satisfy the conditions specified above, it is necessary to control ignition timing under variable operational conditions and to control the heat release rate for different mixture compositions. Additionally, for low combustion emissions, it is necessary that the liquid fuel be completely vaporized before ignition occurs. A great potential for realization of a homogeneous combustion process in engines lies in a porous-medium combustion technology, as described in this paper.

According to the definition given above, three steps of mixture formation and combustion may be selected that define the ability of a given system to operate as a homogeneous combustion system: homogenisation of cylinder charge, ignition conditions, and heat-release process with its temperature field (level).

A key factor defining the ability of the system to operate with a homogeneous combustion is the ignition process. Here, four different ignition strategies may be selected: local ignition (e.g., spark plug), thermal self-ignition (compression ignition), controlled autoignition (low-temperature chemical ignition using active radicals, also called radical combustion), and 3D thermal PM-self-ignition (3D grid structutre with high surface temperature). The mechanism of radical combustion (RC), in the literature also known as activated radical combustion (ARC) or active thermoatmosphere combustion (ATAC), has been explained as the condition that radicals in the residual gas (in a two-stroke engine) remain active until the end of the next compression stroke, due to calm scavenging as a result of scavenging throttling [27-33].

For a homogeneous combustion process (with as a key volumetric factor ignition) control of ignition timing and heat release rate under variable engine loads is critical. This is of special importance in HCCI (Homogeneous Charge Compression Ignition) systems being presently under wider investigation (e.g., see [34-40]).

Generally, the following aspects have to be considered for the further development of HCCI systems (in general for all homogeneous combustion systems) assuming a wide range of operational conditions: controlling ignition timing, controlling burn rate, extending the operational range to high engine loads, minimizing $\mathrm{HC}$ and $\mathrm{CO}$ emissions, $\mathrm{NO}_{\mathrm{x}}$ 


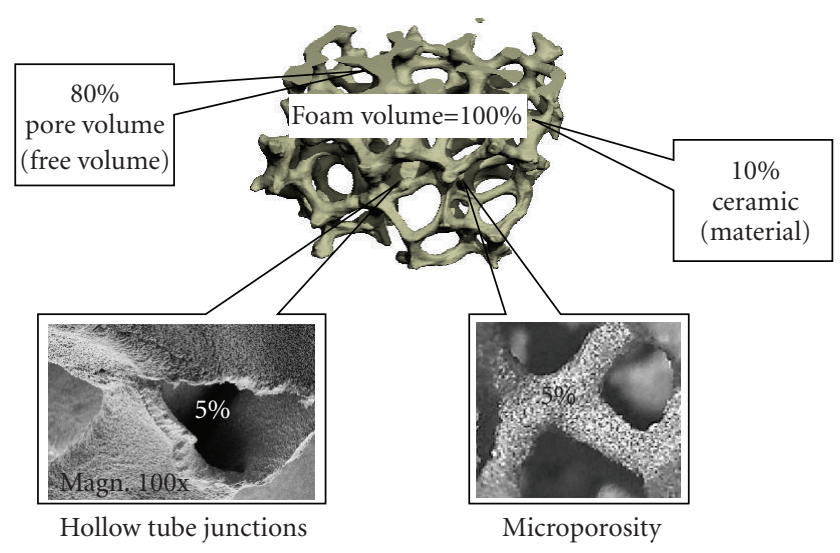

FIgURE 2: Volume distribution of highly porous media.

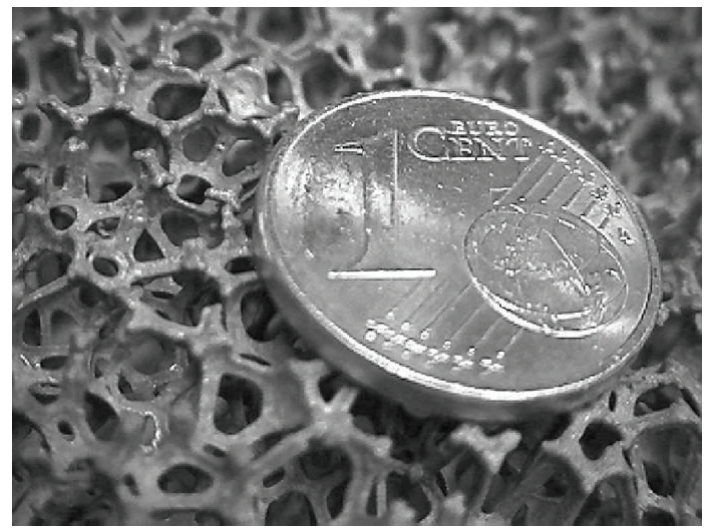

FIGURE 3: 10 ppi foam structure as compared to a one euro cent coin.

emissions at high loads, cold start conditions, and engine transient response.

One of the promising technologies to support engine processes for homogenization of the combustion process is porous-medium (PM) technology, especially as applied to the control of combustion process. In this case, a clean and flameless combustion with homogeneous temperature field in volume of porous reactor is possible. This can be a very promising alternative to ongoing research on HCCI systems.

\section{Porous-Medium (Combustion) Technology}

Combustion in porous reactors is a very complex process which is not quite understandable, yet. Such a process as performed in internal combustion engine is even more complex since the conditions, for example, for fuel supply are nonstationary, and the following processes are very time dependent. To better understand the nature and potential of combustion in porous reactors, a short introduction to stationary (premixed) combustion in porous structures is given in this chapter. For further analyses presented in this paper, it will be very useful to define "porous-medium combustion technology" by "porous-medium combustion technology".

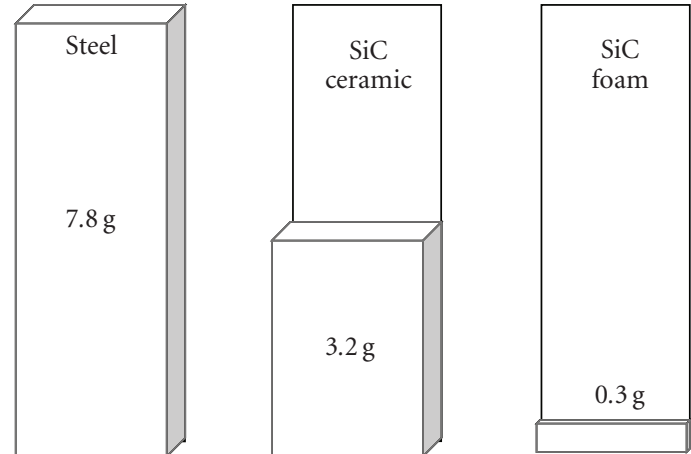

FIGURE 4: Density of ceramic foam as compared to the solid material.

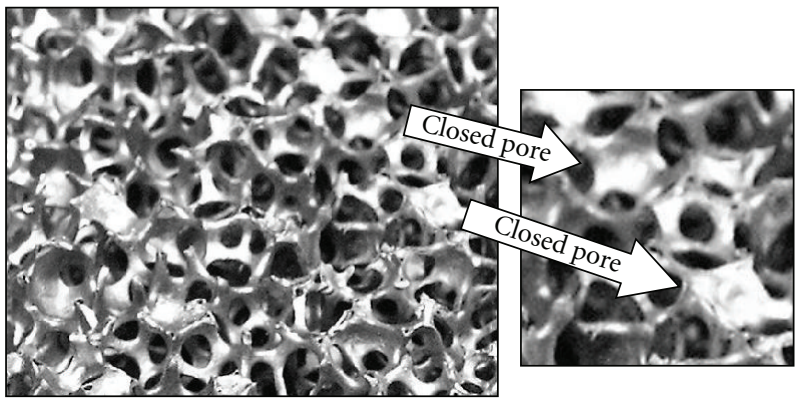

FIGURE 5: Structure ceramic foam with open and closed cells.

The author understands the utilization of unique features of highly porous open-cell 3D structures (as described in Sections 3.2 and 3.3) to control and to improve individual engine processes, especially fuel distribution in space, fuel vaporization, mixture formation, ignition, combustion process, and heat recuperation. These processes will be improved so as to reduce engine fuel consumption and to significantly reduce pollutants (exhaust) emissions. Potential of this technology as applied to a stationary combustion processes will be described in Section 4. It should be understood that not the presence of a porous structure itself but proper support of individual engine processes by a porous medium may be the key for better engines. In this section are defined the most important features of porous structures useful for supporting different processes performed in internalcombustion engines.

3.1. Definition of Highly Porous Media. A very unique component of combustion in porous reactors is a porous reactor. The features of the combustion reactor significantly influence the mixture formation and combustion process itself. From this point of view, it seems to be useful to give the reader a short introduction to porous structures and materials suitable for combustion process. This is not necessary a typical topic known in area of internal combustion engines. Porous structures considered in this paper are characterized by high porosity (approx $80 \%$ and more) and by opencell structure; for example, see foam structure in Figure 2. Important is that the pores exhibit open connections with 


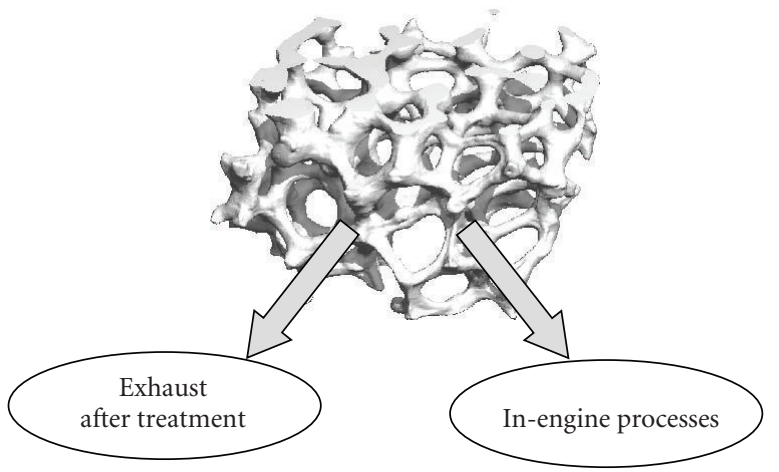

FIGURE 6: Characteristic types of porous structures application to internal combustion engines.

their surrounding pores. Especially for supporting engine processes important are pore volume (free volume) and the specific surface area of the solid structure for heat transfer, fuel distribution, and vaporization processes.

In order to better visualize highly porous metal foam with a pore density of $10 \mathrm{ppi}$ the pore sizes are compared to a one Euro-cent coin (Figure 3). The coin is approximately $10 \mathrm{~mm}$ in diameter and $1 \mathrm{~mm}$ in thickness. The typical pore size of foam structure considered for in-cylinder engine applications is on the order of 1 to $3 \mathrm{~mm}$ (or more). An additional feature of porous structures is much lower density compared with the solid material. An example of ceramic ( $\mathrm{SiC}$ ) foam density as compared to a solid material is shown in Figure 4. Proper utilization of highly porous structures for supporting engine processes requires that the cells of the porous structures be fully open, instead of closed pores, the latter being shown in Figure 5. The number of closed pores (a problem typical for high-density foam structures) increases with the decrease of mean pore diameter, that is, with increasing pore density, defined by the number of pores per linear inch (ppi). The closed cells may increase pressure loss, may block liquid fuel distribution in a porous-medium volume, and increase the mass (heat capacity) of the foam.

Of course, other materials than $\mathrm{SiC}$ are feasible but are not readily available for the high-temperature processes in internal combustion engines. It must clearly be noticed that there is still open questions which materials and structures are already suitable for application to real engine conditions. There is a complex of thermal and mechanical load conditions which a porous reactor must withstand under real engine conditions. This topic needs an intensive parallel development to the research on the individual engine processes to be supported in porous reactor. For a number of such development activities, a presently available materials and structures are already suitable, but the reactors for real engines are still under development. As a recent activity in this field a development of nonfoam $\mathrm{SiC}$ macrocellular three-dimensional structures could be reported indicating a great potential for future application to internal combustion engines [45]. Of course, this is absolutely necessary to look for and to develop new materials and structures for application to internal combustion engines. This development, however, should be performed in a close cooperation with development of processes performed in porous reactors. From this point of view, the next chapter describes presently available materials and structures, at least suitable for performing of individual engine processes.

\subsection{Different Materials and Structures Available for Engine} Application. There are two main groups of different applications of porous materials and structures to internal combustion engines (Figure 6):

(i) porous structures applied to exhaust after-treatment systems for reduction of engine emissions, (outside the engine cylinder (combustion chamber),

(ii) porous structures applied to engine processes, especially inside the engine cylinder (combustion chamber) to support different individual processes as well as a complete combustion process. In the last case, heat recuperation in a material made of porous structures performs automatically, as the structure has contact with hot burned gases.

As already stressed, the present paper concerns possible applications of porous structures to in-engine (preferably in-cylinder) processes, especially for supporting the following processes: fuel vaporization, fuel distribution in space (combustion chamber), mixture formation (mixing) and charge homogenization, catalytically supported and thermal ignition as well as the combustion process itself, and heat recuperation in a PM reactor. The combustion process may partly be supported by the porous structure or may completely be performed in the porous reactor volume being homogeneous in nature.

From the point of view of the application of porousmedium technology to in-engine processes (e.g., fuel distribution and vaporization in the intake port) and incylinder processes (e.g., fuel distribution, vaporization, mixing, ignition, combustion, and heat recuperation), there are a number of requirements on structures and material properties. For example, considering foam structures, porous media may have a mean pore diameter of 1 to $3 \mathrm{~mm}$. In the case of nonfoam structures, characteristic dimensions may be many millimetres to centimetres. Examples of 3D porous structures available are presented in Figure 7. Beside foam structures made of different (mostly high temperature ceramic) materials it is possible to create a $3 \mathrm{D}$ frame-like structure having large pores which may be homogeneous in space or may have different structures in different directions. Such structures may perfectly be adapted to the engine processes being supported by the porous structure. The side walls of a mixer structure in Figure 7(a) have small holes (opening) making necessary connections with surrounding pores possible). In the structure of Figure 7(c), the frames are distributed in space having all necessary features of highly porous open-cell structure. The cells of ceramic foam can be idealized as a pentagonal dodecahedron $[49,50]$. The edges of the dodecahedron are the struts of the ceramic foam. In the case of gas or liquid flowing through the foams, the flow is forced to separate and reattach at the struts, resulting in 


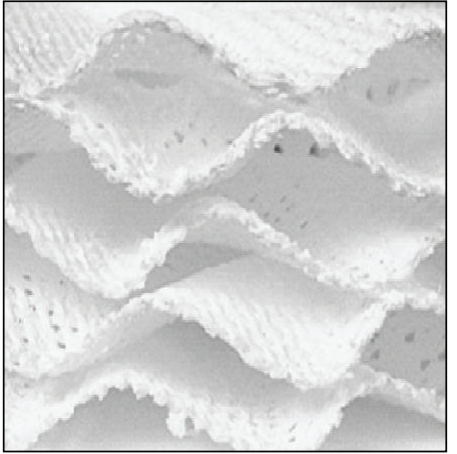

(a)

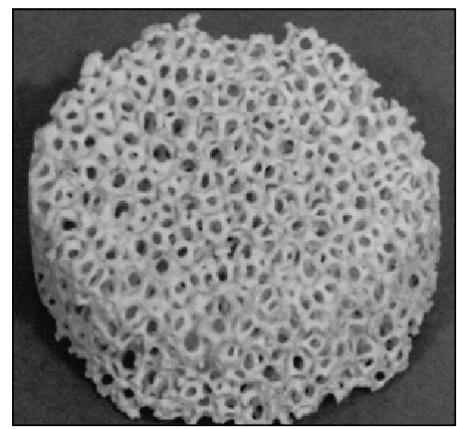

(d)

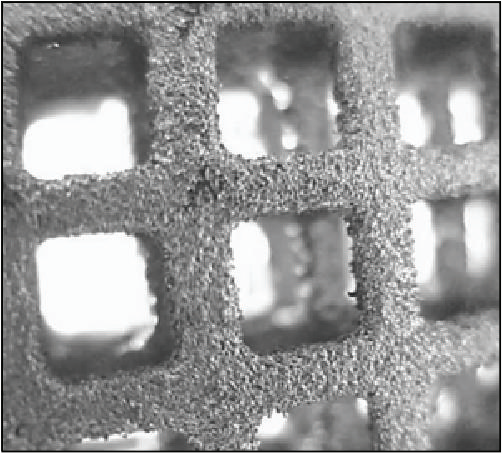

(b)

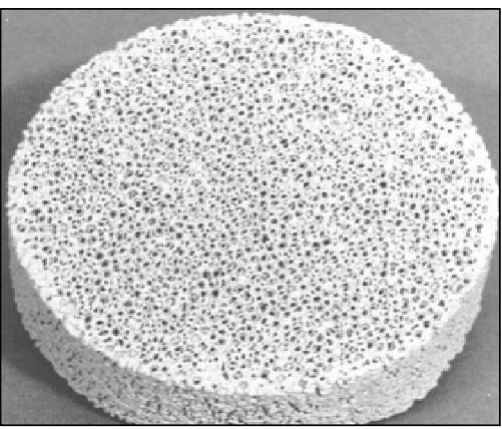

(e)

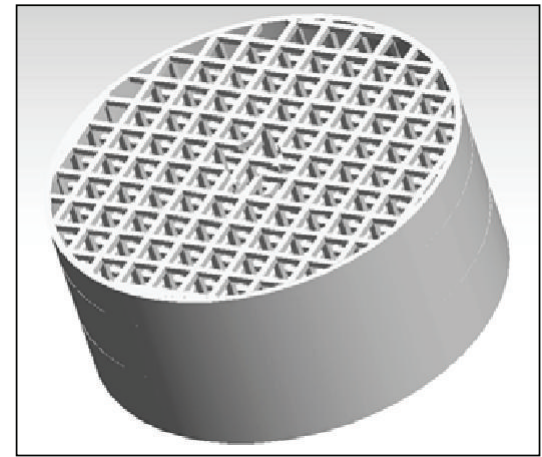

(c)

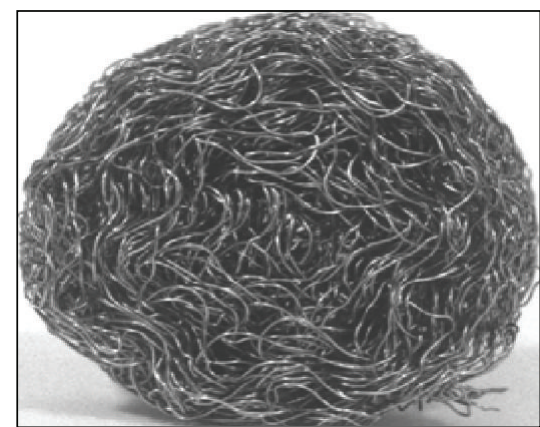

(f)

Figure 7: Examples of different 3D porous structures: (a) static mixer structure with small opening in surface $\left(\mathrm{Al}_{2} \mathrm{O}_{3}\right) ;(\mathrm{b}, \mathrm{c})$ frame structures ( $\mathrm{SiC})$; (d) low-density foam structure $\left(\mathrm{ZrO}_{2}, 10\right.$ ppi); (e) high-density foam structure $\left(\mathrm{ZrO}_{2}, 45 \mathrm{ppi}\right)$; (f) high-density wire packing.

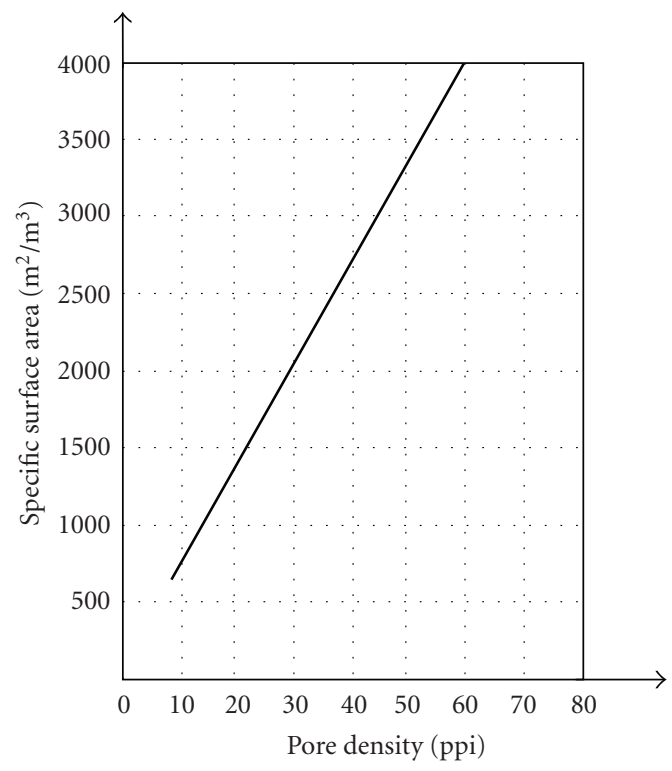

FIGURE 8: Specific surface area of foam structure as a function of pore density (ppi).

good mixing and strong interaction between flowing fluid and the PM material. A similar effect is expected if a highvelocity liquid jet (e.g., Diesel jet) penetrates throughout the PM volume [51-54] (see Section 6.2).

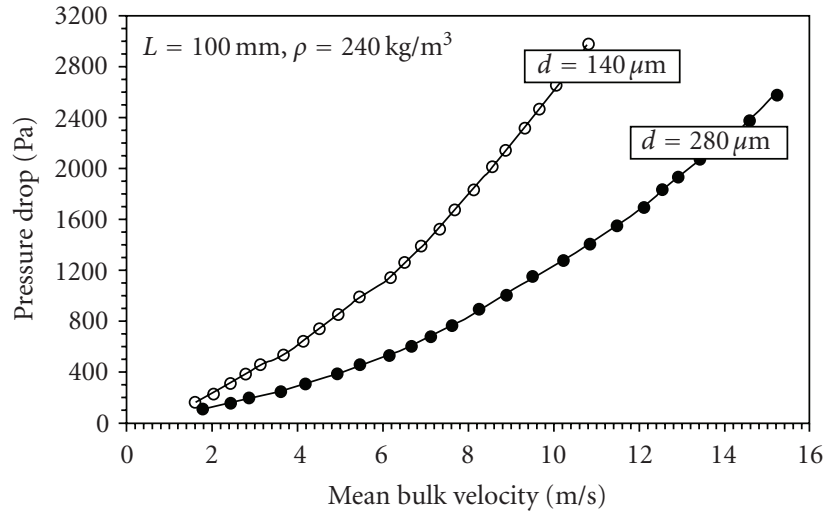

Figure 9: Pressure drop over wire packing as a function of mean bulk flow velocity for two wire diameters $d=140 \mu \mathrm{m}$ and $280 \mu \mathrm{m}$ (packing density $240 \mathrm{~kg} / \mathrm{m}^{3}$ ).

3.3. Characterization of Porous Media for Engine Applications. Generally, the most important parameters of PM structures as applied to engine processes, and especially to the combustion process, can be specified as follows: porosity, specific surface area, heat capacity, heat transport properties (optical thickness for radiation, emissivity, and conductivity), transparency for fluid flow and flame propagation, pore size, pore density, pore structure, thermal resistance, mechanical resistance and mechanical properties under heating-cooling conditions, PM material surface properties, and electrical properties (for electrical heating of PM structures). 


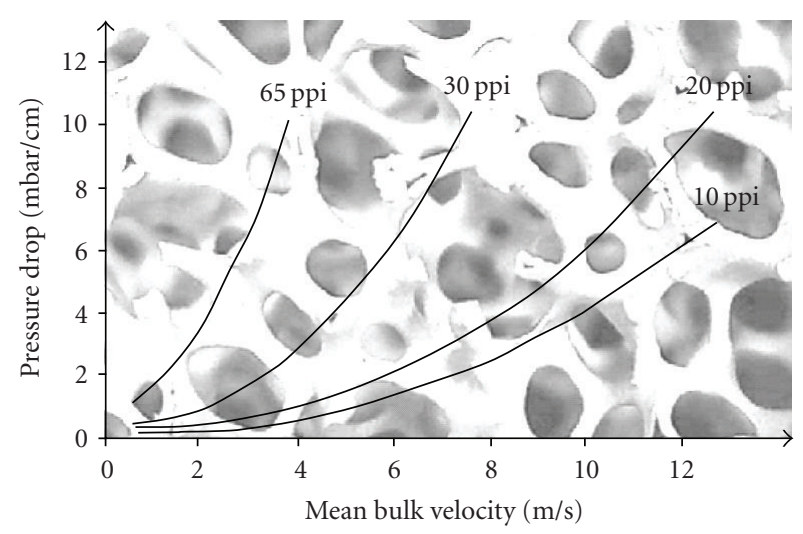

Figure 10: Pressure drop over ceramic foam structures for different pore densities.

Large Inner Surface Area. Owing to its large inner surface area, the porous structure permits very effective interphase heat transfer and liquid vaporization as well as the enlargement of the reaction (combustion) zone (Figure 8). Additionally, this large specific surface area SSA (on the order of $10^{2}-10^{4} \mathrm{~m}^{2} / \mathrm{m}^{3}$ ) recommends the medium to be applied as a vaporizer and heat exchanger. This inner surface area depends on pore density, its geometry, and the structure used for the manufacturing of PM. For example, for metal foam made from $\mathrm{Ni}-\mathrm{Cr}-\mathrm{Al}$, the specific surface area according to the mean pore diameter is: for $d=0.9 \mathrm{~mm}, \mathrm{SSA}=1700 \mathrm{~m}^{-1}$, for $d=1.4 \mathrm{~mm} 1000 \mathrm{~m}^{-1}$, and for $d=2.3 \mathrm{~mm}$ is SSA $=$ $500 \mathrm{~m}^{-1}[63]$.

A large specific surface area may be utilized for an excellent interphase heat transfer in PM volume, fuel (spray) distribution throughout the PM volume, and for very fast liquid vaporization in a PM volume. This is supported by excellent heat transfer properties, especially by strong heat radiation of the solid phase. Together with the high heat capacity and thermal resistance of the PM material, this kind of 3D structures may be used for realization of very clean and efficient combustion in a porous-medium volume. Depending on the application of a porous medium, a combination of thermal and mechanical properties of the materials, as well as their inner structure and pore size has to be chosen and optimized for the particular engine process. These requirements become especially critical if the porous medium is used directly for controlling the combustion process (PM reactor) under high-pressure conditions.

Large Heat Capacity. Owing to a large heat capacity of the solid phase compared with the heat capacity of the gas in the PM volume, it is possible that a part of the heat released during the combustion process may be "accumulated inside" the porous material, resulting in a high temperature of the solid-phase surface. The heat capacity of the porous reactor is on the order of hundreds to many thousands higher than the combustion-gas heat capacity trapped in the reactor volume. This could allow controlling the combustion temperature over a wide range of mixture compositions $\lambda$ (corresponding to the air-to-fuel ratio) and engine operational conditions [64-71].

Very Good Heat Transport Properties. Heat transport and heat transfer properties of PM are characterized by efficient heat conductivity and very effective heat radiation of the solid phase inside PM. These excellent heat transport properties allow combustion in porous medium at much higher heat-release (combustion) rates than for a free flame. Additionally, there is strong cooling of the reaction zone and as a consequence the thermal NO formation may significantly be reduced (lower-temperature combustion). The porous-medium structure and pore density influence volumetric heat transfer conditions. A strong heat radiation of a solid phase permits very effective heat transfer inside the porous structure resulting in a homogeneous temperature field throughout the reactor volume [72-84].

Transparency for Fluid Flow and Flame. Highly porous materials imply structures of porosity above approx. $80 \%$. Owing to this large porosity, the PM materials are transparent for gas and liquid flows as well as for flames. This transparency permits very low-pressure losses in fluid (gas) flow through the PM volume [85-91]. Example of pressure losses measured for wire packing is given in Figure 9, and for ceramic foams in Figure 10. The porous media in Figures 9 and 10 are characterized in different ways because of different structures to be considered (in Figure 9 wire packing is characterized by density and wire diameter; in Figure 10 foam structure is characterized by pore density ppi). Please note that pressure losses are individual for a given reactor, as they depend on porous-structure geometry, number and thickness of the pore junctions, number of closed pores, and homogeneity of the structure. The efficiency of the flow process through a porous structure may be described by the permeability of the porous medium employed. Permeability is regarded as a macroscopic measure of the ease with which a fluid (e.g., gas) driven by a pressure gradient flows through the voids of a porous structure. Thus, permeability reflects the effectiveness of the interaction between fluid and porous structure [92].

For the practical application of porous structures to the combustion process (stationary and nonstationary combustion systems) the reaction can be developed according to the Peclet number criterion. According to this criterion, combustion can only occur when the Peclet number based on the properties of the solid material and the gas is higher than 65 , using the following definition [93-98]:

$$
P e=\frac{S_{L} d_{p} c_{p} \rho_{g}}{\lambda_{g}}
$$

where $S_{L}$ is the laminar flame velocity, $d_{p}$ is the equivalent pore diameter (corresponding to the mean pore size in Figures 9 and 10), and $c_{p}, \rho_{g}$, and $\lambda_{g}$ are the specific heat, density, and heat conductivity of the gaseous mixture, respectively. This relationship indicates that the flame front can penetrate through the porous medium only when the heat release rate is higher than the rate of heat transport from 


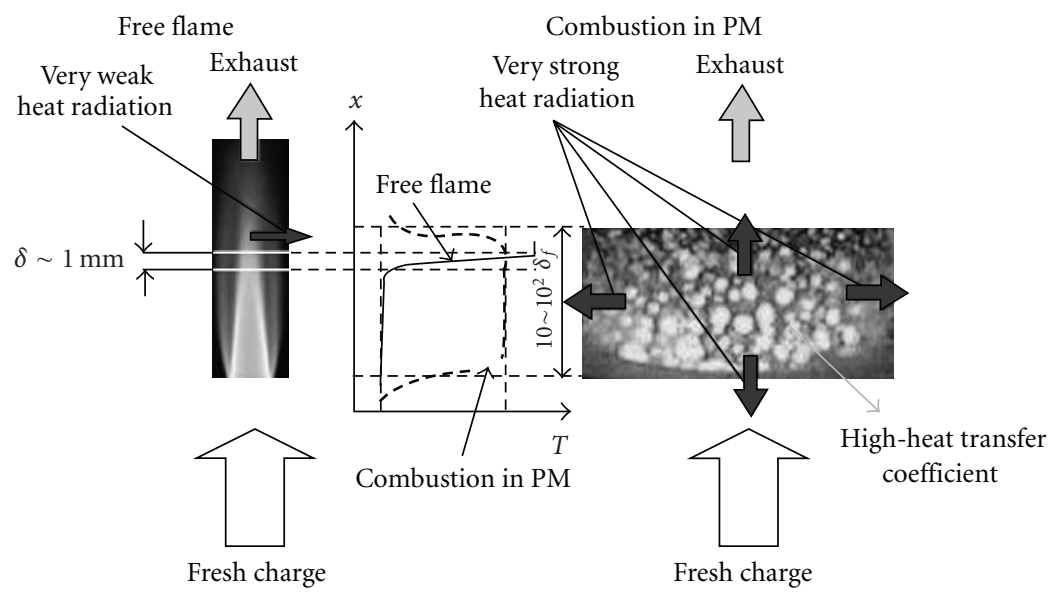

(a)
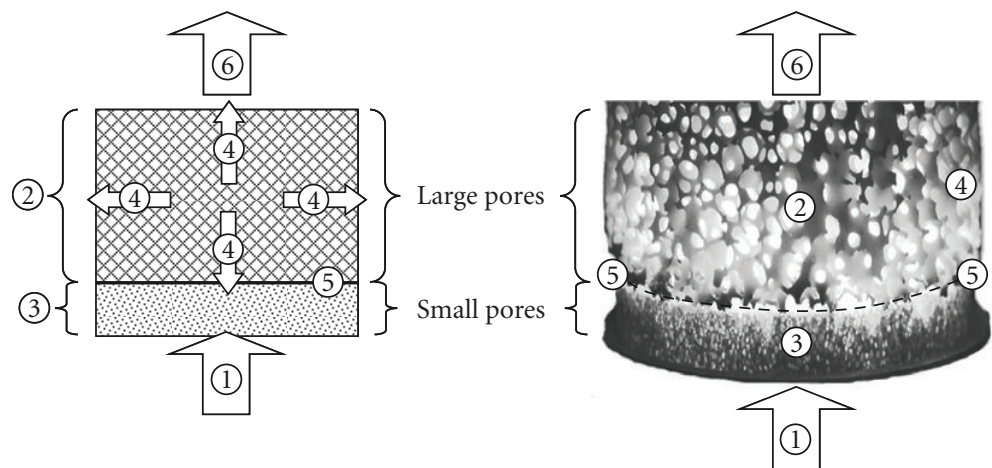

(b)

FIGURE 11: (a) Comparison of free flame combustion (left) and flameless combustion in porous reactor (right); (b) explanation of operation of porous reactor with flame stabilization using a pore size gradient: 1-fresh mixture; 2-combustion reactor; 3-flame stabilization zone (small pores); 4-heat radiation; 5 -flame stabilization plane; 6-exhaust gases.

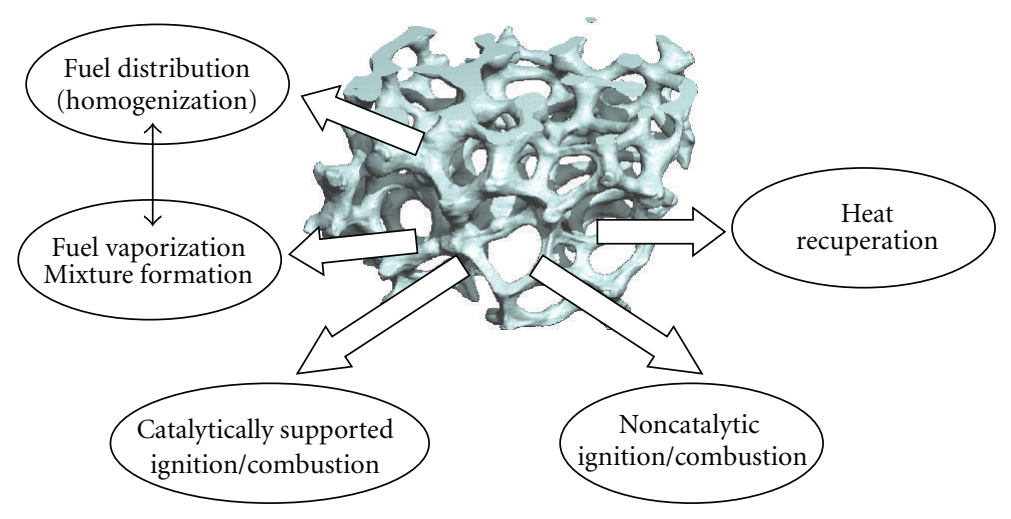

FIGURE 12: Characteristic application types of porous-medium combustion technology to in-cylinder engine processes (the arrows point in to direction of application fields in engines).

the gas mixture to the solid material of the porous structure. Practically, there is a critical pore size, necessary to permit the combustion process in PM volume. An important feature of combustion in a porous medium is that the heat released in the reaction zone can be transported by both the solid (radiation and conduction) and the gas (convection) phases.
Variable Pores Size, Pores Density, and Pores Structure. There are a number of available PM materials characterized by different pore sizes (pore densities) as well as pore shape and geometry. Foam structures of mean pore diameter of from 0.1 to $5 \mathrm{~mm}$ to mixer structures of a characteristic dimension of many centimetres are available (see also Figure 7). 
New development on macrocellular reactors and hightemperature wire structures offers quite variable size and pore structure quite dissimilar to foam structures $[45,99]$.

Thermal Resistance. One of the most important features of porous materials used in combustion technology are their high thermal resistance, thermoshock resistance, and high heat capacity. Thermal shock resistance is of special interest for high-temperature application, for example, for combustion processes in the engine. Thermal shock is related to changes in the temperature leading to thermal stress [100]. Usually, two different measures characterize the thermal shock properties of the porous structure: hard and soft thermal shock parameters [100]. The hard thermal shock parameter defines the maximum allowable temperature difference for a rapid superficial thermal shock. A real-case experiment could consists in placing a high-temperature porous structure (glowing at a high temperature, e.g., above $1000 \mathrm{~K})$ in a cold-water reservoir. The soft thermal shock parameter includes thermal conductivity and considers a long-term effect of temperature gradient in the porous structure. In a practical case, it would consist of a glowing reactor slowly cooling in the air at ambient temperature.

Mechanical Resistance and Mechanical Properties under Heating-Cooling Conditions. Mechanical stability and mechanical resistance for combustion applications under pressure are important especially under high-temperature operation conditions. The mechanical properties correspond to primarily elastic moduli (Young's modulus), Poisson's ratio, fracture toughness, tensile strength, compressive (crushing) strength, and thermal stress/shock resistance.

Different materials and structures have different mechanical properties in high-temperature operation with a typical tradeoff: the higher operating temperature, the lower mechanical stability [101-103].

PM Material Surface Properties. For porous structures it is necessary to define their macroporosity and microporosity in relation to their surface properties. This surface can also be catalytically coated or modified. To practically operate a porous-medium structure in engine, there are additional properties required, such as an electrical heating of the structure for cold start conditions.

Electrical Properties. A porous structure may directly or indirectly be electrically heated, resulting in a homogeneous temperature field throughout the PM volume [104, 105]. This feature could be utilized for cold-start conditions or for liquid-fuel vaporization. A similar effect may be achieved by indirect electrical heating, owing to very good heat transfer properties of the porous structure. Time-dependent temperature distribution in electrically heated structures depends on the electrical properties of the material, pore size and structure, as well as on the electrical contacts with the foam, assuming that a (nearly) homogeneous temperature field is achieved in the PM volume. The dielectric properties of a porous structure mainly depend on the porosity and type of ceramic material.

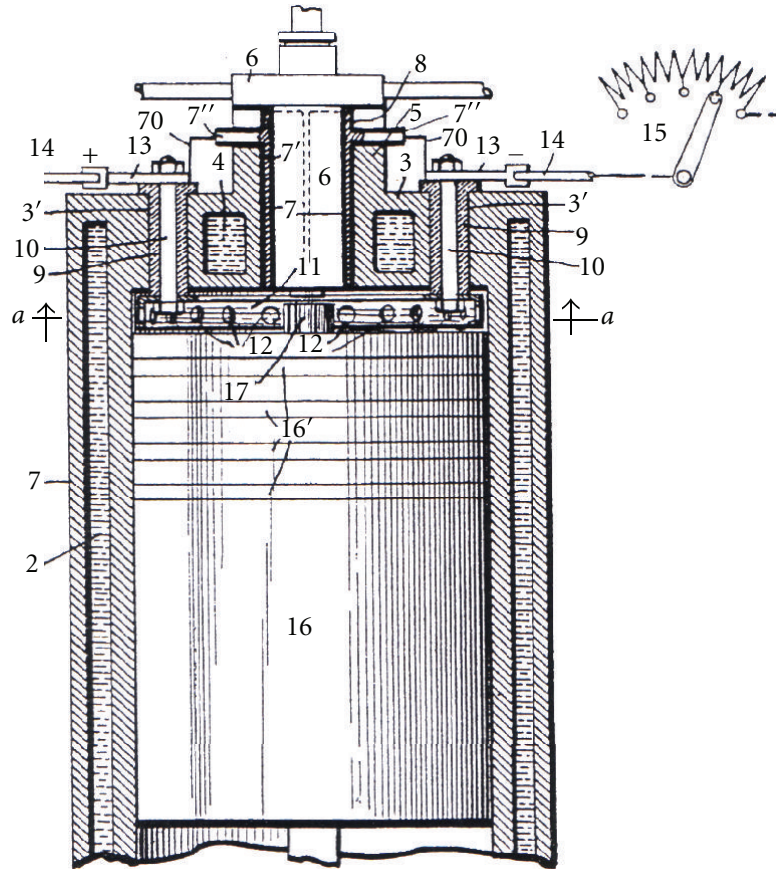

FIGURE 13: Engine concept with perforated plate (considered as a porous element) for better fuel distribution [41]: 1-cylinder; 2water-jacket; 3-engine head; 4-water-jacket; 5-collar; 6-fuel injector; 7,8-sleeve; 9-porcelain plugs; 10-stud bolts; 11-ring of a high temperature material; 12-apertures; 13-terminals; 14-conducting wires; 15-rheostat; 16-piston; 17-extending section; 70-branch wires.

The most important features of porous materials and structures for engine applications are summarized in Table 1. This table is given for fast reference to the various properties and features of porous structures as applied to internal combustion engines.

\section{Short Introduction to Stationary Combustion in Porous Reactors}

The demand for a new approach towards IC to improve the emissions performance of combustion engines suggests the possibility of applying the PM combustion technique, which has already been developed for steady state operations [93-98, 107-116]. To extend this work towards unsteady combustion applications, it is necessary to point out briefly the essential features of stationary combustion in a porous reactor and to underline the difference with respect to free flames (flame front combustion). This difference can readily be seen from Figure 11(a), showing free flame combustion and a highly porous $\mathrm{SiC}$ foam also under combusting conditions. The primary reaction zone in the left-hand picture in Figure 11(a), that is, the free flame, is limited to the thin, blue shining high-temperature zone, which cannot easily be extended owing to the problem of effective heat transport from the region of the reaction zone to the region upstream of the flame. The only means of increasing this heat transport in premixed combustion is to increase 
TABLE 1: The most important properties of porous materials for engine applications.

\begin{tabular}{|c|c|}
\hline Parameters & Range of values (required/expected) \\
\hline Specific surface area & Large: must be adapted to particular application for supporting individual processes \\
\hline Heat transport properties & $\begin{array}{l}\text { Excellent: especially important for PM engine concept with combustion in porous reactor in order } \\
\text { to permit homogeneity of combustion zone }\end{array}$ \\
\hline Heat capacity & $\begin{array}{l}\text { Large: must be adapted to particular application. In case of PM engine defines engine dynamic } \\
\text { properties and influences cycle thermodynamics. Also influences cold-start conditions }\end{array}$ \\
\hline $\begin{array}{l}\text { Permeability to flow and } \\
\text { flame propagation }\end{array}$ & $\begin{array}{l}\text { High porosity: For gas or liquid flow more than } 80 \% \text { porosity, preferably more than } 90 \% \text { porosity } \\
\text { with open pores (cells). Pore size influences different processes in PM volume. For example, an } \\
\text { optimum pore size for fuel distribution in space, for heat recuperation and for combustion process } \\
\text { is different }\end{array}$ \\
\hline $\begin{array}{l}\text { Pore size and size } \\
\text { distribution }\end{array}$ & $\begin{array}{l}\text { Typical foam pore density from } 8 \text { ppi to } 30 \text { ppi: for flame propagation under pressure see Pecklet } \\
\text { number criterion. Directly influences pressure losses, multijet splitting by injection, homogenization } \\
\text { in the volume. For nonfoam structures, for example, 3D-frame structure, the pore size and } \\
\text { distribution in space may be optimized for particular application }\end{array}$ \\
\hline Pore shape & Principally all available shapes are suitable: cells must be open and have radial connections \\
\hline Thermal shock resistance & $\begin{array}{l}\text { High: Especially for in-cylinder application and for PM engine concept. Depending on reactor } \\
\text { location and kind of assembly within engine components }\end{array}$ \\
\hline Corrosion resistance & High: especially in atmosphere of burned gases inside the engine cylinder \\
\hline Electrical properties & $\begin{array}{l}\text { For direct heating: high electrical resistance and homogeneous energy distribution (preferably } \\
\text { voltage } 12 \mathrm{~V} \text { and current } 10 \text { to } 80 \mathrm{~A} \text { ). Attainable temperatures up to } 1500 \mathrm{~K} \text {. Could be important for } \\
\text { cold-start conditions }\end{array}$ \\
\hline $\begin{array}{l}\text { Available maximum } \\
\text { temperature }\end{array}$ & $\begin{array}{l}\text { Depends on application: for example for combustion in PM reactor } T_{\max }<2000 \mathrm{~K} \text {; for vaporization } \\
\text { and mixture formation } T_{\max }<1500 \mathrm{~K} \text {; for two-stage combustion concept } T_{\max }<1800 \mathrm{~K}\end{array}$ \\
\hline $\begin{array}{l}\text { Porous medium } \\
\text { mechanical stability }\end{array}$ & $\begin{array}{l}\text { Important under high temperature and pressure conditions: very critical factor in case of ceramic } \\
\text { material mounted in piston top. Accelerations up to } 500 \text { times earth acceleration typical and large } \\
\text { temperature gradients usual }\end{array}$ \\
\hline $\begin{array}{l}\text { Porous medium fitting } \\
\text { within engine components }\end{array}$ & $\begin{array}{l}\text { Very critical: especially in case of ceramic materials. Possible gluing using high temperature ceramic } \\
\text { glues. Important also that porous reactor at one time cold and at another may be very hot. Metal } \\
\text { foams could be more useful if application temperature high enough }\end{array}$ \\
\hline Variable geometry & Important: for all engine applications (adapting to available space and shape) \\
\hline Long-time stability & Should be very high: as yet almost unknown area for engine applications \\
\hline
\end{tabular}

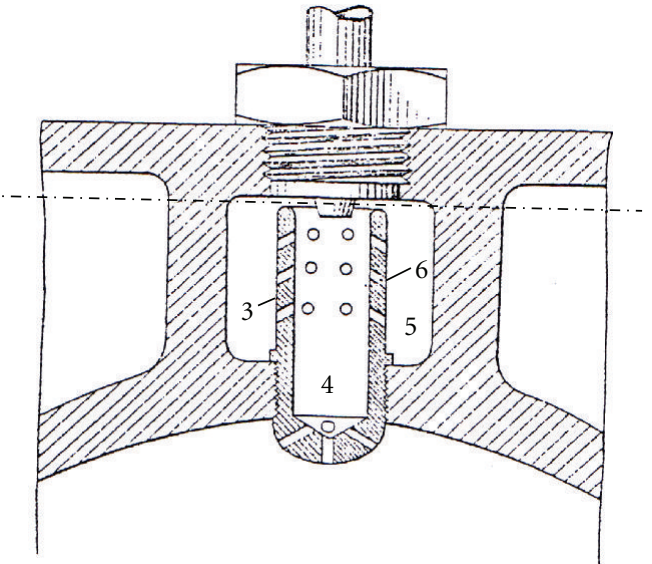

FIGURE 14: Engine concept with perforated cylindrical element (considered as a porous element) for better fuel distribution [42]: 3 -sleeve; 4,5-two parts of the explosion chamber; 6-apertures.

the turbulence level in the region of the free flame. Increasing the turbulence intensity and reducing the turbulence scale are, to some extent, the mechanisms that can be used to improve the performance of free flame combustion systems. However, experience shows that the improvements are minimal in comparison with the improvements needed for high reductions of exhaust gas emissions, especially with respect to combustion in an IC engine.

A different situation is observed in the case of combustion in porous media (see the right-hand side of Figure 11(a)), in which excellent heat transport properties (mostly by radiation) exist and a large heat capacity of the solid material permits the reaction zone to be extended over a large part of the volume of the porous material. In this way, combustion does not take place in the form of thin flames but is carried out over an extended region of the porous-medium volume (flameless). The process is flameless with respect to the reactor boundaries. This flameless process is also result of combination of homogeneous gaseous mixture with simultaneous ignition in porous-medium reactor volume (see definition of homogeneous combustion process). For the practical employment of PM combustion, the flame is stabilized in a well-defined manner according to the Pecklet number criterion (1) $[93,94,96]$. According to this criterion, combustion can only occur when the Pecklet number based on the properties of the solid material, and the gas is higher 


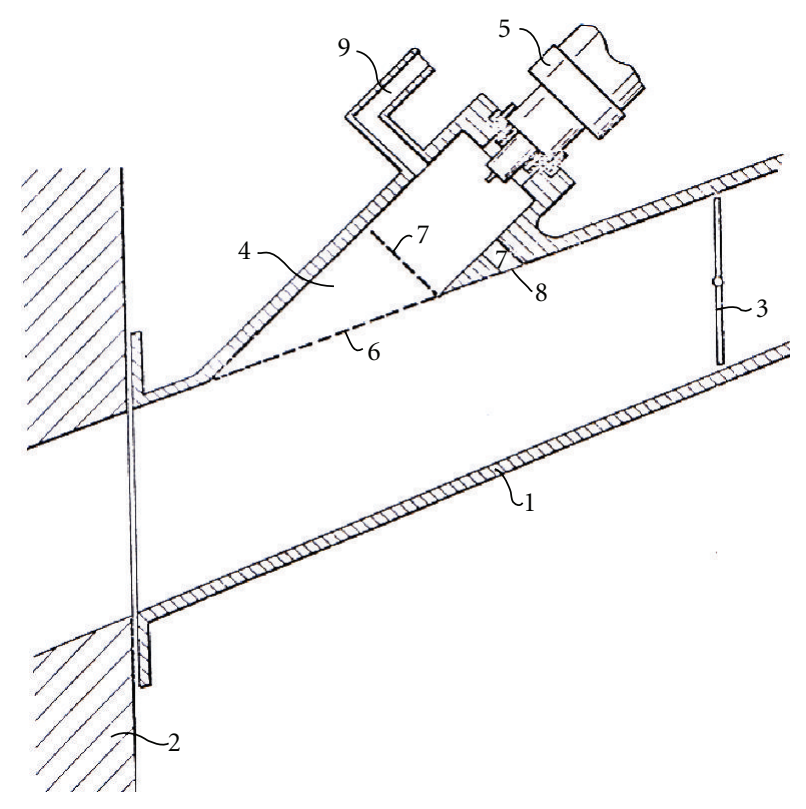

Figure 15: Device for fuel preparation in spark ignition engines with porous element for better fuel vaporization [43]: 1-intake pipe; 2-engine head; 3-throttle; 4-connector; 5-fuel injector; 6,7-sieve (mesh); 8-connecting channel; 9-additional air channel.

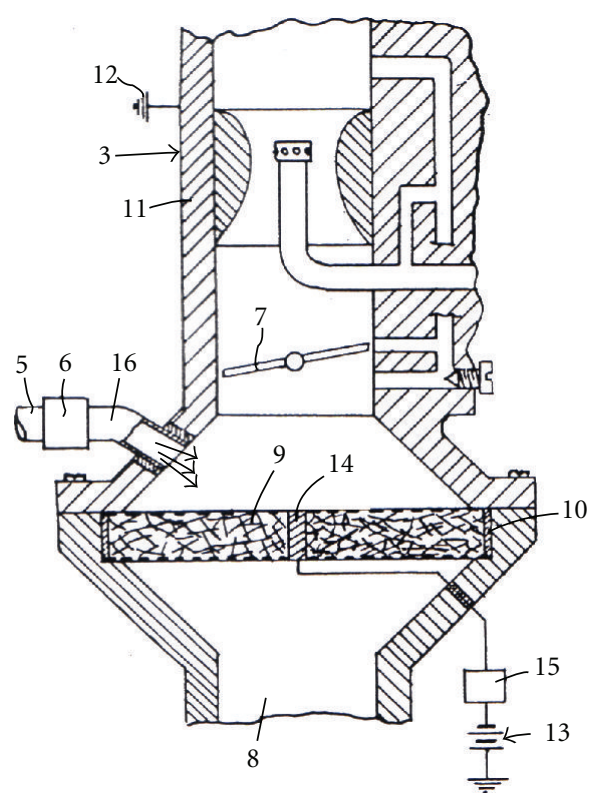

FIGURE 16: Device for fuel vaporization in engines with porous element [44]: 3-carburator; 5-exhaust gas recirculation pipe; 6-valve; 7-throttle; 8-intake pipe; 9-porous structure (heat exchanger); 10,11-housing.

than 65 . In a practical realization, it is possible to stabilize the reaction zone in a porous reactor volume by the application of a pore-size gradient (see Figure 11(b)). In the bottom porous medium having small pores (3), no combustion is possible, contrary to the gas flow and upstream heat transport. The combustion process is only possible in the upper reactor with large pores (2). The reaction zone will then be localized (flame stabilization) on the border of layers of different pore size (2) and (3) and extended along the reactor (2). An important feature of combustion in a PM reactor is that the heat released in the reaction zone can be transported by both the solid (radiation and conduction) and the gas (convection) phases (Figure 11(b)). Generally, the main features of the stationary flameless combustion in a porous-medium volume are: low-temperature combustion due to effective heat transfer to the solid material and due to its high heat capacity (reduced thermal NO), homogeneous temperature distribution in the reaction zone and, hence, controlled combustion conditions, very thick reaction zone (in the volume of porous reactors the thickness is many hundreds of times higher than the thickness of the free flame front), very fast combustion with a combustion velocity many times higher than for free flames, flameless reaction zone (on a macroscopic scale with respect to $\mathrm{PM}$ reactor surroundings), very stable and complete combustion and controlled combustion conditions, very low emissions level, high power density (approximately $40 \mathrm{MW} / \mathrm{m}^{3}$ ), high dynamic range of energy modulation (modulation between minimum and maximum thermal power on the order of 20 and more), wide range of air access ratios permitting stable combustion, low level of combustion noise due to controlled combustion, and mixture formation conditions practically independent of the spray microstructure (in the case of liquid fuels). The above features of combustion in porous media readily suggest that this combustion technique will be extensively used in the future in all fields where highly efficient combustion processes are needed and low emissions are required.

These unique features of stationary combustion in a porous-reactor volume render this combustion technique attractive in applications of nonstationary combustion in internal-combustion engines.

\section{Engine Processes to be Supported by Porous Media}

This section describes possible engine processes (especially in-cylinder processes) which could be supported and improved by application of porous media combustion technology. This section gives an overview of different concepts, and not necessary of all them have practically been proved. The intention of this overview is to present a wide spectrum of possible applications of porous structure for controlling of in-cylinder engine processes making this topic interesting to researchers searching for new and alternative solutions. Indeed, there is still a limited number of experimental data available, only concerning engine processes controlled in porous reactors. A great potential of this concepts, however, suggests necessity for spreading information on this technology and for intensifying research activities in this field. This is rather an "opening" of the field rather than summarizing of already "well-known" and "well-verified" knowledge.

5.1. Characteristic Types of Application. Characteristic applications of porous-medium combustion technology to inengine, especially to in-cylinder engine, processes may be classified in the following groups (Figure 12). 


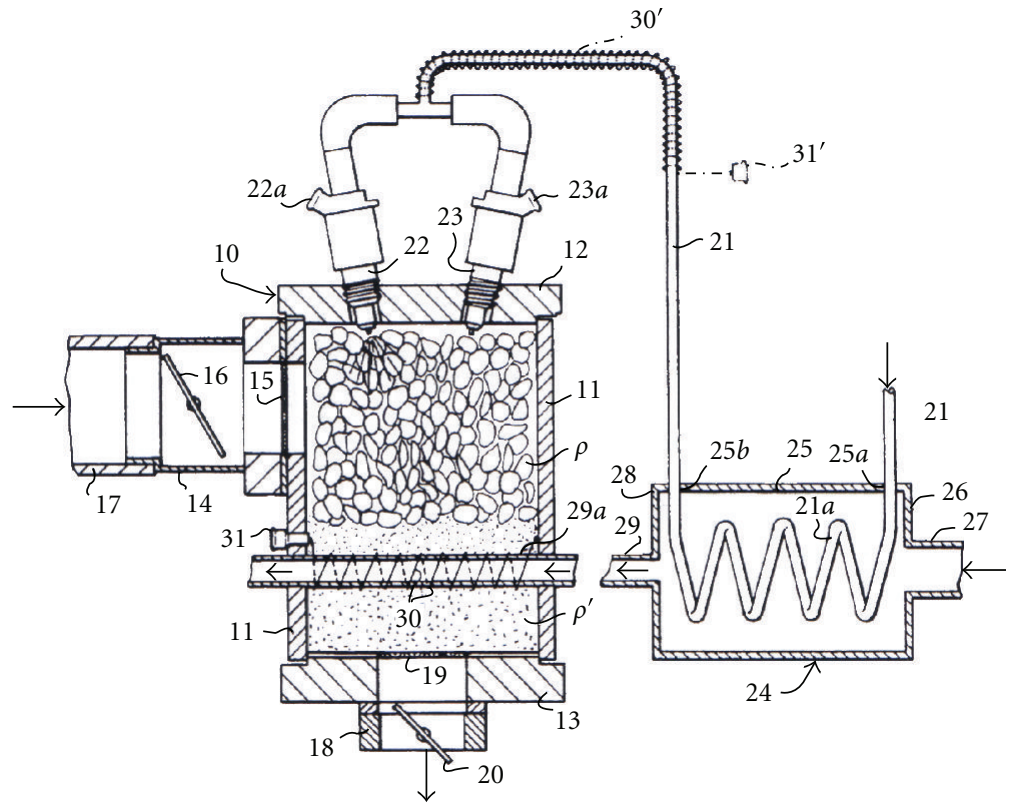

FIGURE 17: Carburettor for fuel vaporization in engines with porous element [46]: $\rho$-porous ceramic pieces; 10-carburetor; 11-housing; 12,13-closures; 14-air intake nipple; 15-filter screen; 16-throttle; 17-intake pipe; 18-outlet nipple; 19-outlet screen; 20-outlet throttle; 22,23fuel injectors; 24 -heat exchanger; 30-electrical heating coil.

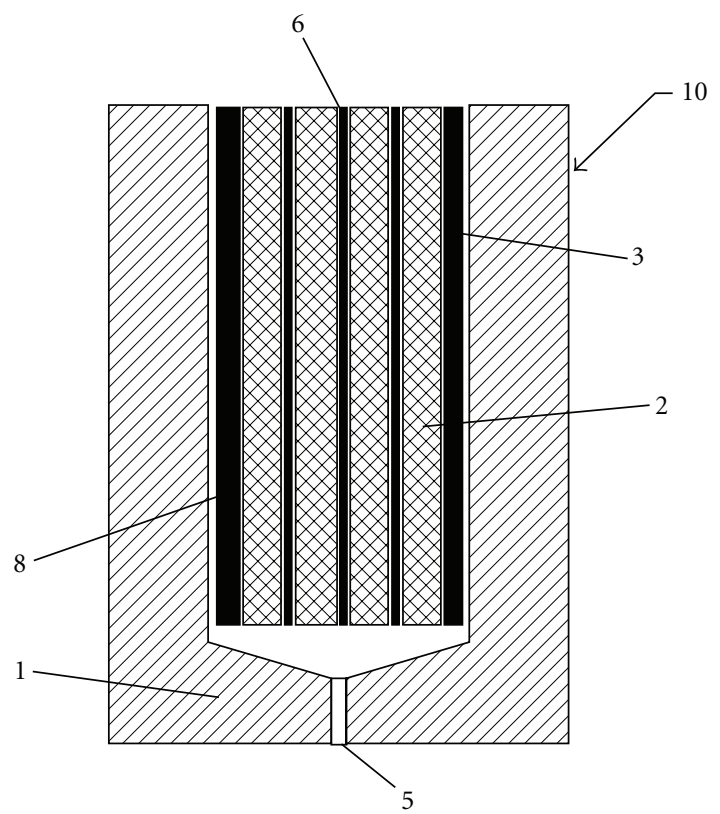

FIGURE 18: Fuel atomization device for engines with porous element [47]: 1-base; 2-heating element; 3-vaporizer contact baffles; 5-inlet orifice; 6-fuel outlet; 8-vaporizer chambers.

(1) Fuel distribution (homogenization): mostly concerns Diesel and Gasoline jets interaction with porous structures (wall junctions).
(2) Fuel vaporization and mixture formation: mostly concerns liquid fuel vaporization inside the porous structure volume, interphase heat transfer and mixing of different fluids in the PM reactor.

(3) Catalytically supported ignition and combustion: concerns porous structures with catalytic coating of surface for controlling the ignition conditions and (at least partly) the combustion process.

(4) Noncatalytic ignition and combustion processes: utilizes the PM volume as a combustion chamber and requires a proper level of the solid phase temperature and interphase heat transfer (utilization of reactor volume).

(5) Heat recuperation: PM is considered as a heat capacitor and heat exchanger only, without influencing other processes.

These characteristic application types include a number of different, individual engine processes to be influenced by a porous-medium structure. Mostly these individual processes perform drastically different inside the PM volume from those under free-volume conditions.

The following in-engine processes may be supported by porous-medium technology.

Heat recuperation in PM, fuel injection in PM, fuel vaporization in $\mathrm{PM}$, fuel distribution in $\mathrm{PM}$ volume, mixing in a PM volume, homogenization in space (PM volume), preignition reactions (chemical recombination of charge), 3D Ignition in a PM volume, homogeneous (flameless) 
TABLE 2: The most important parameters of porous reactor influencing processes in selected application groups as applied to internal combustion engines (see definition of application groups in text).

\begin{tabular}{|c|c|c|c|c|c|}
\hline Parameter & AG1 & AG2 & AG3 & AG4 & AG5 \\
\hline pore size & +++ & ++ & ++ & ++ & ++ \\
\hline pore structure & ++ & + & + & + & ++ \\
\hline thickness of PM reactor & +++ & ++ & ++ & ++ & + \\
\hline diameter of PM reactor & + & + & ++ & ++ & + \\
\hline porosity & + & + & + & + & + \\
\hline number of junctions in porous reactor & +++ & ++ & ++ & ++ & ++ \\
\hline gas/liquid flow velocity & +++ & +++ & ++ & +++ & +++ \\
\hline quality of pores & ++ & + & + & ++ & + \\
\hline spray angle and nozzle hole diameter & ++ & ++ & & ++ & \\
\hline injection pressure & ++ & + & & + & \\
\hline injection duration & + & + & & + & \\
\hline number of nozzle holes & +++ & ++ & & ++ & \\
\hline $\begin{array}{l}\text { reactor homogeneity and nozzle position } \\
\text { with respect to the reactor }\end{array}$ & +++ & +++ & & +++ & \\
\hline specific surface area & + & +++ & +++ & +++ & +++ \\
\hline heat capacity & & +++ & +++ & +++ & +++ \\
\hline $\mathrm{PM}$ reactor temperature & & +++ & +++ & +++ & +++ \\
\hline Time & ++ & +++ & +++ & +++ & +++ \\
\hline interphase heat transfer & & +++ & +++ & +++ & +++ \\
\hline microporosity of the surface & & ++ & +++ & ++ & + \\
\hline mixture composition $(\lambda)$ & + & ++ & +++ & +++ & + \\
\hline gas pressure & + & + & + & + & ++ \\
\hline
\end{tabular}

$\mathrm{AG}=$ application group according to definition in text; Maximum value $=+++$.

combustion with controlled combustion temperature, and heat recuperation in the solid phase of the porous reactor.

There are a number of concepts known in the literature (mostly in patent applications) of utilizing the PMtechnology for in-engine processes; however, not all of them support a controlled homogeneous combustion process directly. Most of them have not been practically verified yet. In the following analysis, a potential of these systems for improving in-cylinder engine processes will be discussed. For a better overview of systems applying porous-medium combustion technology to in-engine processes, it is useful to classify them according to the following characteristic application groups (AG) (see Table 2).

AG1: Liquid-fuel flow and distribution in a PM volume (homogenization of distribution)

AG2: Liquid-fuel vaporization and mixing in a PM volume (homogenization of charge).

AG3: Catalytically supported ignition and combustion.

AG4: Ignition and combustion in a PM volume (noncatalytic).

AG5: Heat recuperation in a PM reactor.
As shown in the table there is a number of different parameters of porous reactor influencing particular process in PM. Generally, the most important of them for different application groups are: pores size, pores structure, thickness of the porous reactor, diameter of the reactor, porosity, number of junctions in the porous structure, liquid or gas velocity, specific surface area, heat capacity, quality of pores (number of closed pores), spray angle and nozzle hole diameter, number of nozzle holes, reactor homogeneity and nozzle position with respect to the reactor, injection pressure and duration, interphase heat transfer, $\mathrm{PM}$ reactor temperature, microporosity of the surface, mixture composition $(\lambda)$ and time.

In the following subsection, the most important engine concepts with application of a porous structure for supporting in-engine, especially in-cylinder, processes will be presented and shortly described.

5.2. Short Overview of the Most Important Concepts for Fuel Distribution and Homogenization. There have been various attempts in the past to support engine processes by application of porous media (or similar structures) to internal combustion engines.

Historically, a very early engine concept with application of a perforated plate (considered as a porous element) had 


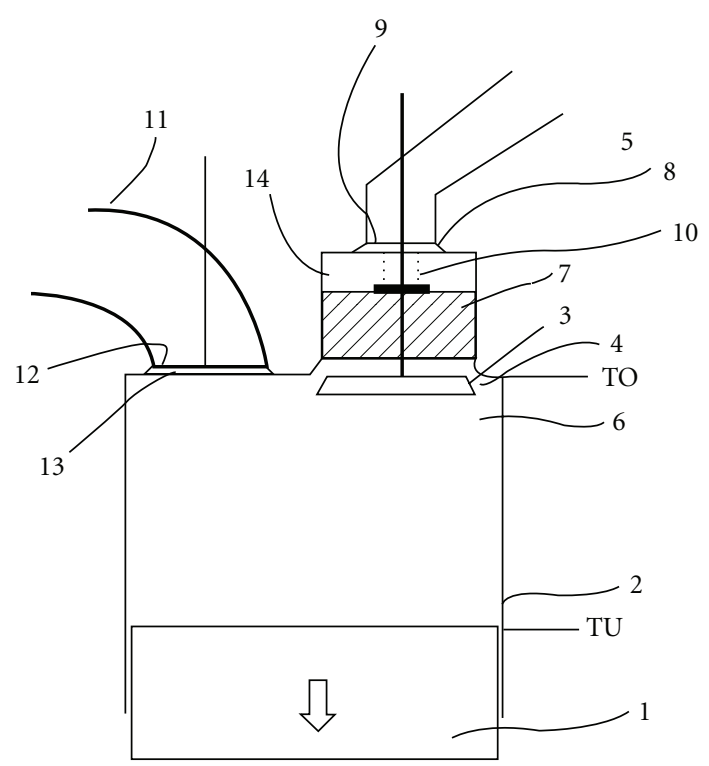

FIGURE 19: Method of mixture preparation in engines with porous element [48]: 1-piston; 2-cylinder; 3 -exhaust valve; 4 -valve seat; 5-exhaust port; 6-combustion chamber; 7-porous material; 8additional valve; 9 -valve seat; 10 -spring; 11 -inlet port; 12 -valve seat; 13-inlet valve; 14 -chamber with porous structure; TO- TDC; TUBDC.

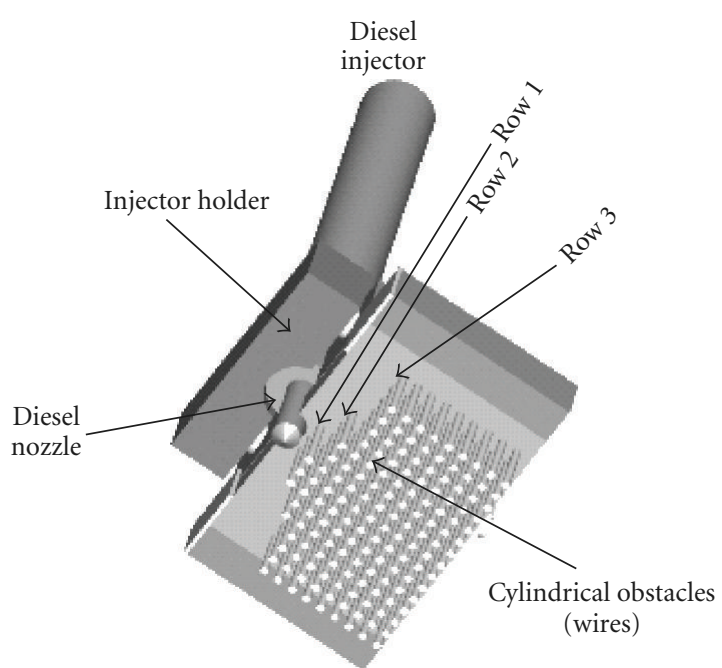

Figure 20: Method of liquid fuel distribution in combustion chamber with small obstacles (considered as a porous element) $[47,51]$.

been proposed by Lake and described in a US patent in 1918 [41]. This concept uses a ring (11), see Figure 13, made of a high-temperature material having radially oriented apertures. This invention concerns heavy-oil fuels and uses a perforated plate or wires to be electrically heated for improving ignition conditions. Additionally, it was assumed that the annulus plate or wire absorb enough energy from the combustion process, so that it might be used for preheating the fuel (charge) and for supporting the ignition process in the next engine cycle. This application does not apply a clear porous structure, but the annulus plate or wire play a similar

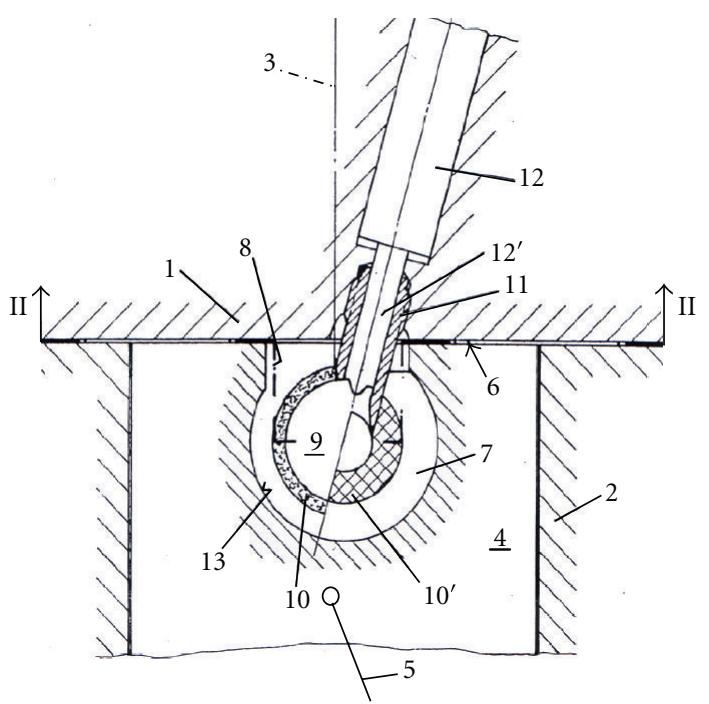

FIGURE 21: Internal-combustion engine with porous structure to promote mixture formation and combustion [55]: 1-engine head; 2-cylinder liner; 3-cylinder axis; 4-piston; 5-connecting rod; 6-main combustion chamber; 7-piston bowl; 8-bowl outlet; 9-chamber limited by porous matrix; 10,10' -porous matrix; 12 -injection nozzle.

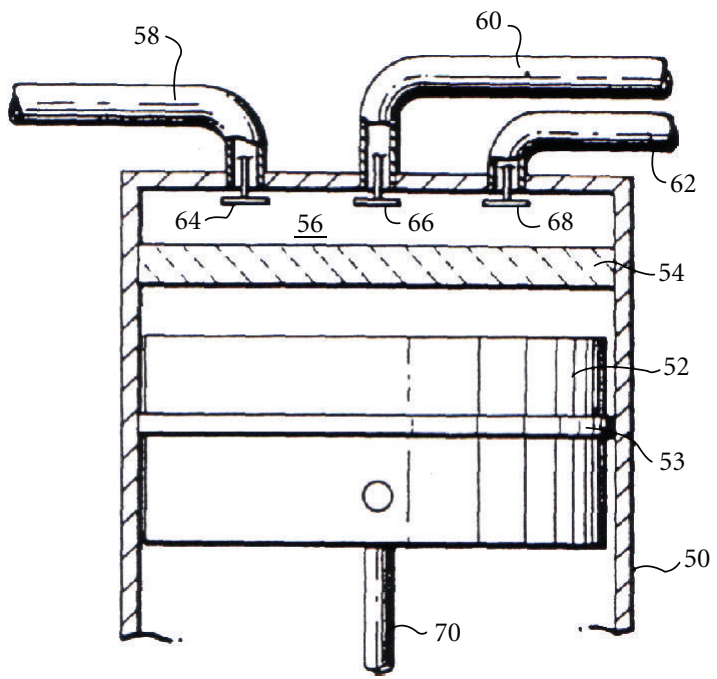

FIGURE 22: Internal-combustion engine with catalyst (porous structure) to promote combustion [56]: 52-piston; 53-piston ring; 54 -catalyst member (porous structure with catalytic coating); 56combustion zone; 58 -intake port (air); 60-fuel supply port; 62exhaust port; 64-intake valve; 66-fuel supply valve; 68 -exhaust valve; 70-piston rod.

role to that of a highly porous media. The problem of fuel trapped and deposits on the surface should be considered.

Another concept was proposed by Leissner as described in a US patent in 1918 [42]. It was an engine concept with a perforated cylindrical element (considered as a porous element) for better fuel distribution (Figure 14). The combustion chamber is permanently divided by a sleeve into two compartments: one inside and one outside the sleeve. 


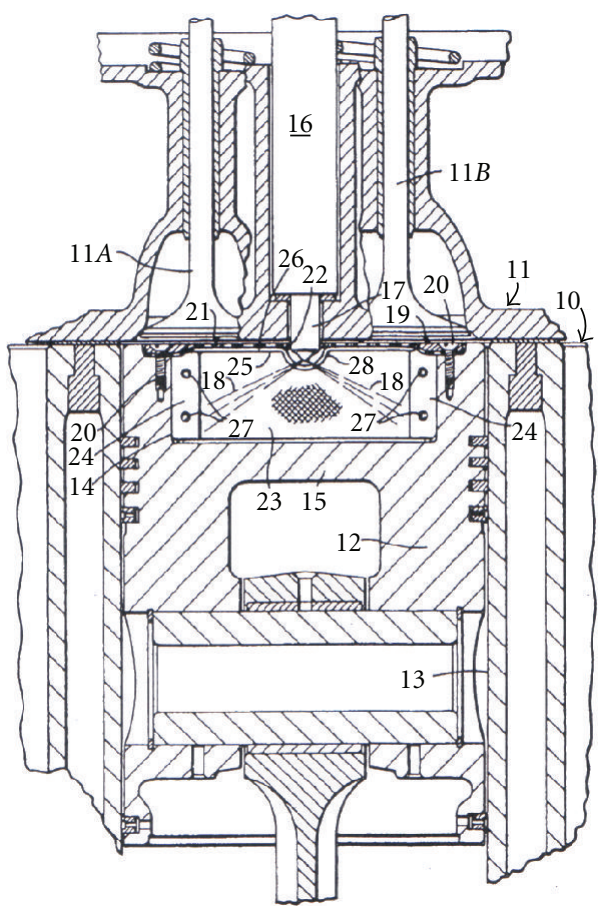

FIGURE 23: Internal-combustion engine with catalyst (porous structure) to promote combustion [57]: 11-cylinder head; 11A,11Bpoppet valves; 12-piston; 13-cylinder; 14-recess; 15-piston crown; 16-fuel injector; 17-nozzle; 18-fuel jets; 19-mounting ring; 20screws; 21-gauze disc; 22-hole; 23-vertical gauze sheet (catalytic); 24-liner; 25-edge; 26-wire; 27-screws; 28-cutaway.

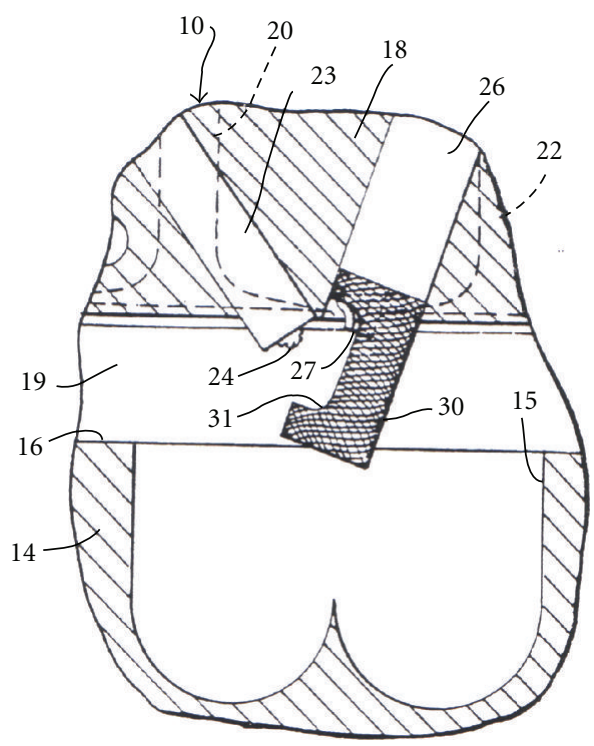

FIGURE 24: Catalytic late direct-injection spark-ignition engine with (catalyst as a porous structure) [58]: 10-catalytic late directinjection spark-ignition engine; 14-piston; 15-combustion chamber (piston bowl); 16-piston top; 18-cylinder head; 19-combustion chamber; 20 -inlet valve; 22 -exhaust valve; 23 -injection nozzle; 24 spray tip; 26-spark plug; 27-spark plug gap; 30-catalytic grid; 31opening in catalytic grid.

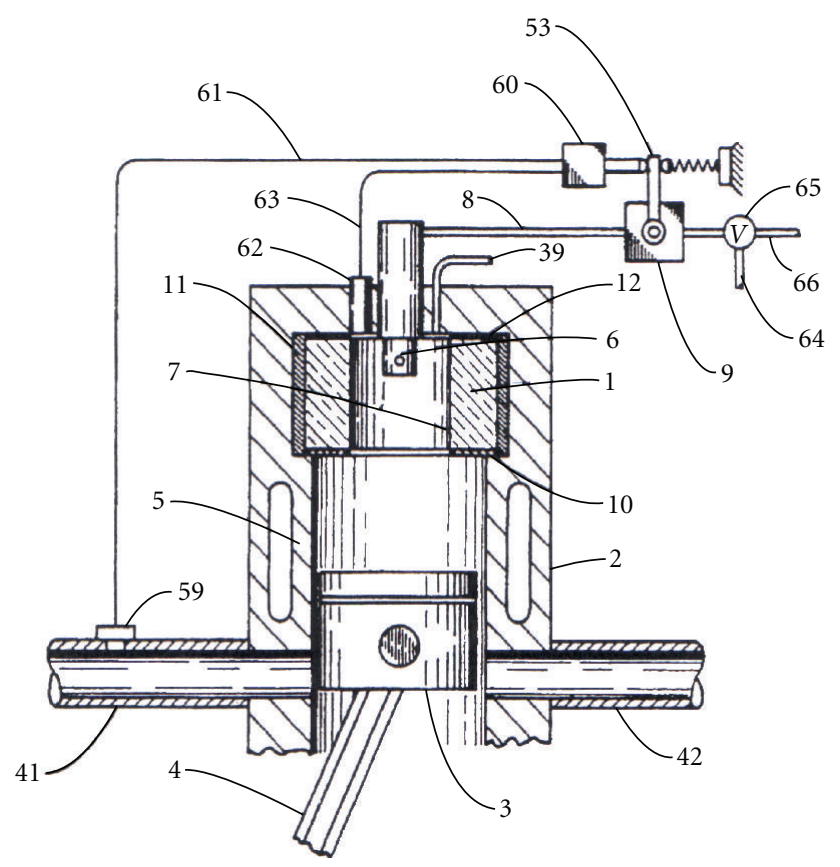

FIGURE 25: Diesel engine with porous burner [59]: 1-porous burner; 2-engine; 3-piston; 4-connecting rod; 5-cylinder wall; 6fuel nozzle; 7-outer surface of porous burner; 8-fuel pipe; 9-fuel meter; 10,11,12-external surface of the porous burner; 39-steam admission nozzle; 41 -intake pipe; 42-exhaust pipe; 59 -air pressure sensor; 53,60-controller.

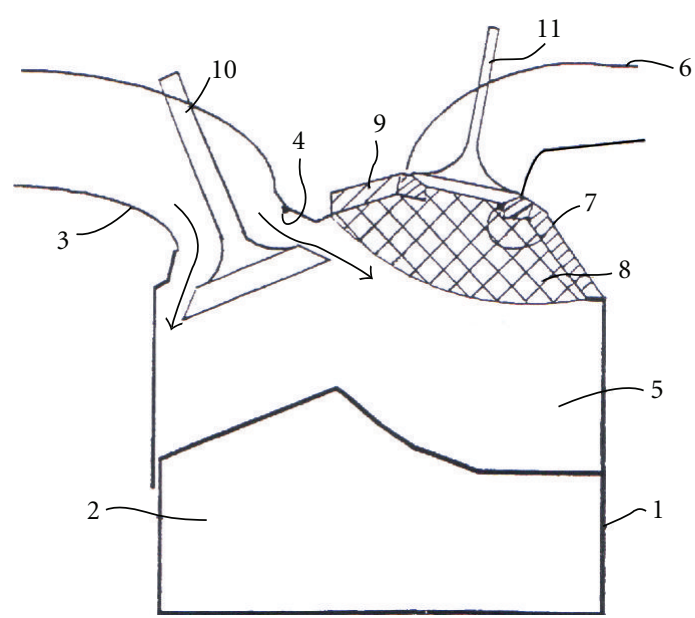

Figure 26: Engine with mixture formation and combustion in porous reactor [60, 61]: 1-cylinder liner; 2-piston; 3-inlet port; 4-valve seat; 5-cylinder; 6-exhaust port; 7 -valve seat; 8 -porous material (combustion chamber); 9-engine head; 10-inlet valve; 11exhaust valve.

In such an engine, the fuel is injected by the nozzle directly into the compartment inside the sleeve at the moment of the highest compression. This allows fuel ignition almost immediately after injecting, thereby effecting a pre-explosion in the inner compartment. As a result, a part of the charge is forced into the compartment outside the sleeve through its apertures. It was expected that this invention might 


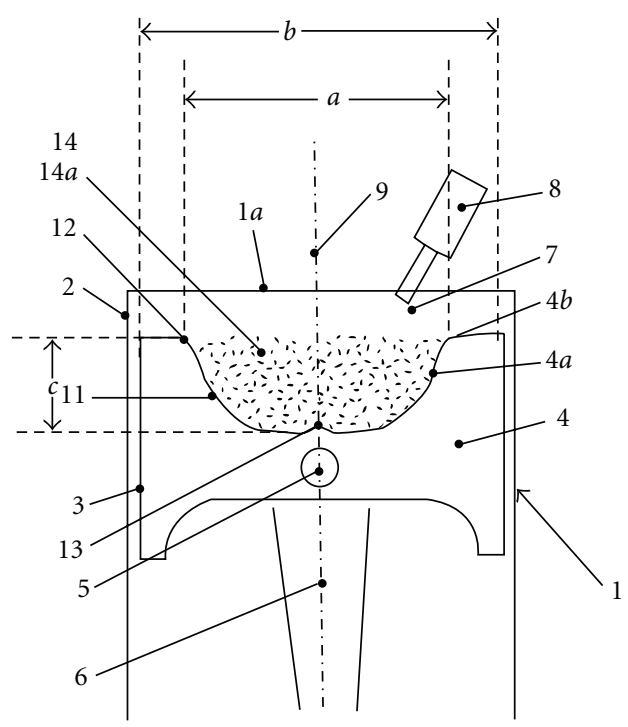

FIGURE 27: Engine with porous reactor [62]: 1-cylinder; 2-cylinder liner; 3-piston coat; 4-piston; $4 a$-piston bowl; $4 b$-piston surface; 5-gudgeon pin; 6-connecting road; 7-combustion chamber; 8injection nozzle; 9-longitudinal axis; 11-piston bowl; 12-corner; 13bowl hill; 14,14a-porous structure.

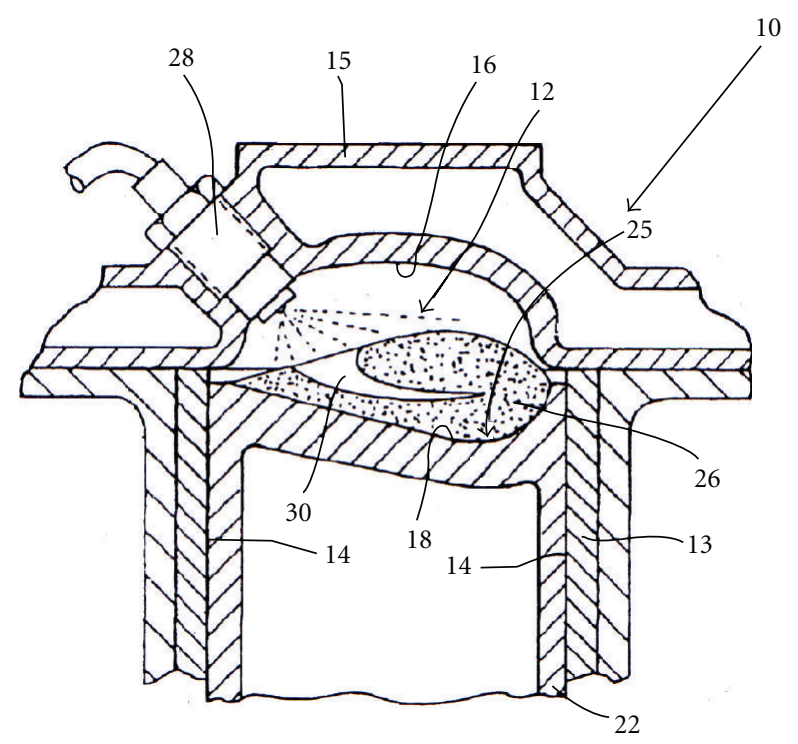

FIGURE 28: Engine with porous reactor [62]: 10-steel cylinder; 12combustion chamber; 13-cylinder; 14-cylinder wall; 15-cylinder head; 16-combustion chamber wall; 18-piston crown; 22-piston coat; 25-piston bowl; 26-porous medium (structure); 28 -injection nozzle; 30-expansion channel in porous structure.

accelerate mixture formation and combustion process in the engine. The problem of fuel trapped and deposits on the surface as well as a pressure loss by reaction forcing from inside to outside of the sleeve should be considered. There is rather difficult to expect that the reaction will be supported on the outer side of the sleeve.

A different concept was proposed by Scherenberg in 1974 as described in a German patent application [43]. In this idea, a porous element in the form of a sieve (mesh) $(6,7)$, see Figure 15, is positioned in the intake port downstream of the fuel injector. These sieves act as a porous structure. The role of the porous element (plate) is to facilitate cold start conditions and engine operation by improving initial fuel vaporization. In conventional port injection under cold-start conditions, it is necessary to inject much more fuel to guarantee the formation of an ignitable mixture in the cylinder (spark plug area). Additionally, with a port injection, a wall film formed in the intake port and on the valve surfaces makes the problem even more complex [119-124]. By improving fuel vaporization, it is possible to significantly improve mixture formation and reduction of the mass of fuel necessary for controlled ignition under cold start conditions. The porous element (sieve, mesh) may be electrically heated, and fuel is injected onto the porous surface (element). The problem of porous surface wetting, the deposits as well as reduced volumetric efficiency (filling the cylinder with air) should be considered.

A real 3D porous structure positioned downstream of the throttle of the engine carburettor was proposed by Schladitz and Hutzenlaub as described in a German patent in 1978 [44]. This system uses a porous element which can electrically be heated for better vaporization of fuel flowing through the throttle toward the engine cylinders-Figure 16. In order to reduce the amount of electrical energy, it is suggested to accumulate a part of the exhaust gases enthalpy in the porous elements (heat exchanger) and to utilize this energy for fuel vaporization. So, the necessity of the electrical heating is reduced to cold start conditions. However, as known in engines, any heat supply to the system on the intake air side makes problems with cylinder filling with air, not only the increased intake temperature nut but also increased pressure loss in the intake system is here important. The problem of fuel trapped and deposits on the surface should also be considered.

A system very similar in function system was proposed by Bernecker, 1978 [46]. As described in this US patent, the carburettor has a housing filled with ceramic pieces (as a porous element) fulfilling the task of vaporization and homogenisation (Figure 17). The liquid fuel is directly injected (supplied) onto the porous structure. The goal of the system is to permit complete fuel vaporization before the fuel enters the intake manifold of the engine. The role of the porous medium is to support not only fuel vaporization but also simultaneously mixture formation (mixing with air). Also, in this invention, it is foreseen that the porous element will be (at least partly) heated by the engine exhaust gases. This system would probably have reasonable pressure loss and reduction of volumetric efficiency of the induction process. Especially, the problem of the heat supplied to the porous medium (side of intake air) and significantly increased pressure loss in the intake system make this concept less applicable to real engines. Additionally, the problem of fuel trapped and deposits on the surface should also be considered.

A liquid-fuel vaporizer concept was proposed by Gladigow and Schaetzing in a US patent, 1997 [47]. In this system, there is a porous vaporizer chamber (see Figure 18). 


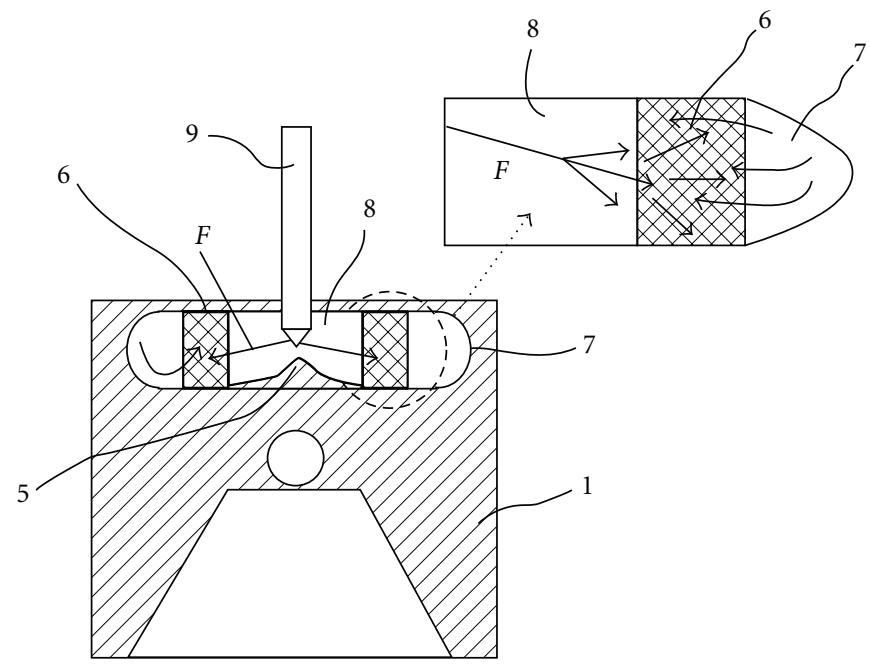

FIGURE 29: Engine with two-stage combustion with porous ring [106]: 1-piston; 5-piston bowl hill; 6-porous medium ring; 7-outer room; 8-inner room; 9-injector; $F$-fuel jet.

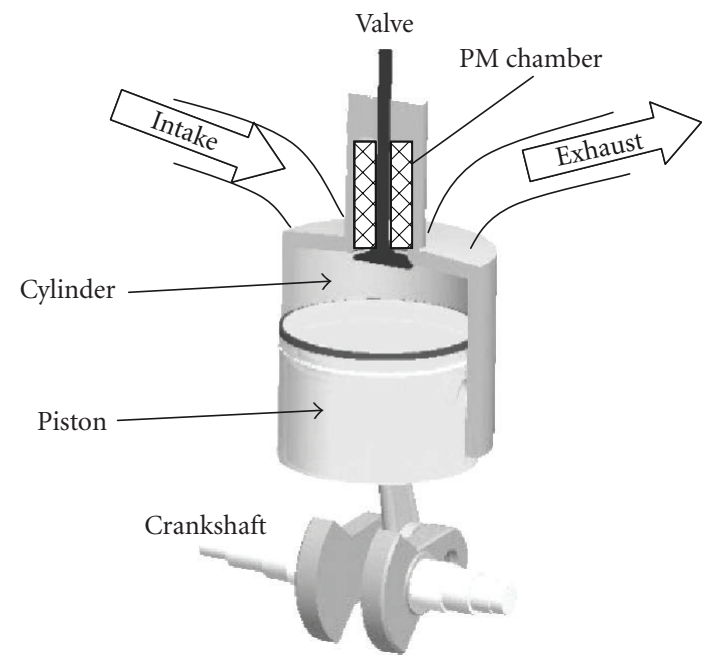

FIgure 30: "Intelligent engine" concept with PM chamber.

A fuel atomization device is equipped with a fuel injection system. The device includes a base (1) (in Figure 18) in which a number of heating elements (2), and profiled vaporizer contact baffles (3), for example in form of a honeycomb structure, are arranged in a sandwich-like manner. This is a kind of "external" vaporizer which could be applied to any engine; however, the vaporizer operation dynamics, deposits on the surface, controlled temperature, and integration with engine air supply system could be questionable for real engine application.

Quite a different system with 3D porous structure for fuel vaporization and homogenization was proposed by Weclas in a German patent application (1999) [48]—Figure 19. A modified version of this idea has been described in [53]. In this case, an additional prechamber containing a porous structure is not located in the exhaust system, but is localized in the engine head between intake and exhaust valves.
The chamber is equipped with a special valve permitting connection with the cylinder. This system will be described in detail in Section 6 of this paper.

Recently, the author has proposed the use of a kind of 2Dstructure modelling a 3D porous foam reactor (Figure 20) for supporting fuel distribution in space for high-pressure direct-injection systems (e.g., Diesel injection). In this system, a porous structure consists of small (e.g., cylindrical) obstacles positioned in the way of Diesel or gasoline jets $[49,52,125,126]$. More detailed description is given in Section 6 of the paper.

Another system with a porous element for in-cylinder engine application was proposed by Mueller as described in a German patent application in 1975 [55]. In this system, a porous matrix $\left(10\right.$ or $\left.10^{\prime}\right)$, see Figure 21 , is positioned in the piston bowl and late in the compression stroke is in proximity to the fuel injector (the figure shows two different configurations of the system). The porous matrix is made of a high-porosity and high-temperature material having also the function of a heat exchanger. Preferably, the porous structure is mounted in the pre- or swirl-chamber of the engine. Figure 21 shows the solution according to which the porous element is positioned in the piston bowl and forms an inner chamber limited by the matrix (10 or $\left.10^{\prime}\right)$. Moreover, in this system, a liquid fuel is injected directly onto the porous structure promoting vaporization and mixture formation. In order to get an effect of fuel distribution and vaporization by interaction with a porous structure a high injection pressures should be applied. For engine application, it would be preferable to reduce the inner volume of the system and to keep the volume of the porous element relatively small.

5.3. Short Overview of Most Important Concepts for Catalytically Supported Ignition and Combustion. This class of PM applications to in-cylinder engine processes concern porous structures having a catalytic coat to support the ignition and combustion processes in the engine. In this case, the volume 


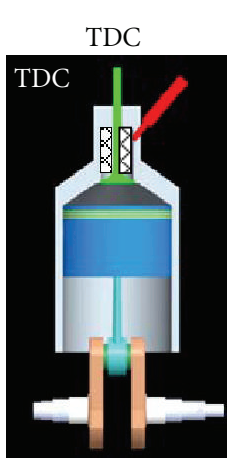

(a)

Exhaust

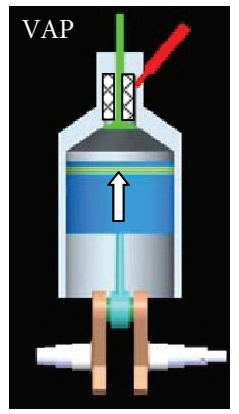

(g)

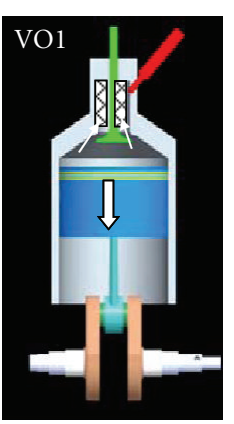

(b)

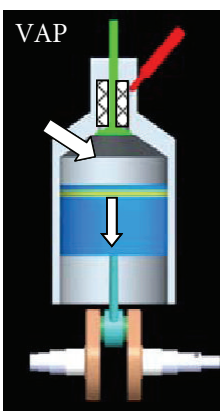

(h)

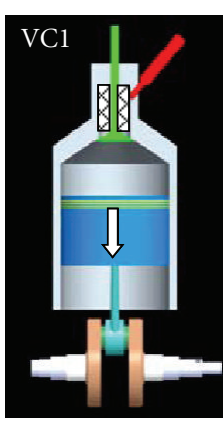

(c)

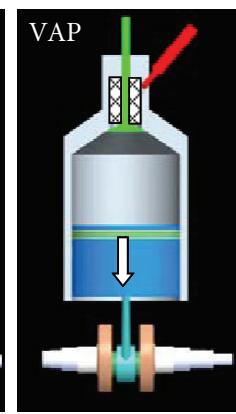

(i)

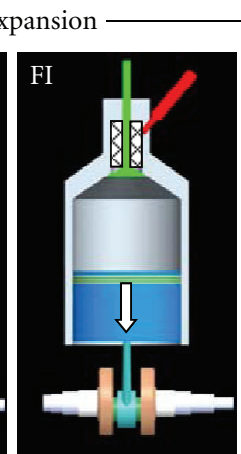

(d)

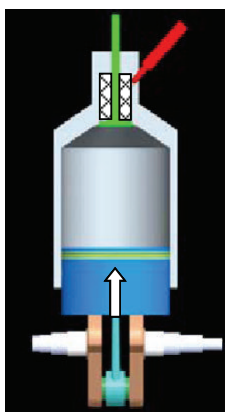

(j)

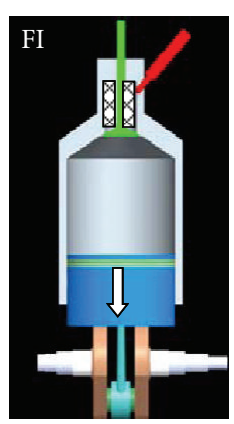

(e)

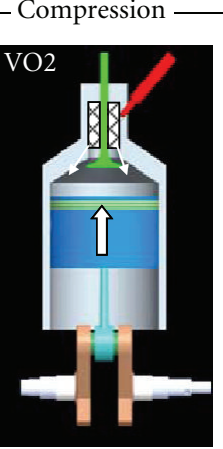

(k)
Exhaust

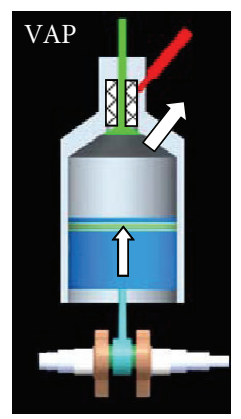

(f)

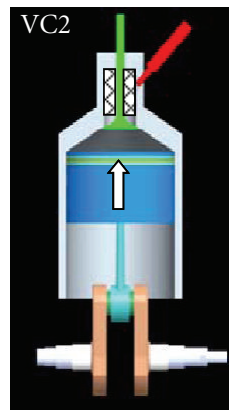

(1)

FIGURE 31: Characteristic phases of "intelligent engine" with PM chamber: TDC: top dead centre of compressions; VO1: first opening of PM chamber valve; VC1: first closing of PM chamber valve; FI: fuel injection in PM chamber; VAP: fuel vaporization in PM chamber; VO2: second opening of PM chamber valve; VC2: second closing of PM chamber valve.

of the reactor may not be utilized for combustion, but rather the catalytic surface.

Pfefferle proposed an engine with a porous element having catalytic coating, as described in a US patent in 1975 [56]. The catalyst member (a porous structure with catalytic coat) (54) in Figure 22 is positioned inside the engine cylinder permitting gas flow through the porous element according to the piston motion in the cylinder. This system will be presented in detail in Section 6 of this paper.

An engine concept with a catalytic gauze sheet in the piston bowl was proposed by Haslett and described in a US patent in 1978 [57] - (see Figure 23). The major part of the combustion chamber is afforded by a recess (14) in the piston crown and a catalytic element (e.g., of mesh, grid, perforated) is carried by the piston in a position at least partly overlying the recess. The fuel is injected into the recess to contact and pass through the catalytic (porous) element. The ignition process of the air-fuel mixture is also promoted by the catalytic element. The catalytic element may be made in the form of multiple apertures or passages through which the injected fuel passes and may extend completely across the open top of the recess. This element may be of a gauze matrix or mesh and porous or perforated sheet structure. The goal of this invention is to significantly reduced hydrocarbon emissions as well as to extend ignitability limits for lean charges to be catalytically ignited. However, the process in catalytic element is not supported in the whole volume of the combustion chamber and the jet interaction with porous element would play an important role. The element would not contribute to the mixing process and homogenization in combustion chamber. 1984 Siewert proposed a catalytic grid to be applied in proximity to the fuel injector of a gasoline direct-injection engine, as shown in Figure 24 [58]. This concept utilizes a late direct gasoline injection strategy for a stratified charge with catalytic ignition. The air is compressed with a swirl motion in the cylinder and the fuel is injected and finely atomized nearly to TDC and mixes with air. A catalytic member (grid) is provided in the combustion chamber in the path of the fuel spray and downstream of the spark plug. The catalytic grid serves the purpose of promoting combustion of the burning mixture and of igniting and burning the fuel which reaches the grid in the unburned state. In the author's opinion, an interaction of a (relatively) high-velocity gasoline spray with a porous surface would promote a spatial distribution of fuel in space preventing controlled charge stratification. It would, however, be used for charge homogenization. The ignition process could be positively influenced.

5.4. Short Overview of the Most Important Concepts for (Noncatalytic) Ignition and Combustion in a Porous-Structure Volume. This type of porous-medium application to incylinder engine processes refers to engine concepts in which the ignition and combustion processes are at least partly 


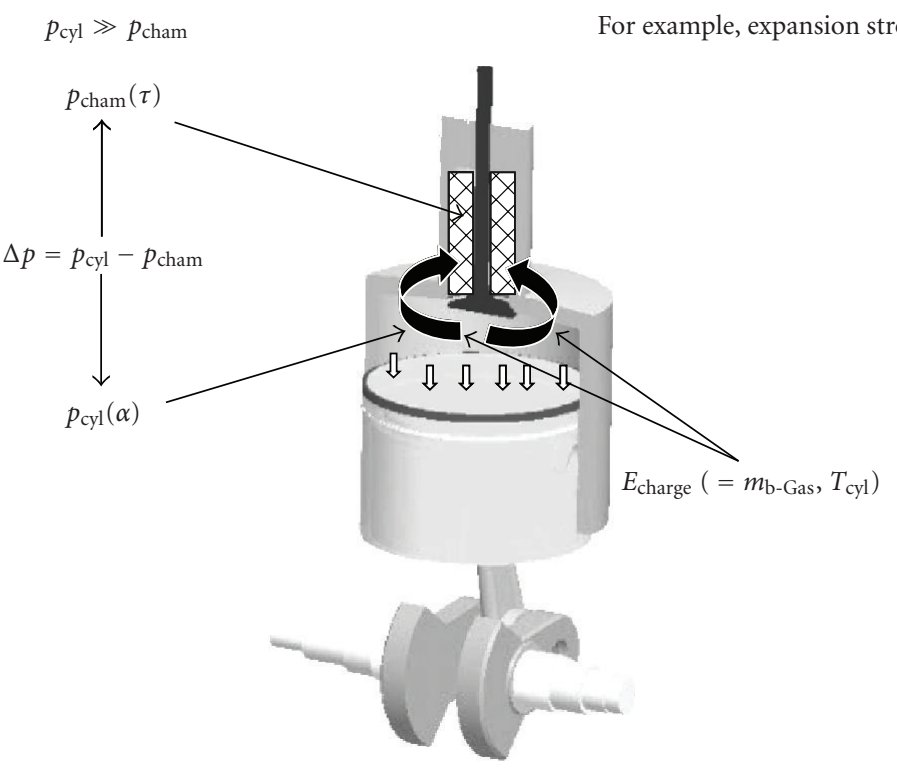

FIGURE 32: First opening of PM chamber valve: chamber charging with energy $E_{\text {charge }}$.

$p_{\text {cyl }} \ll p_{\text {cham }} \quad$ For example, compression stroke

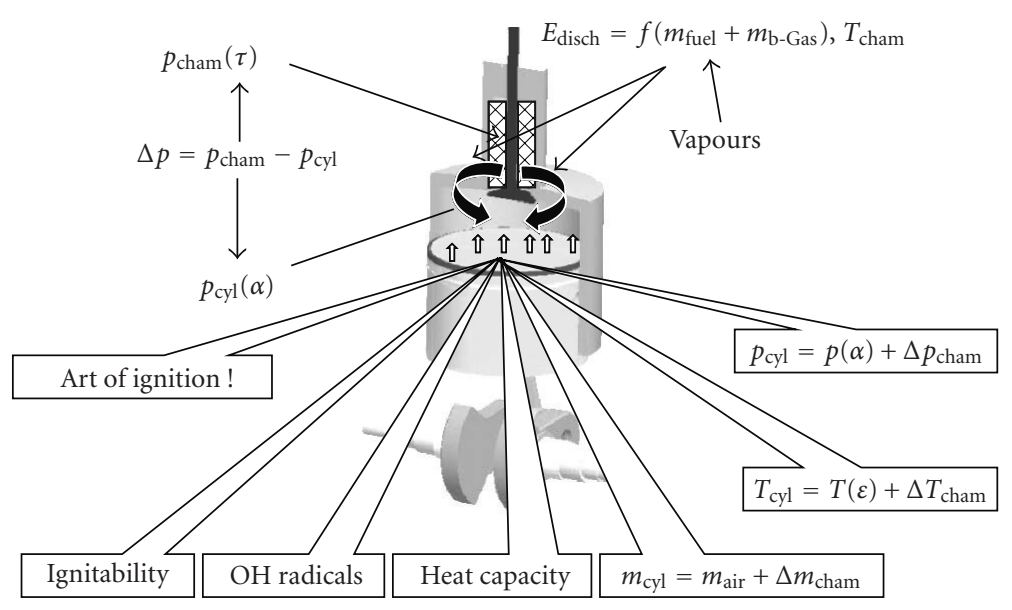

FIGURE 33: Second opening of PM chamber valve: chamber discharging with energy $E_{\text {disch }}$ supply to the cylinder.

performed in a noncatalytic porous reactor volume. In this case a volume of the PM reactor is utilized for performing engine processes.

As a first system, the engine with porous burner proposed by Firey is considered, as described in a US patent in 1983 [59]. In this system, a ring-like porous structure located around the cylinder plays a role like a porous-medium burner with fuel injection onto the outer surface (7) of the reactor (1) in Figure 25. In this invention, a porous medium burner is installed in the engine combustion chamber. A porous burner system comprises a porous-burner volume located within the engine combustion chamber. The fuel is directly injected onto the external surface of the porousburner volume. During the compression stroke this fuel is forced by cylinder pressure into the pore spaces of the porous structure and spreads out over the large internal pore surface area for promoting rapid fuel burning. It is expected that the combustion in a pore space is incomplete owing to the fuel excess, and that the afterburning of the gaseous mixture in the space outside the porous burner is necessary to complete the combustion process. This combustion system may operate with high-viscosity liquid fuels, slurries of wholly liquid fuels with particles of coal or other solid suspensions therein. For a real engine application, it would be advantage that the fuel is distributed throughout the porous medium (burner) volume by application of a highpressure injection. The main problem is that only part of the combustion chamber (PM volume) may be utilized for clean combustion and air utilization for combustion of fuel trapped in the porous medium volume would rather be bad. 


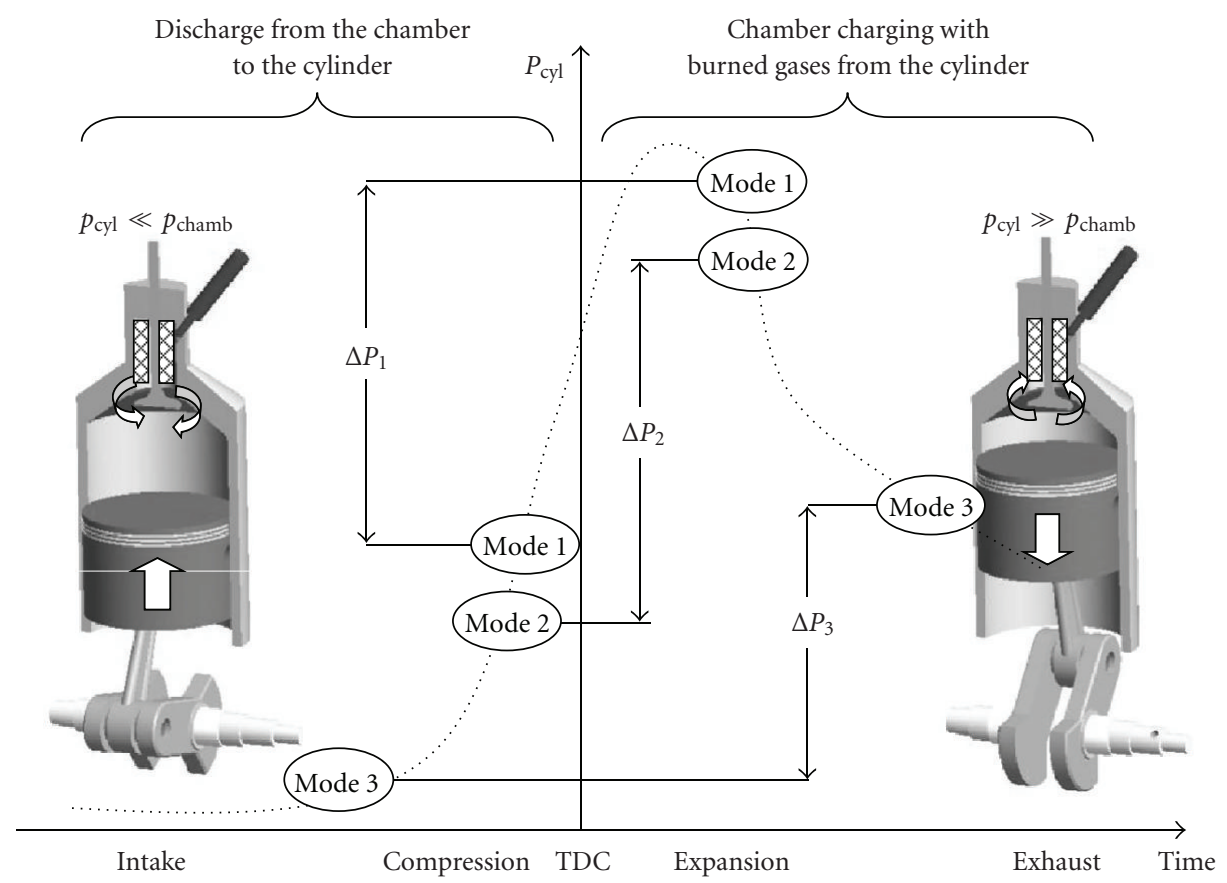

Figure 34: Different operating modes (characteristic timings) of PM chamber valve.
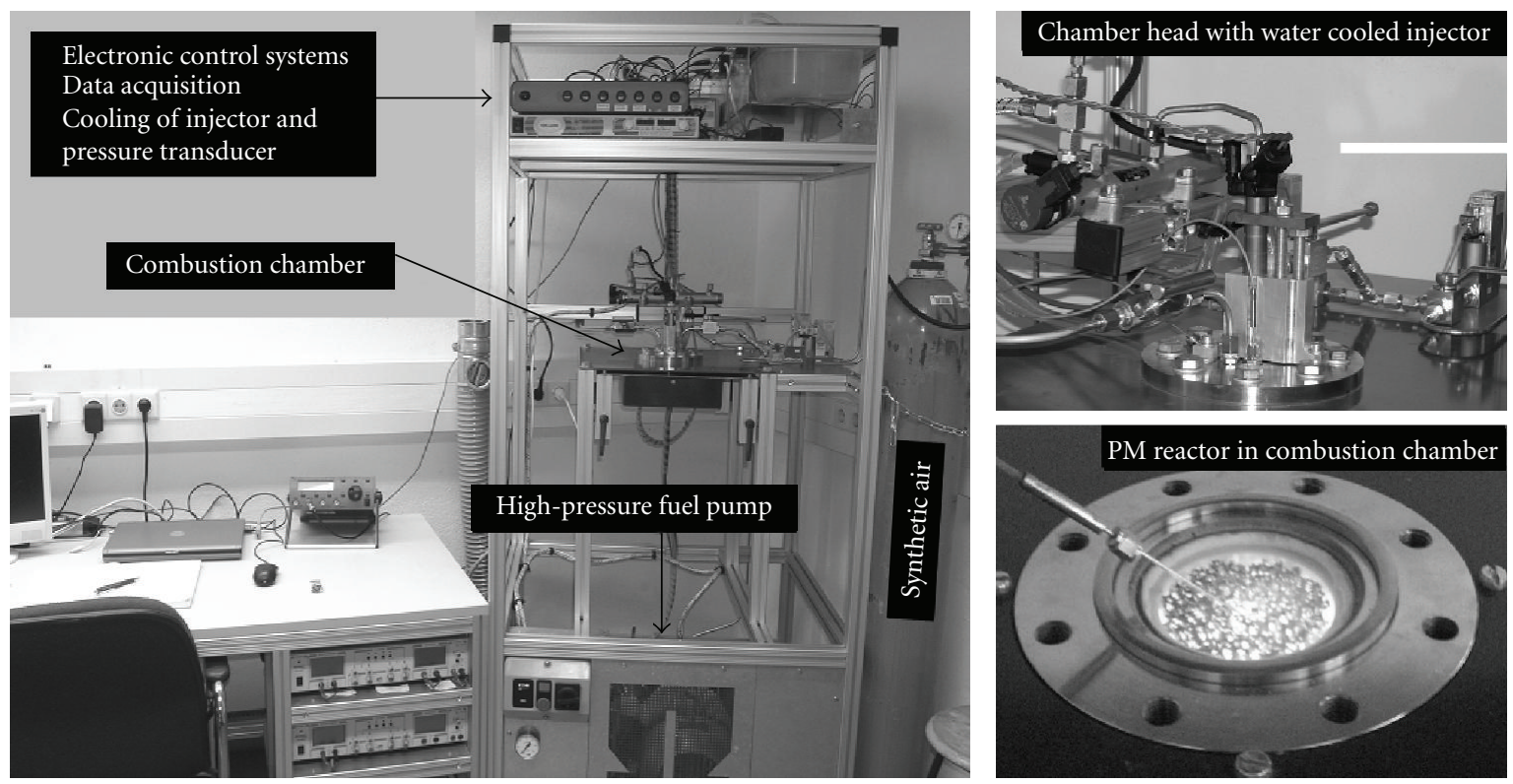

FIGURE 35: View of a high-pressure, high-temperature, constant volume adiabatic combustion chamber for investigating of low- and hightemperature oxidation reactions under engine-like conditions (equipped with Diesel common-rail injection system).

Porous burner volume extension to the whole combustion chamber would be a promising way (see the next system and also Section 6.4).

An overall concept of an internal-combustion engine with mixture formation and combustion completely performed inside the porous-reactor volume has been proposed by Durst and Weclas $[60,61]$ (Figure 26) and later described in the literature $[66,67]$. In this concept, the complete combustion chamber in the engine is limited to the porousreactor volume only. Fuel injection, vaporization, mixture formation, ignition, and heat release are realized in the porous-medium volume only. In more detail, the system will be described in the next section of this paper. More or less, a similar system to that of Durst and Weclas was described 


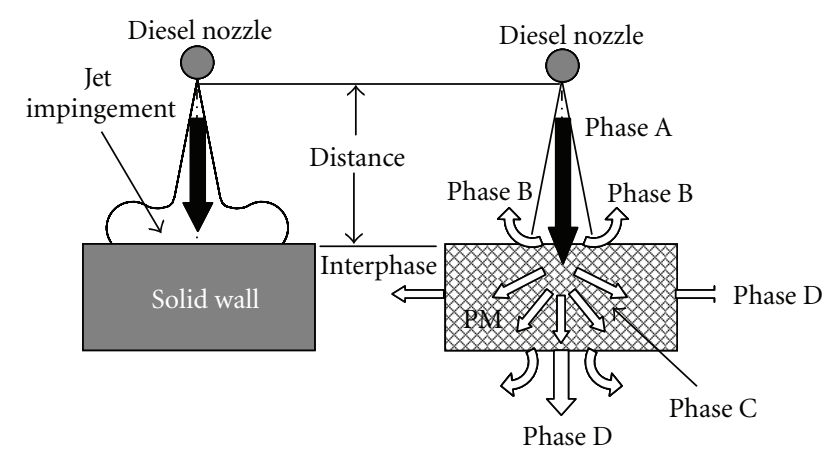

FIGURE 36: Characteristic phases of fuel-jet (Diesel) interaction with porous structure (wide distance between nozzle and wall or porous structure).

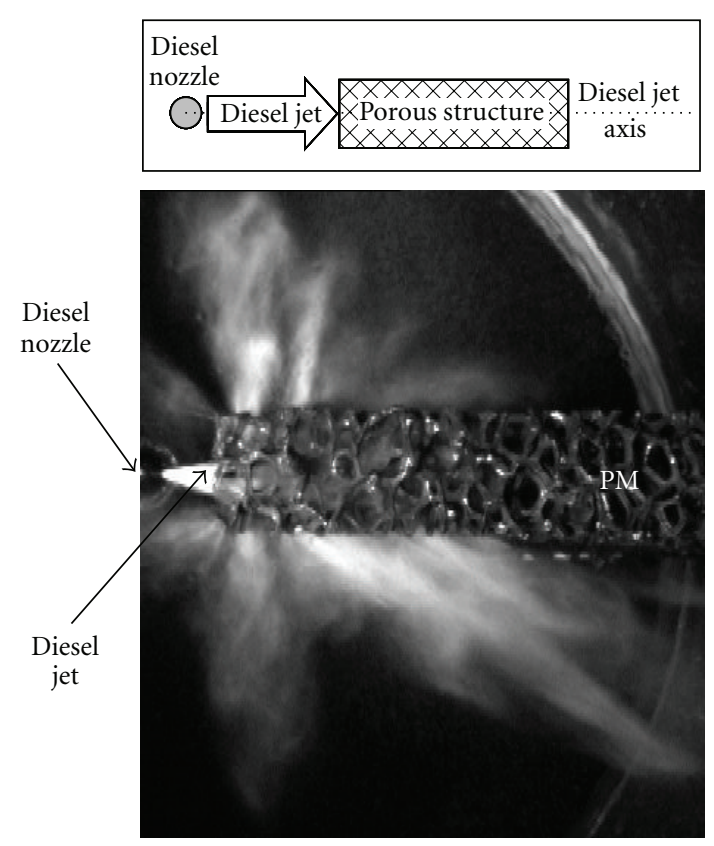

FIGURE 37: High-velocity Diesel-jet interaction with a highly porous medium (strong radial distortion of the initial jet).

three years later by Pott in a German patent application [62] — see Figure 27. In this case, the combustion chamber is positioned outside the porous medium, and only part of the process is influenced by the porous reactor. The fuel is not directly injected into the porous medium as presented in $[66,67,127]$ but onto the porous-medium surface. The fuel may partly penetrate through the porous structure. The main expectation of this invention is reduction of the combustion temperature for reducing $\mathrm{NO}_{\mathrm{x}}$ emissions. However, the system is not able to achieve the homogeneity of the charge in the porous medium volume making following combustion process worse. Additionally, in this system part of the injected fuel will not penetrate inside reactor volume having bad conditions to be completely combust.

A little later, Hoffschmidt et al. (2000) in their German patent application described an engine concept similar to the above one; however, the reactor had such a small

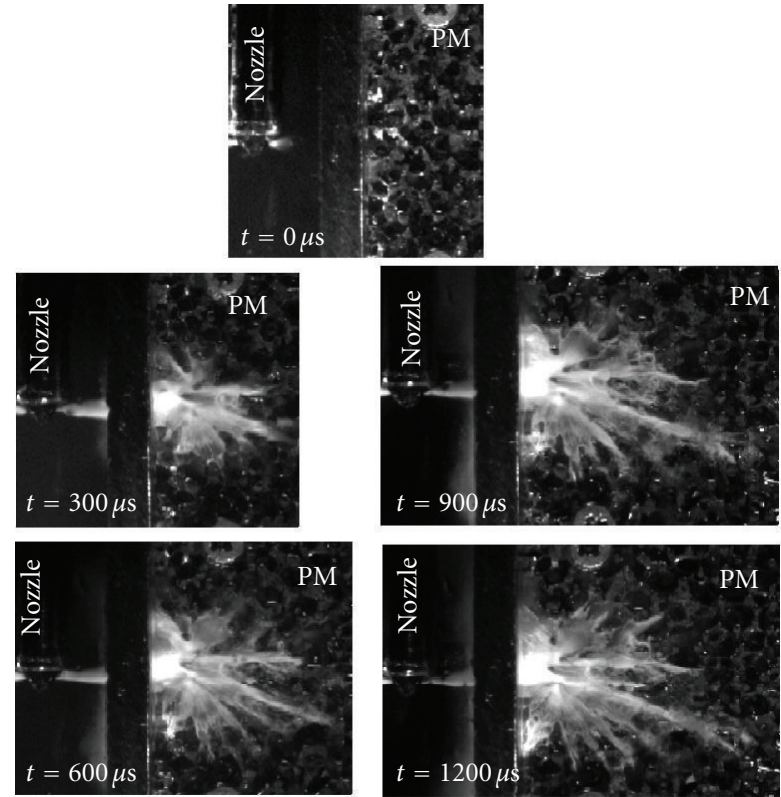

FIGURE 38: Diesel-jet impingement on to porous structure as a function of time after PM contact at $X=7 \mathrm{~mm}$ and $P_{\text {inj }}=1200 \mathrm{bar}$ (in air).

pore size that special "expansion channels" for liquid-fuel distribution inside the porous reactor would have been necessary (Figure 28) [62]. The pore size suggested in this invention makes it impossible for the real engine processes to proceed inside the PM reactor volume. This idea of application of porous reactor to engine combustion is rather unrealistic owing to wrong choice of the combustion reactor parameters.

The last concept considered in this overview combines different aspects of application of a porous structure for supporting in-cylinder engine processes. In a German patent application (2003), the author has proposed a so-called twostage combustion system in which a porous ring divides the combustion chamber into three zones and the process into two phases according to the upward and downward piston motion [106]. The principle of this system is presented in Figure 29. This engine concept applies special effects of highvelocity Diesel jet interaction with a porous structure (see Section 6.2) resulting in controlled distribution of mixture composition outside and inside the porous medium ring. Depending on the injection pressure the liquid fuel may be trapped by the porous ring and then occupies the inner volume of the combustion chamber limited by the porous ring. The upward and downward motions of the piston force the mixture to flow through the porous ring and to occupy different parts of the combustion chamber. The combustion process is principally divided into two phases: phase 1 in the period from the beginning of fuel injection and TDC of compression (upward piston motion) and phase 2 after TDC during downward piston motion. Basically, the mixture composition in both phases is different (rich and lean). Combination of both combustion phases and mixture compositions (two-stage combustion) render the 

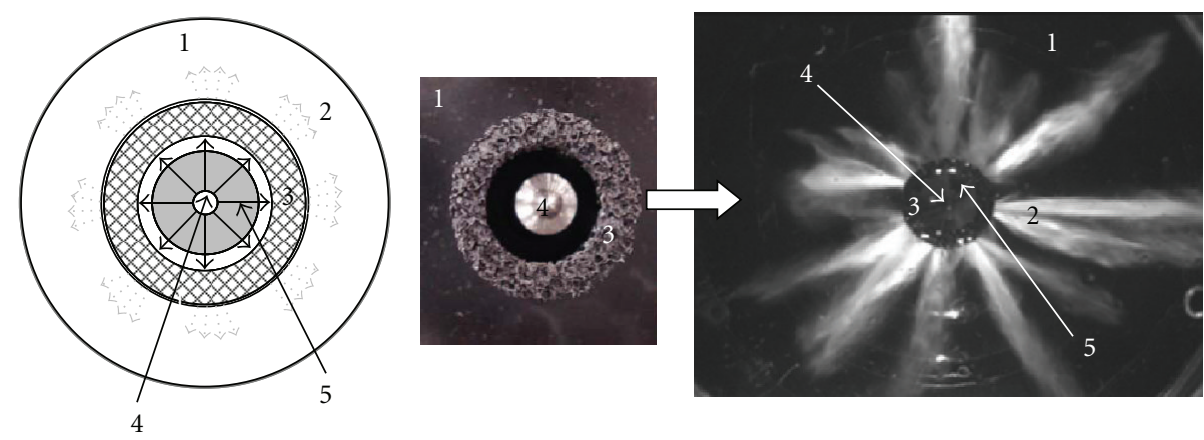

FIGURE 39: Interaction of Diesel jet with a small porous ring under atmospheric conditions resulting in jets spreading in a free space $\left(P_{\text {inj }}=\right.$ 1000 bar, $\tau=1000 \mu \mathrm{s}$ ): 1-free space (combustion chamber); 2-fuel spreading behind the porous ring; 3-porous ring; 4 -Diesel nozzle; 5-free Diesel jets.

overall combustion process very complete and clean through reduced combustion temperature [54, 128]. Experimental investigations on Diesel jet interaction with porous structures confirm applicability of this system to real engine $[52,53,126]$.

\section{Analysis of Selected Engine Concepts with Porous Structures for In-Cylinder Processes, Especially for Combustion}

6.1. Intelligent Engine Concept: PM Reactor for Fuel Distribution, Vaporization, and Chemical Recombination. A future engine operating with a homogeneous combustion process over a wide range of engine speeds and loads and having good transient response will have to satisfy the following conditions or combination of them:

(i) variable temperature history during compression stroke,

(ii) variable TDC compression temperature,

(iii) completely vaporized fuel prior the ignition process,

(iv) variable mixture composition (air-to-fuel ratio),

(v) variable reactivity (ignitability) of the charge,

(vi) homogeneous and premixed charge prior ignition,

(vii) variable charge heat capacity,

(viii) fuel supply and fuel vaporization conditions independent of engine load,

(ix) controlled volumetric ignition conditions.

The engine combustion system which allows adoption of its in-cylinder conditions to actual operational conditions for a permitting homogeneous combustion process is defined as an intelligent engine [128-130]. This concept applies a porous-medium structure for interphase heat exchange, heat accumulation, liquid fuel distribution in the PM volume, vaporization of liquid fuel, as well as for chemical recombination of the charge (cool- and blue-flame reactions [131-135]). An overall concept of an intelligent engine is presented in Figure 30. This figure shows a simplified design. A special prechamber with porous reactor is equipped with

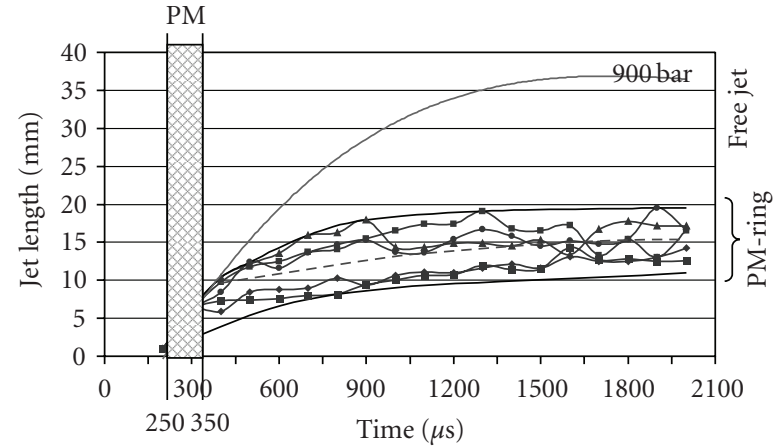

FIGURE 40: Jet penetration length after interaction of Diesel jet with a small porous ring under atmospheric conditions as compared to a free Diesel jet (injection pressure 900 bar).

a special poppet valve which can be operated independently of the intake and exhaust valves. Main phases of the engine cycle are presented in Figure 31. The engine cycle described below, models the real engine cycle, and others than the presented timings for the PM chamber may be used.

Characteristic phases of the cycle with mixture preparation in PM chamber are as follows.

(i) Phase I: the PM chamber is charged with burned gases containing energy (Figure 31(b)).

(ii) Phase II: liquid fuel is injected into PM chamber and fuel vaporization is carried out (Figures $31(\mathrm{~d})$, and $31(\mathrm{e}))$.

(iii) Phase III: gas (evaporated fuel, energy, active radicals) is discharged from the PM chamber to the cylinder (noncombustible mixture) (Figure 31(k)).

(iv) Phase IV: mixing with cylinder air takes place and ignition of the combustible mixture is realized (Figure 31(l)).

Let us start this analysis from the time point corresponding to an early-middle expansion stroke (Figure 31(b)). A chamber contains the porous medium which is thermally isolated from the cylinder head walls. During this period of the engine cycle the valve in the PM chamber opens, and owing 


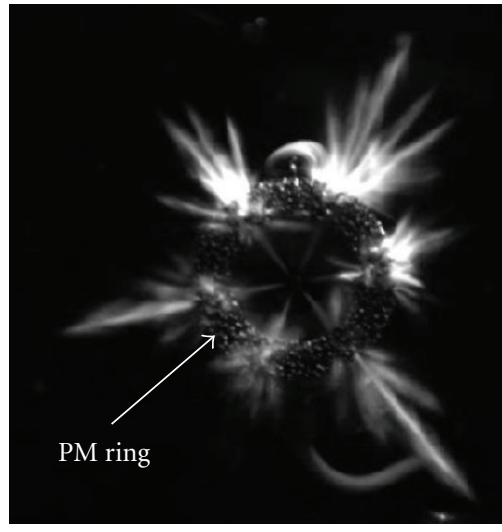

Figure 41: Wide radial spreading of the Diesel jet after interaction with a small porous ring.

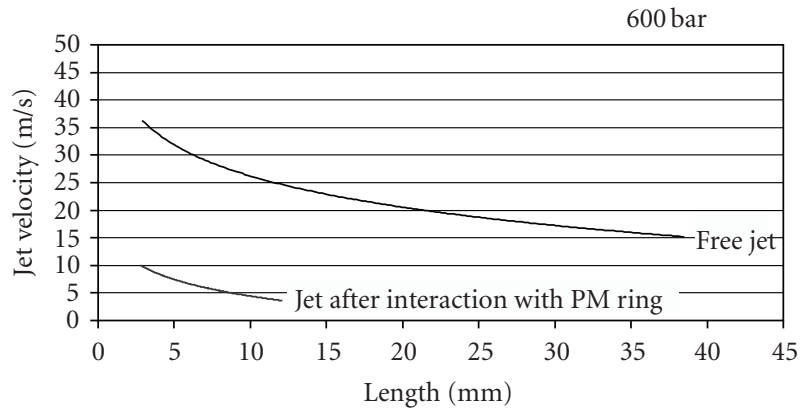

Figure 42: Jet velocity after interaction of Diesel jet with a small porous ring under atmospheric conditions (in air) as compared to a free Diesel jet velocity (injection pressure 600 bar).

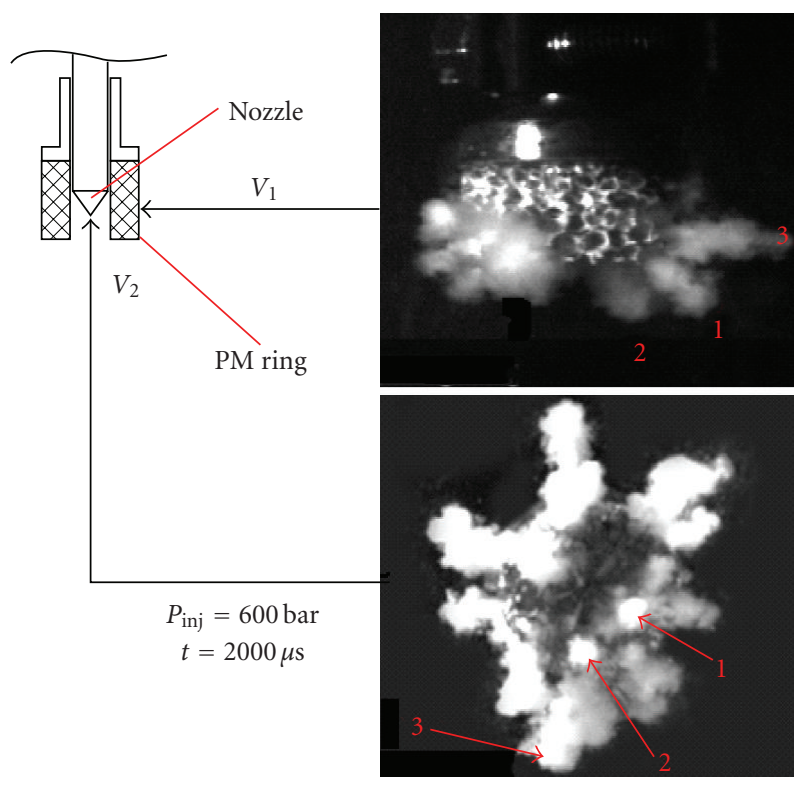

FIgURE 43: Three dimensional jet distribution after interaction of Diesel jet with a small porous ring observed after $2000 \mu$ s after trigger signal $\left(P_{\text {inj }}=600\right.$ bar $)$.

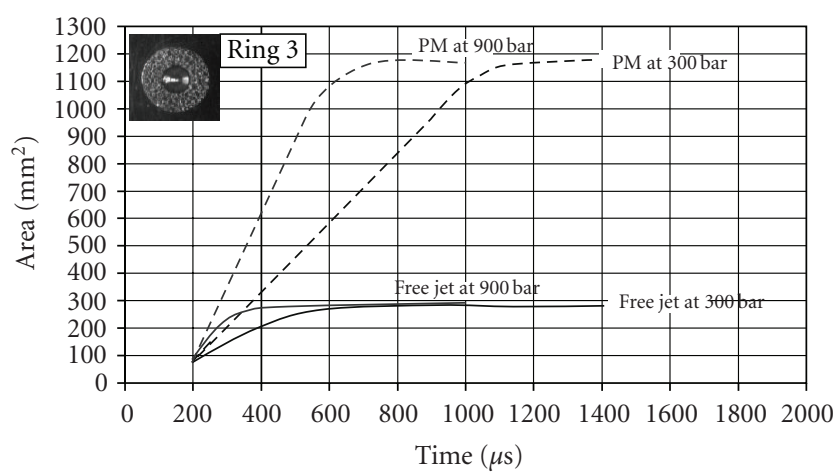

FIGURE 44: Jet surface area after interaction of Diesel jet with a small porous ring under atmospheric conditions (in air) as compared to a free Diesel jet velocity (for two injection pressures).

to the pressure difference between cylinder and PM chamber, a certain mass of a high-temperature burned gas flows into the PM volume (Figure 32). This figure shows mass and energy flows during the first opening of the valve mounted in the PM chamber. By closing the valve (Figure 31(c)), this gas is trapped inside the PM chamber. Control of the rate of the gases trapped in the PM chamber is permitted by controlling the valve timing (moment of valve opening and opening duration). After closing the PM chamber, the expansion and exhaust processes continue in the cylinder without any contact with the PM chamber content (Figures 31(d), and 31(e)). After closing the PM chamber, liquid fuel is injected into the PM volume, and the time available for this process as well as for fuel vaporization is very long. Important is that the vaporization process is independent of spray atomization, engine load or of engine rotational speed. Because the fuel is injected into the gas atmosphere with a very low oxidant concentration the resulting mixture in the PM cannot ignite (thermal ignition), even at high gas/PM temperature. However low-temperature oxidation reactions (cool- and blue-flame reactions) can be performed. These reactions change not only the chemical composition of fuel but, depending on the gas temperature, significantly influence the ignitability of the charge in the cylinder. This noncombustible gaseous charge formed in the PM volume is "injected" back to the cylinder when the PM chamber valve opens again (Figure $31(\mathrm{k})$ ) since the pressure in the PM chamber is much higher than cylinder pressure. Possible timing for this process is from the beginning of the intake process to the late compression period. This highpressure gas discharge from the PM chamber to the cylinder generates highly turbulent flow conditions in the cylinder supporting mixing and homogenization of the cylinder charge (Figure 33). This figure shows mass and energy flows during the second opening of the valve mounted in the PM chamber. The resulting mixture discharge (injection) to the cylinder permits additional energy and chemically active radicals to be supplied together with a completely vaporized fuel. This gaseous charge supplied to the cylinder may be used for significant extension of the effective leanlimit of the homogeneous charges, for increasing of the 


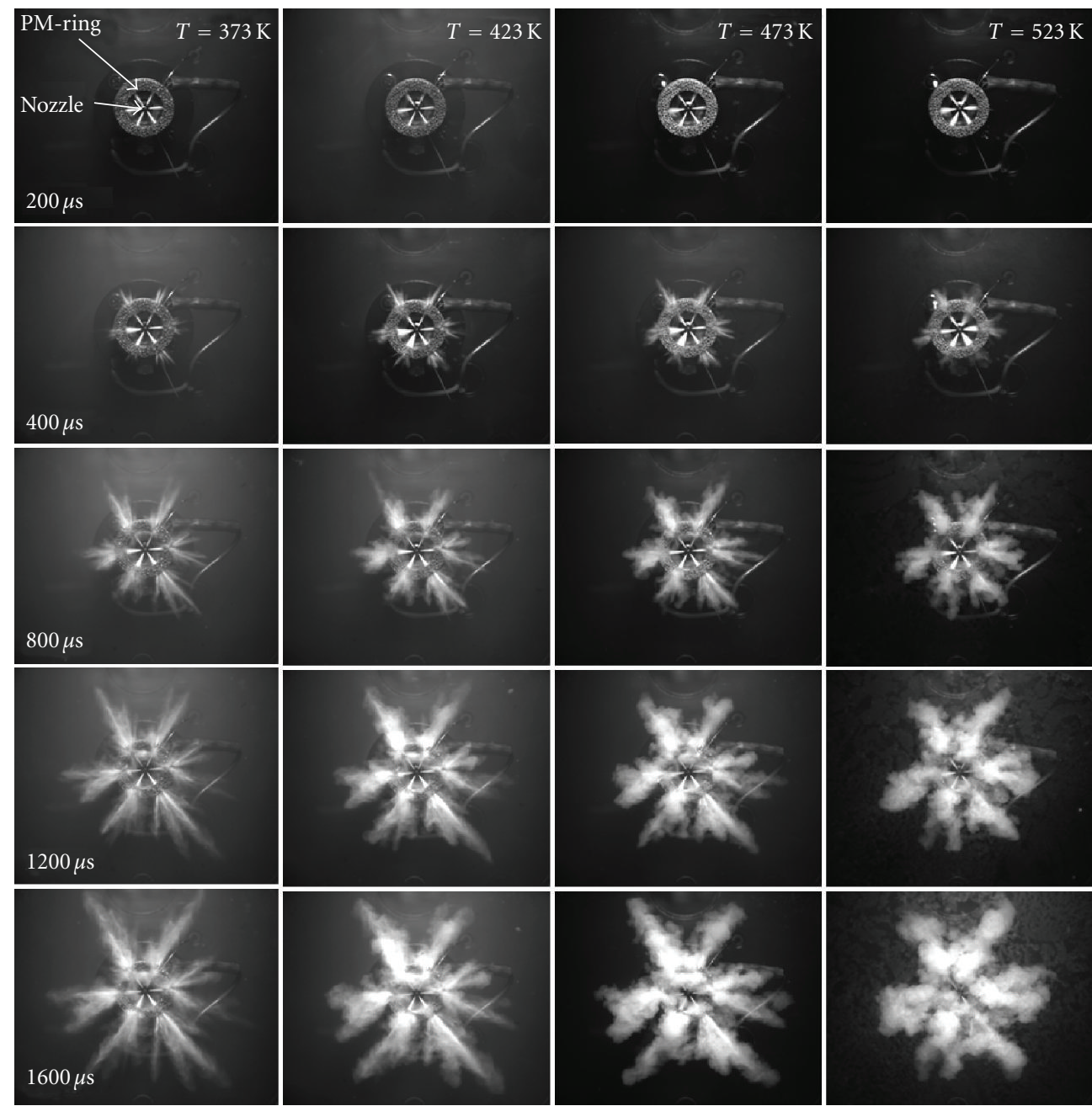

Figure 45: Diesel jet interaction with hot porous ring as observed at different time instances and four PM ring temperatures $\left(P_{\text {inj }}=500\right.$ bar $)$.

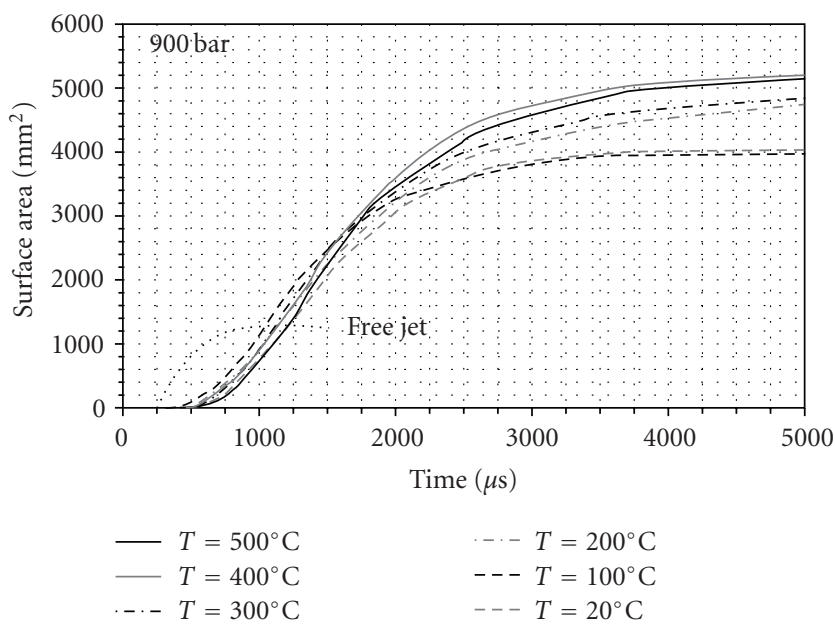

FIGURE 46: Surface area after Interaction of Diesel jet with a small porous ring made of wire packing for six ring temperatures $\mathrm{TPM}=$ $20^{\circ} \mathrm{C}, 100^{\circ} \mathrm{C}, 200^{\circ} \mathrm{C}, 300^{\circ} \mathrm{C}, 400^{\circ} \mathrm{C}$, and $500^{\circ} \mathrm{C}$.

charge ignitability and for controlling the thermodynamic conditions of the charge depending on the operational conditions of the engine.
Thus, the variable timing of the chamber permits variability of the following cylinder charge (cylinder) parameters: TDC compression temperature, temperature history during compression stroke, TDC cylinder pressure, mixture composition (air-to-fuel ratio and burned gases), reactivity (chemical activity) of the charge, homogeneity of the charge (with completely vaporized fuel), and heat capacity of the charge.

The valve timing for chamber charging and discharging forms pairs of valve operation depending on the engine load and speed (combustion mode), as shown in Figure 34. Each pair of valve opening/closing timing defines a different combustion mode which can continuously be adapted to the varying operational conditions. Experiments performed in a special high-pressure, high-temperature, constant volume adiabatic combustion chamber (Figure 35) confirmed possibility of controlled realization of low-temperature oxidation reactions under very rich mixture conditions.

6.2. Fuel Distribution and Mixture Homogenization by Diesel Jet Interaction with Porous Structures. There is hardly any information available in the literature concerning 

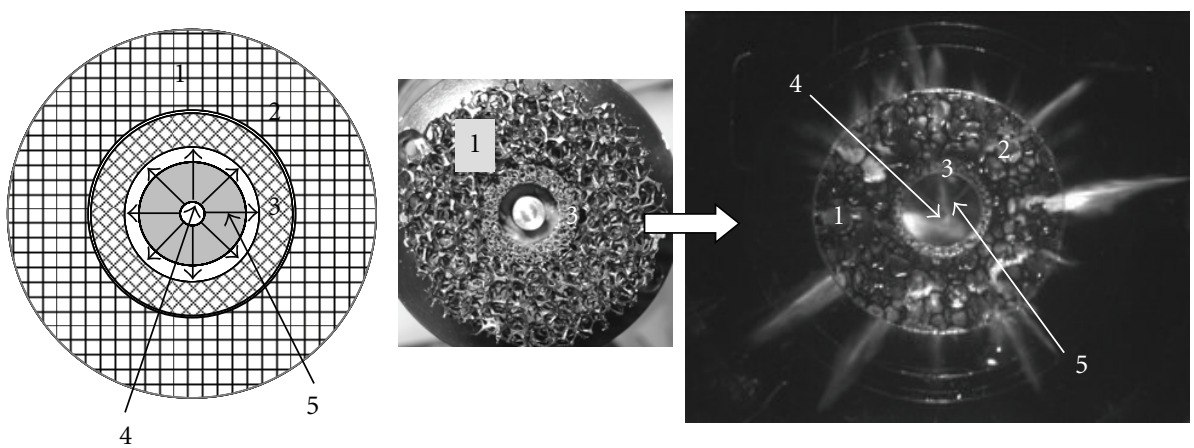

FIGURE 47: Interaction of Diesel jet with a small porous ring under atmospheric conditions resulting in jets spreading in PM volume $\left(P_{\text {inj }}=\right.$ $1000 \mathrm{bar}, \tau=1000 \mu \mathrm{s}$ ): 1-PM volume (combustion chamber); 2-fuel spreading behind the porous ring; 3-porous ring; 4-Diesel nozzle; 5-free Diesel jets.

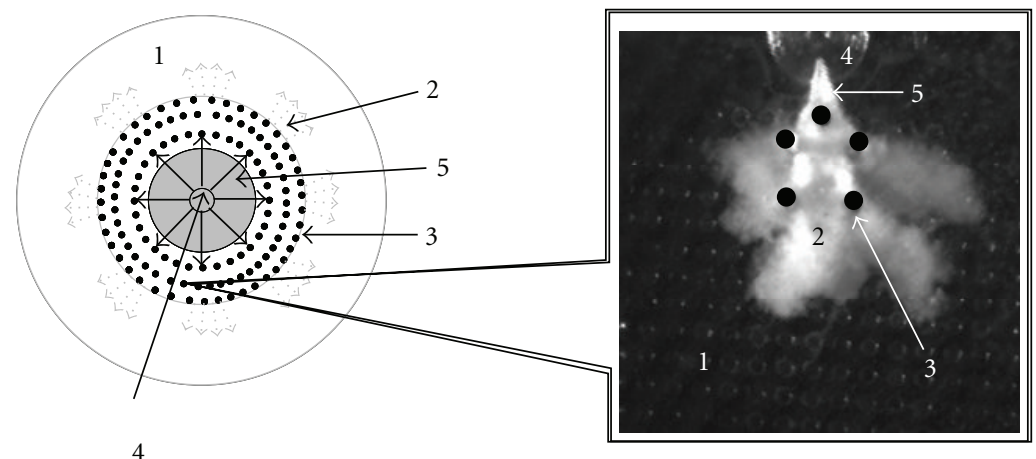

FIGURE 48: Interaction of Diesel jet with a small porous ring under atmospheric conditions resulting in jets spreading in PM volume $\left(P_{\text {inj }}=\right.$ $1000 \mathrm{bar}, \tau=1000 \mu \mathrm{s}$ ): 1-PM volume (combustion chamber); 2-fuel spreading behind the porous ring; 3-porous ring; 4-Diesel nozzle; 5-free Diesel jets.

high-velocity jet interaction with highly porous structures for mixture homogenization. Even less experimental data have been reported till now. In order to specify the very unique features of jet interaction with a porous medium, the impingement process will be compared to the process of jet impingement on the solid wall [136-144] as shown in Figure 36. This figure shows Diesel jet interaction with a solid wall (left hand side picture) and an interaction with a highly porous structure (right hand picture) for two characteristic distances between wall and nozzle outlet: wide and narrow distances.

There are four characteristic phases of liquid-jet interaction with the cold porous medium which are highlighted in this paper (see Figure 36) [51-54].

Phase A: liquid outlet from the nozzle and free jet formation.

Phase B: jet interaction with PM interface.

Phase C: liquid distribution throughout the PM volume.

Phase D: liquid leaving the PM volume.

It must be noticed that the Phases B and D can significantly be reduced or eliminated relative to pore density, impingement velocity and PM thickness and geometry.
Phase A: In a free space between nozzle outlet and porous medium surface, a free jet penetrates throughout the available space defined by the distance between nozzle and PM until impinging onto the PM surface. A free jet in Phase A is characterized by the jet angle, its velocity and propagation angle with respect to the PM surface. Depending on the distance from PM, a free jet may partly or fully be developed in space.

Phase B: The jet impingement onto the PM surface may be divided into two parts: jet reflection from the interface (phase B) and jet propagation throughout (inside) the PM volume (phase $\mathrm{C}$ ). This impingement and division between phases $\mathrm{B}$ and $\mathrm{C}$ depend not only on the injection parameters (e.g., injection pressure) and nozzle geometry (e.g., nozzle hole diameter) but also on the distance from the nozzle outlet as well as on the pore size, its density and the wall thickness of the pore junctions.

Phase C: In this phase, the jet is distributed (propagates) throughout the PM volume, and this process is characterized by a wide jet spreading (self-homogenization) in the PM volume. This effect is related to a multijet splitting [5154]. The multijet splitting is a result of jet interaction with a large number of pore junctions (walls) present in the PM volume [52]. Depending on the jet momentum, impingement velocity, PM geometry, and pore size and 


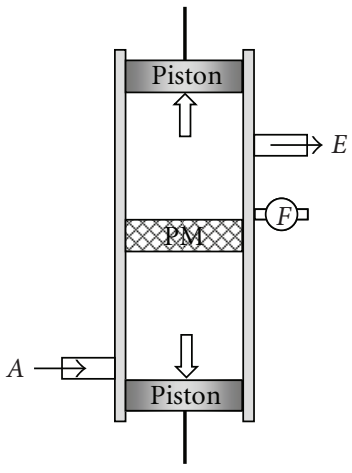

(a)

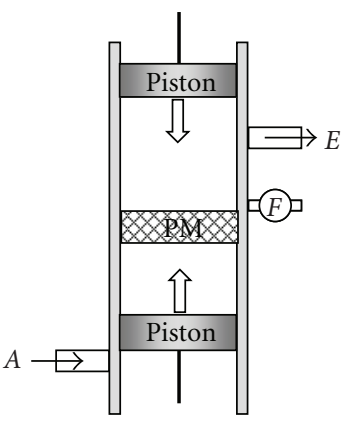

(b)

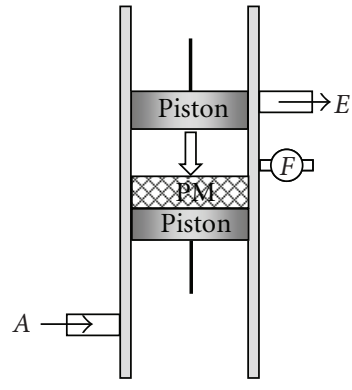

(c)

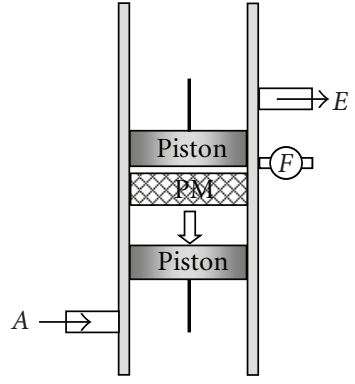

(d)

FIGURE 49: Engine cycle with porous catalytic member in the cylinder acc. to [56]; F-fuel supply; $A$-air supply; E-exhaust.

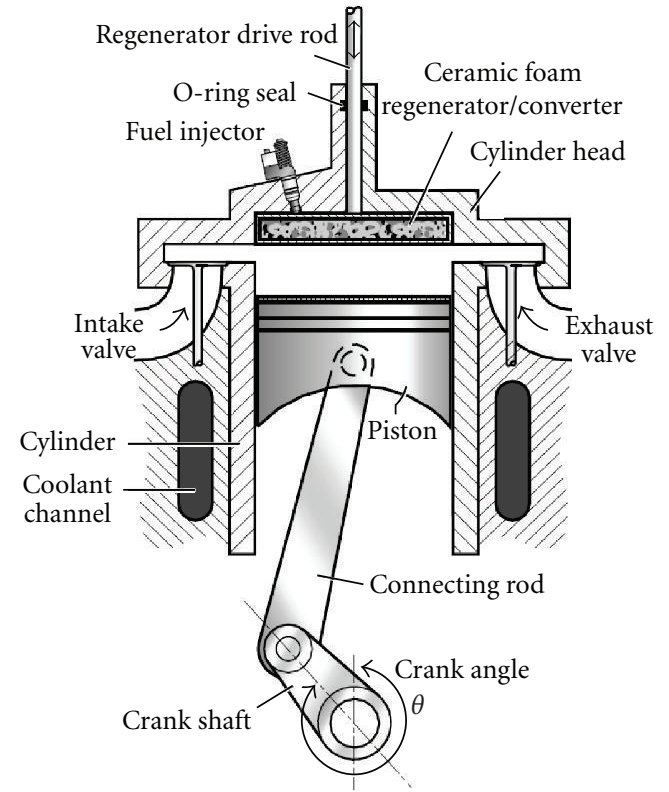

Figure 50: Compression-ignition engine cycle with a moveable porous regenerator [117].

density, the injected fuel is completely trapped inside the porous medium volume or part of the liquid may leave the PM volume (Phase D). This effect may be utilized for different applications in internal combustion engines, as described below.

To demonstrate a unique effect of Diesel-jet spatial distribution during interaction with a porous structure, the author has carried out an experiment presented in Figure 37. The Diesel jet impinges on to porous plate having the thickness of a few pores, only allowing visualization of strong radial jet spreading in the porous medium volume. Diesel-jet interaction with the porous medium is presented at a single time instance ( $900 \mu$ s after contacting the porous medium). After the initial jet contacts the porous structure the initial jet is divided into a number of smaller jets penetrating at a large angle across the initial direction. This radial-like distribution in a PM is much more intense than the axial one along the jet propagation direction. After contacting the PM surface, part of the injected fuel is "reflected back" upstream and downstream across the primary jet. This strong spatial distribution (it may be used for homogenization in space) of a Diesel jet throughout the PM volume is significantly influenced by the pore density (i.e., mean pore diameter), number of pores as well as junction wall thickness [53].

In order to get more insight into the process of fuel distribution throughout the porous- medium volume a quasi 2-dimensional distribution inside the PM has been recorded, as shown in Figure 38 [51-54]. The Diesel jet impinges onto the porous structure with thickness of a few pores thickness having on the view side a glass wall connected to the PM plate. The data are given for different instances after a free jet has touched the PM with its pore density of $10 \mathrm{ppi}$. The axial jet propagation inside the porous structure is reduced, and rapid radial fuel distribution may be observed giving rise to a very quick homogenization effect in space.

There are different concepts utilizing an interaction of a high-velocity liquid jet (e.g., Diesel or gasoline spray) with a highly porous structure.

A case of a porous ring integrated with the Diesel nozzle for initial spreading of the Diesel jet (multijets created by initial jet interaction with a porous structure) and their distribution in space is shown in Figure 39. In this case, a ring made of a porous medium (foam) has a diameter of $20 \mathrm{~mm}$ and thickness of approx. $3 \mathrm{~mm}$. Diesel jets leaving a sevenhole nozzle with a piezo-actuator may not develop in space, but they interact with a ring made of porous structure. As a result a wide spreading of initial jets may be observed indicating a multijet nature of the process. In this case, spreading Diesel jets propagate throughout a free space outside the PM ring. General observations on the Diesel jet interaction with a small porous ring can be summarized as follows [126]: reduced axial penetration of jets and reduced (eliminated) wall impingement (Figure 40), wide radial spreading of jets (Figure 41), significantly reduced jet velocity after interaction with distribution element (Figure 42), the distribution process is 3-dimensional (Figure 43), significantly increased surface area (Figure 44), and very rapid vaporization of 

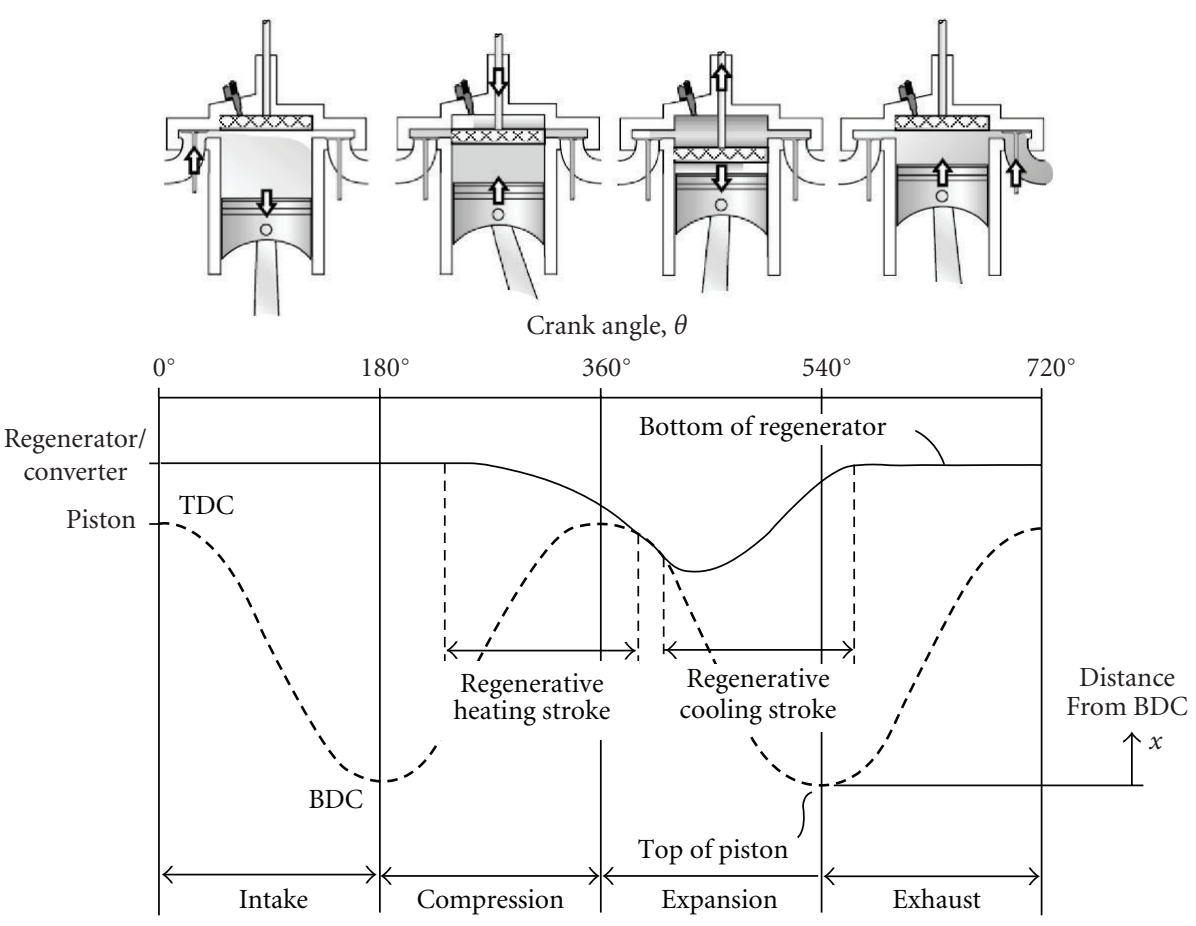

FIGURE 51: Motion profile of piston and porous heat regenerator over complete engine cycle (taken from [118]); Y-piston location.
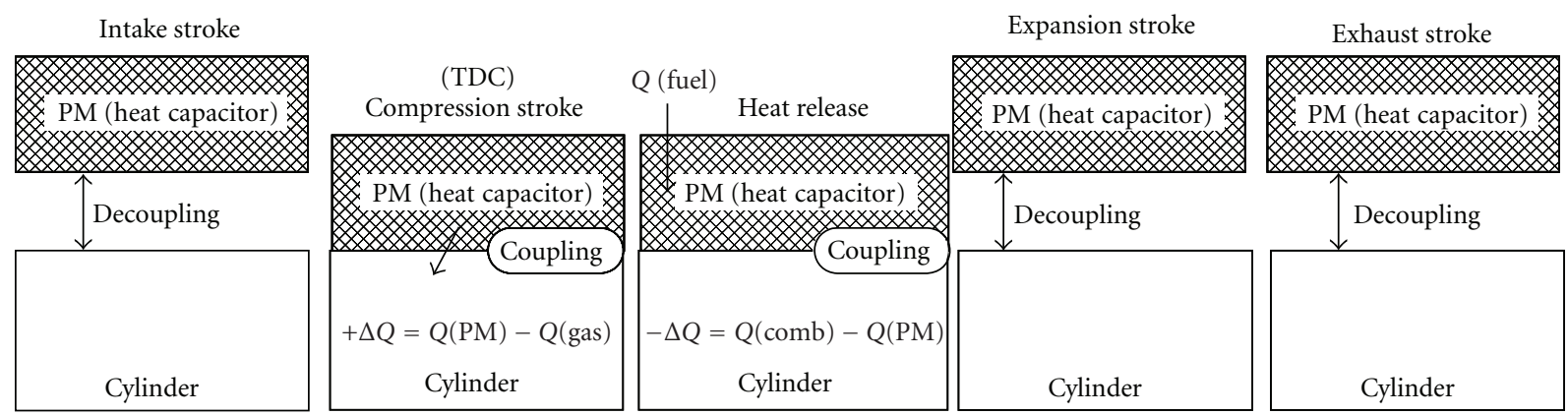

FIGURE 52: Thermodynamic model of engine with heat recuperation and combustion in porous reactor [66].

the fuel on hot distribution element after interaction with PM ring (Figure 45). The effect of porous ring temperature on the distribution of surface area of Diesel jets after interacting with the ring is shown in Figure 46. This figure shows results obtained for jet impingement on porous ring made of wire packing having wire diameter of $120 \mu \mathrm{m}$ [99]. This figure shows the surface area distribution in time after injection begins for 900 bar injection pressure and for different temperatures of the porous ring. First insight in to the surface distribution confirms significantly increases fuel area as compared to free jet injection. Here, fuel distribution process dominates (multijet splitting) in creating the surface area, and the effect of porous ring temperature is limited and reduces with increasing temperature. It is also indicated that at low distribution element temperature the surface area correspond to the cold conditions.

The space outside the PM ring may be filled with porous structure creating a combustion chamber (Figure 47). Here, the initial jets spreading on the PM ring is further supported by secondary-jet interaction with a porous reactor having larger pore size suitable for the performing of the combustion process. A similar effect may be obtained by a Diesel- (or gasoline-) jet interaction with small cylindrical obstacles, as shown in Figure $48[52,126]$. In this case, small obstacles simulate wall junctions of a 3D porous structure. For the fuel spreading in space not a number of obstacles but their geometrical configuration is critical. The case presented in Figure 48 consists of 5 obstacles resulting in very good Diesel-jet distribution in space (presented is a single Diesel jet). The dominant role in this process is played by a first obstacle: its diameter, distance from the nozzle outlet, and the injection pressure (impingement velocity) are major factors (parameters) of jet distribution in space. This distribution is based on a multijet splitting model. In Dieseljet impingement on a single obstacle with smaller diameter, the distribution angle decreases with increasing injection 


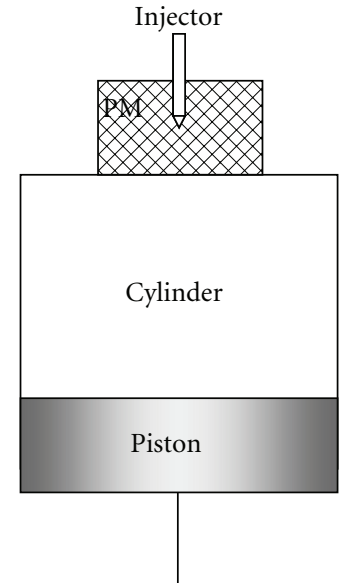

(a)

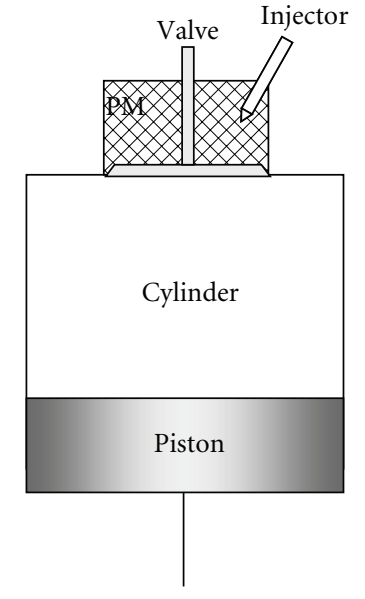

(b)
FIgUre 53: Two thermodynamic realizations of engine with heat recuperation and combustion in porous reactor: (a) engine with open chamber; (b) engine with closed chamber.

pressure. For larger obstacles, the angle between both jets increases almost independently of the injection pressure. This angle does not change with time after the beginning of the impingement process, but decreases with increasing distance between nozzle and obstacle $[52,126]$. References $[117,145]$ also discusses fuel distribution and diesel jet interaction with the porous media.

\subsection{Engine Concept with a Catalytic Component: PM Reactor} with Catalytic Coating for Heat Recuperation, Ignition, and Combustion. The engine cycle described in this section is based on the description given in [56] and presents one of different possible realizations of the engine with catalytic porous structure in the cylinder (for catalytic supported combustion). One of the advantages of such an engine is possibility of engine operation at lean-charge conditions giving rise to lowered combustion temperature and reduced exhaust emissions. It is also assumed that the catalytic member accumulates part of the combustion enthalpy having proper operational temperature to promote the desired oxidation process. In a typical engine, the oxidation catalyst is mounted inside the engine cylinder. In Figure 49, a case of two pistons in a cylinder with a catalyst member (further called a catalyst) between them is considered for detailed analysis. The detailed engine analysis on the engine design of Figure 49 was performed by Hanamura et al. [146, 147]. This engine (Figure 49) consists of a cylinder with two oppositely moving pistons and of a catalytic porous component or member positioned between both pistons. The cylinder is equipped with an air supply system $(A)$, fuel supply $(F)$, and exhaust system $(E)$. In this case, a catalytic porous member is centrally positioned in the cylinder and preferably has a honeycomb structure. Let us start analysis of the engine cycle at the point when both pistons are located at their bottom dead centres (BDC)-(Figure 49(a)). The air supply port is open and air may be supplied to the cylinder. Simultaneously, the upper piston, too gives free the exhaust port, and the cylinder scavenging process is possible. During the compression stroke (Figure 49(b)), both pistons move toward their TDCs (i.e., means movement toward the catalytic porous structure). In this case, the air supply port is closed and the exhaust port is still open, while both pistons do not move simultaneously. This allows completing the cylinder scavenging process. Farther piston movement (Figure 49(c)) results in compression in the cylinder in the volume between both moving pistons. The bottom piston reaches its TDC and is located in proximity to the catalyst. The upper piston does not reach its TDC yet, and the fuel may be supplied to the volume between the catalytic porous member and the upper piston. Farther movement of both pistons (Figure 49(d)) does not change the volume trapped between them, the only effect is that the mixture is passing the catalytic porous structure completing the combustion process. From this point, the expansion stroke is realized converting heat into mechanical work.

A similar engine cycle with heat recuperation in a porous structure and catalytic support of the combustion process has recently been described by Kaviany et al. $[83,117,118]$.

The original work in the regenerative engine research for was published in [117]. The summarized results of the engine study were used in [118]. The porous regenerator is attached to a rod moving up and down inside the engine cylinder as synchronised with the piston movement (Figure 50). The movement profiles of piston and regenerator in the cylinder are presented in Figure 51 as taken from [118]. There are some characteristic locations of the porous regenerator over the engine cycle: during intake and exhaust strokes, the regenerator is positioned at its TDC close to the engine head. During the compression strokes, the porous regenerator moves down in the cylinder toward the piston which is performing the regenerative heating stroke. During this period, there is a marked noticeable transfer of heat from the insert to the gas, increasing gas temperature as it flows within the insert. At a crank angle near $360 \mathrm{deg}$, the combustion process occurs and the sudden increase in pressure in the top chamber momentarily reduces the mass flow rate through the insert. During the expansion stroke, the porous regenerator moves up toward the engine head while it is in the regenerative cooling stroke. During the regenerative cooling stroke the hot burned gases in the cylinder flow through the porous regenerator playing the role of a heat capacitor (large specific surface area and heat capacity). Part of the exhaust gas energy is stored in the porous regenerator $[117,118]$.

During the regenerative heating stroke, the porous regenerator moves down, and the cold air trapped in the cylinder flows through the hot regenerator and heats up. This process ends the heat recuperation in the porous regenerator by transferring the heat from the hot exhaust gases to cold air supplied to the cylinder during the intake stroke. The increase in thermal efficiency of the regenerative engine cycle is due to the enlargement of the loop due to the higher pressures and temperatures during the expansion part of the cycle. Even with a smaller compression ratio resulting from losing volume occupied by the insert, there is a net increase in thermal efficiency. For the same power 


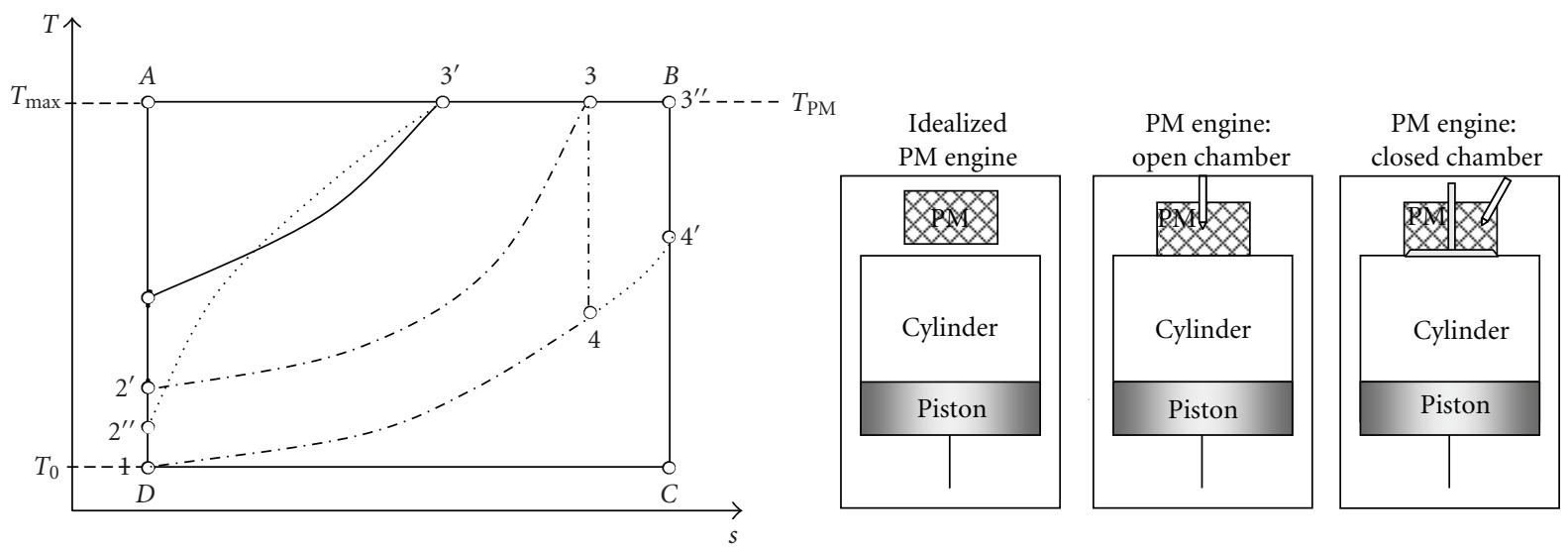

$$
\begin{aligned}
& A-B-C-D-A \text { : Carnot cycle } \\
& 1-2-3-4-1: \text { Idealized Otto cycle } \\
& 1-2^{\prime}-3^{\prime}-3^{\prime \prime}-4^{\prime}-1: \text { PM engine with closed chamber } \\
& 1-A-3^{\prime \prime}-4^{\prime}-1 \text { : Idealized PM engine cycle } \\
& 1-2^{\prime \prime}-3^{\prime}-3^{\prime \prime}-4^{\prime}-1: \text { PM engine with open chamber }
\end{aligned}
$$

Figure 54: Comparison of Carnot, conventional engine (Otto) and PM engine cycles (all cycles are operated between the same low and high temperatures) (taken from $[65,66])$.

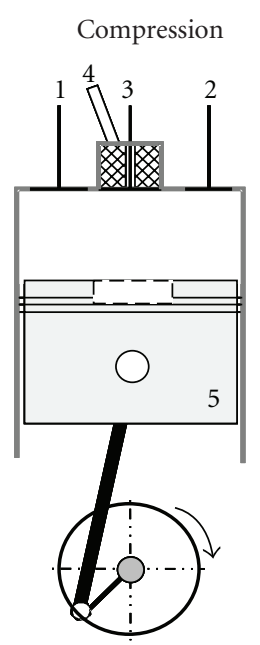

(a)

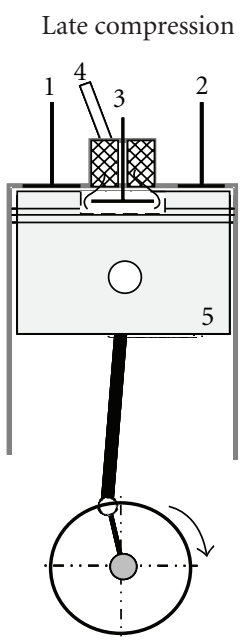

(b)

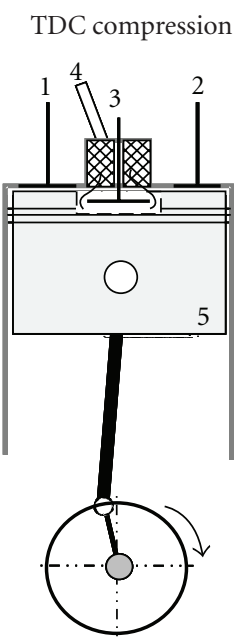

(c)

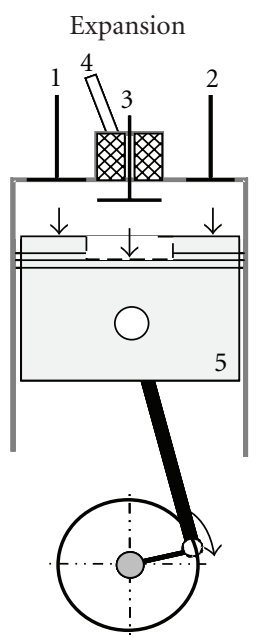

(d)

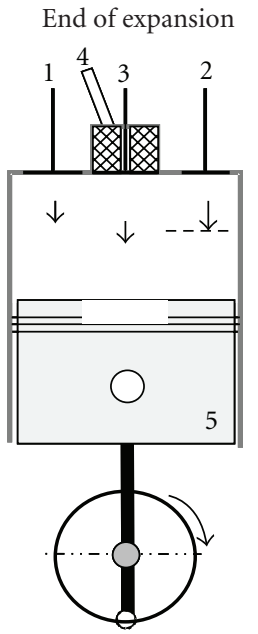

(e)

FIGURE 55: Engine cycle with porous reactor in closed chamber [65]: 1-intake valve; 2-exhaust valve; 3-additional valve; 4-fuel injector; 5-piston

generation, the regenerative engine consumes less fuel than the nonregenerative engine [117]. The result has shown that thermal efficiency increased from $34 \%$ to $46 \%$. In the engine described by Kaviany et al., the combustion process is performed in a free space of the cylinder but not in the porous medium volume. Thus the peak temperature of the regenerative engine is closer to that of the nonregenerative engine, and the level of the thermal $\mathrm{NO}_{\mathrm{x}}$ formation is similar to the nonregenerative engine. The insert can also be used as a catalytic converter for the particulates and some of the exhaust gases. The particulates (soot) can be trapped during the regenerative heating stroke and then burned during the regenerative cooling stroke, when the supply of oxygen in the fresh air and the relatively high temperature of the solid matrix allow for soot oxidation. When coated with a catalytic material, like platinum or palladium, the insert can also oxidize the unburned hydrocarbons and carbon monoxide during the regenerative heating stroke, therefore, before the exhaust gas leaves the cylinder. Irrespective of the details of the considerations, the $\mathrm{NO}_{\mathrm{x}}$ formation by high-temperature process in engine may be reduced by heat accumulated in the porous structure, and $\mathrm{CO}$ and $\mathrm{HC}$ components may also be reduced.

Durst and Weclas [66] has analysed a similar engine concept with a porous heat regenerator for supporting fuel vaporization and combustion process. The superadiabatic flame temperature resulting from heat regeneration in a porous regenerator [145], and the fuel droplet-regenerator 


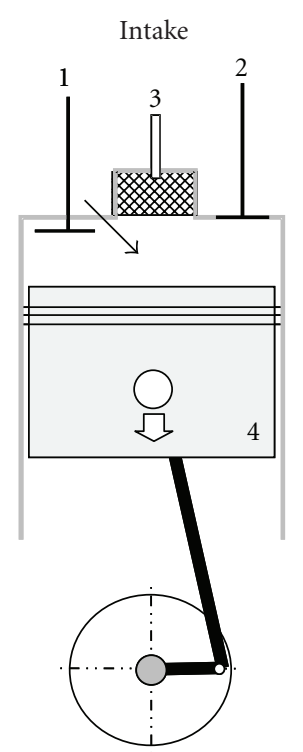

(a)

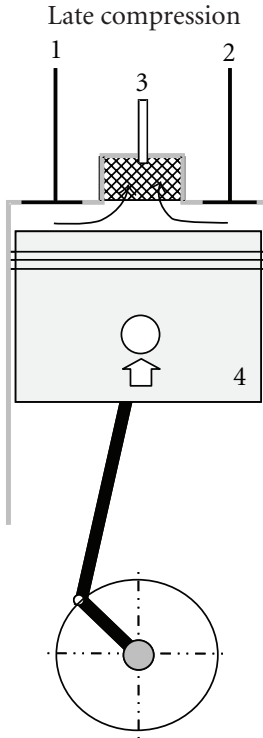

(b)

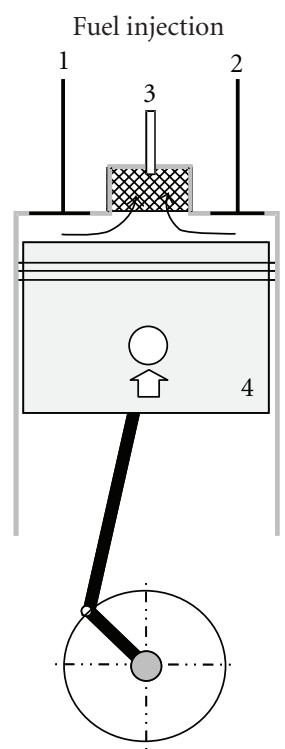

(c)

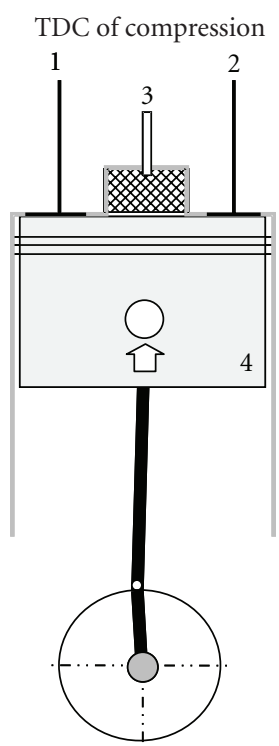

(d)

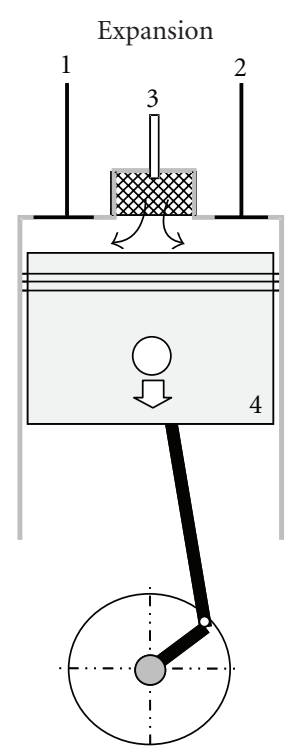

(e)

FIGURE 56: Engine cycle with porous reactor in open chamber [65]; 1-intake valve; 2-exhaust valve; 3-fuel injector; 4-piston.

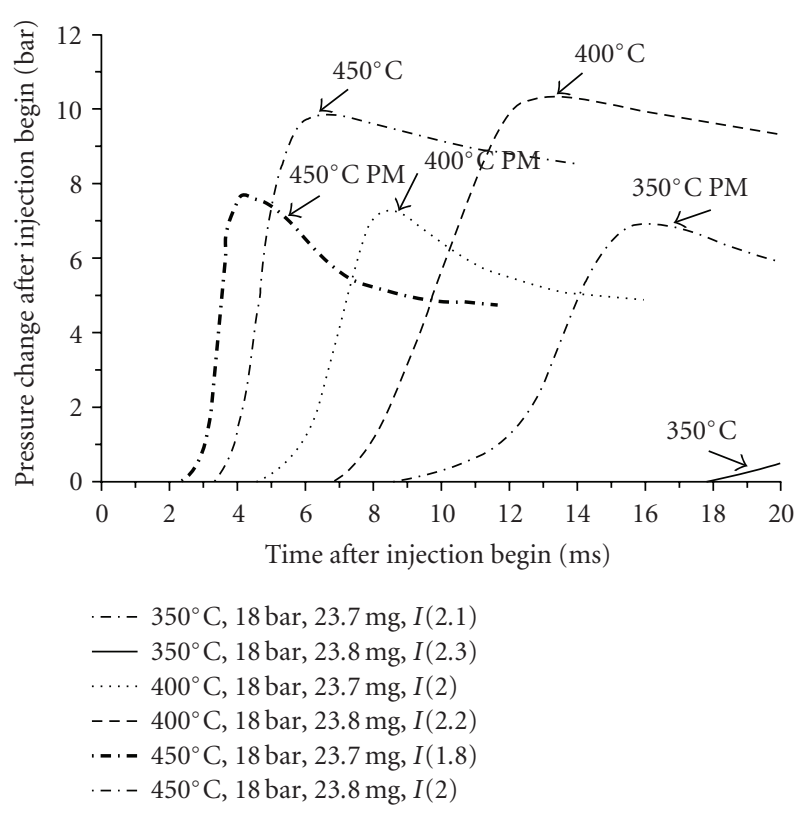

FIGURE 57: Comparison of pressure history after injection begins in a constant volume adiabatic combustion chamber for Diesel injection and SiC porous reactor (marked as PM) for different initial temperatures (lower temperatures correspond to low-temperature oxidation processes).

interaction enhance fuel vaporization and may improve the combustion process. Since the fuel is injected toward the porous regenerator to be located close to the fuel injector, droplet impingement onto the porous structure is likely. The impinging droplets on the surface having a temperature higher than the Leidenfrost temperature may very quickly vaporize. Please note that the process performed with a porous structure moves the Leidenfrost effect toward much higher surface temperatures. Owing to the high temperature from the regenerative heating stroke and fuel impingement onto the high-temperature porous surface, the vaporization process is enhanced, and the necessary time is significantly reduced. The goal is to achieve a complete and fast vaporization of the liquid fuel and a homogeneous distribution of the fuel vapours in the zone above the regenerator. There are a number of publications related to heat recuperation in the engine. Hanamura et al. [146, 147] have performed a one-dimensional numerical calculation on a new reciprocating heat engine proposed on the basis of superadiabatic combustion in porous media. The system consisted of two pistons and a thin porous medium in a cylinder, one being a displacer piston and the other a power piston. These created reciprocating motions at a phaserelation angle. By means of the reciprocating flow system, the residual combustion gas enthalpy was effectively regenerated to induce enthalpy increase in the mixture through the porous medium. Due to heat recirculation, the thermal efficiency reached up to $58 \%$ at a compression ratio of 2.3 .

Pickenäcker and Trimis [116] analysed premixed gas combustion within inert porous media for achieving combustion temperatures higher than the adiabatic flame temperature based on the gas inlet conditions (superadiabatic combustion). The authors in this work analysed the excess enthalpy in free flames and in flames within porous media in order to estimate the amount of excess temperature caused by the presence of the porous matrix. A two-medium treatment was used to model the nonequilibrium between the gas and the solid phases. The superadiabatic temperature was shown to be a function of a modified Lewis number, the ratio of the solid and the gas phases, effective conductivities and the porosity of the porous medium.

Ferrenberg et al. [148-151] investigated and described an engine with heat regeneration in the cylinder having 
the following potential improvements over conventional gasoline or diesel engines: higher thermal efficiency, lower exhaust emissions, less stringent fuel requirements, no ignition system required for steady operation, lower compression ratios, high power density, and similar to conventional engine hardware.

Ruiz [152-156] described a Stirling cycle which can be approximated in an internal combustion engine by means of regeneration of internal heat. Computational results showed that the IC Stirling cycle offers a significantly better thermal efficiency over a conventional IC engine if some effects, such as the tendency for the cylinder air to "hide" inside the regenerator, are overcome.

\subsection{Engine Concept with Mixture Formation and Combustion} in a Porous Reactor. This section describes an engine concept proposed by Durst and Weclas [66, 67, 127, 128, 157], in which the fuel supply, mixture formation, ignition, and combustion processes are performed in the porous-medium volume only. The main goal of application of a porous reactor to in-cylinder processes in the engine is to realize a homogeneous flameless combustion process in the PM volume characterized by a near-zero emissions level. An additional goal is to increase engine cycle efficiency by heat recuperation in the PM or at least to keep the efficiency at the level of the best Diesel-engine cycle. A proper layout of the PM engine yields temperature-controlled combustion that is also characterized by low $\mathrm{NO}_{\mathrm{x}}$ emissions. This is mainly achieved because of the presence of the solid phase of the porous reactor during combustion resulting in lowered temperature level and homogeneous temperature distribution in space. This is the essential difference between the combustion processes which occur in conventional IC engines and the PM engine described in $[66,67]$. In the case of the PM engine, the UHC emissions are mainly eliminated by the very fast and complete vaporization of the fuel injected into the porous-reactor volume and also by the complete combustion process in the PM volume (also by elimination of liquid fuel wall impingement). The two phenomena responsible for UHC emissions in a conventional engine, overmixing (overleaning) and undermixing (overriching), are nearly eliminated in the PM engine, since the fuel is not injected into the free space of the cylinder but is injected inside the PM (see Sections 6.1 and 6.2). Here, a large specific surface area, a huge heat capacity and very intense smallscale motions in the PM pores make the mixing processes homogeneous throughout the reaction zone. Moreover, the processes are relatively independent of spray atomization. Of course, this may be achieved in the PM engine only when spatial homogeneity of the fuel distribution throughout the PM is permitted (Section 6.2).

Most particulate carbonaceous material emitted by a conventional engine results from incomplete combustion of fuel hydrocarbons. Soot formation takes place under hightemperature and high-pressure conditions, and the soot oxidation process takes place in some parts of the cylinder, significantly reducing the net soot emission of the engine [65]. At low temperatures $(T<1700 \mathrm{~K})$, only aromatics or highly unsaturated aliphatic components are very effective in soot formation through pyrolysis. In the case of the PM engine, soot emission is principally reduced by the following factors: the lower temperature in the reaction zone, very fast vaporization, more homogeneous mixture composition and relatively long residence time in the reaction zone of the porous-medium volume with a homogeneous temperature distribution.

A thermodynamic model of an IC engine with mixture formation, combustion, and heat recuperation in a porous reactor is given below-see Figure 52 [127]. The model takes into consideration two parts of the engine combustion system: free volume of the cylinder and a porous-medium reactor volume (heat capacitor). This PM heat capacitor may be thermally coupled to or decoupled from the cylinder gas. It is assumed that no time elapses during thermal coupling (i.e., heat exchange), and the heat capacitor has a very large heat capacitance in comparison with the cylinder gas capacity. This results in a nearly constant reactor temperature during the heat exchange between the heat capacitor and the cylinder content. Moreover, it is assumed that the compression and expansion processes realized in the specified engine are adiabatic. Under these assumptions, the thermodynamic cycle of an IC engine using the PM combustion reactor can be described as follows. In the first step, the cylinder is charged with fresh air during the intake stroke of the working cycle. For this part of the cycle, the heat capacitor is thermally decoupled from the cylinder and has no contact with the working gas. After completion of the intake stroke, the compression stroke is applied; this is assumed to be an isentropic compression process. At the end of the compression stroke, the heat capacitor is coupled to the cylinder, ideally at TDC, so that the working gas immediately reaches the heat capacitor temperature. If this temperature is chosen to be the limiting temperature of the engine material, it is apparent that the engine considered here has an excellent thermodynamic performance. In the phase of the cycle when the working gas is in contact with the heat capacitor, fuel is injected and the combustion process occurs in the porous-medium volume. This process will not result in rapid increase of reactor (gas) temperature, since the heat capacitor acts as a buffer. This idealized thermodynamic model of an engine with heat recuperation by combustion in a porous-medium volume may in a more realistic manner be realized in two different ways:

(i) an engine in which the PM reactor has permanent contact with the cylinder content (so-called openchamber system) — see Figure 53(a),

(ii) an engine in which the PM reactor has periodic contact with the cylinder content (so-called closedchamber system) — see Figure 53(b).

In the case of an open-chamber system, the porous reactor has permanent contact with the cylinder content (gas), and for example the compression process in the cylinder is not nearly adiabatic (idealized isentropic) any more. In the case of a closed-chamber, it is assumed that the valve in the PM chamber opens near to the TDC of compression and remains open during the expansion stroke in the 
cylinder. The thermodynamic properties of all the considered engine concepts; that is, the ideal case (model of Figure 52) and more realistic cases of Figure 53 as compared to the Carnot and Otto engine cycles (heat supply under constant volume conditions) can be presented in a T-s diagram as shown in Figure 54. Principally, the PM engine concept has a great potential for increasing thermodynamic cycle efficiency, which has still to be verified experimentally. As already indicated above, the main reason of the PM engine concept is to change the combustion process for achieving a homogeneous process at lowered temperature and nearzero emissions level. For this reason, the engine cycles with closed and open chambers are shortly presented in this section. An engine cycle with a PM reactor having periodic contact with the cylinder content (closed chamber system) is schematically illustrated in Figure 55. At the end of the expansion stroke (Figure 55(e)), the valve controlling the timing of the PM chamber closes and fuel may already be injected in the PM volume. This chamber is a low-pressure chamber and sufficient time is available for fuel supply and vaporisation in the PM volume. Simultaneously, other processes may be performed in the cylinder volume. These processes may be continued through exhaust, intake, and compression strokes (Figure 55(a)). Near the TDC of compression (Figure 55(b)) the valve in the PM chamber opens and the compressed air flows from the cylinder to the hot PM containing fuel vapours. Very fast mixing of both gases occurs before the mixture is ignited in the whole PM volume (Figure 55(c)). The ignition timing is controlled by timing of the valve in PM chamber. The resulting heat release process performs simultaneously in the entire PM volume. Three necessary conditions for a homogeneous combustion are here fulfilled: homogenisation of charge in the PM volume, $3 \mathrm{D}$ thermal self-ignition in the PM volume, and a volumetric combustion with a homogeneous temperature field in the $\mathrm{PM}$ volume. Additionally, the PM acts as a heat capacitor and controls the combustion temperature level. In the case of a PM engine concept with open chamber, the porous reactor may be positioned in the piston, the cylinder or the engine head. The last case is shown in Figure 56. During the intake stroke (Figure 56(a)) there is weak influence of the PM heat capacitor on the in-cylinder air thermodynamic conditions. Also, during early compression stroke, only a small amount of air contacts the hot PM reactor. This heat exchange process (nonadiabatic compression) increases with continuing compression timing (Figure 56(b)), and at the TDC, the whole combustion air is trapped in the PM reactor volume. Near the TDC of compression, the fuel is injected into the PM volume (Figure 56(c)) and very fast fuel vaporisation and mixing with air occur in the 3D structure of the PM (see Section 6.2). A 3D thermal self-ignition of the resulting mixture follows inside the PM volume together with a volumetric (flameless) combustion characterised by homogeneous temperature distribution in the PM combustion chamber (Figure 56(d)). The ignition timing is controlled by timing of the fuel injection in PM reactor.

During the following expansion stroke, the heat is converted into mechanical work (Figure 56(e)). Again, all necessary conditions for a homogeneous combustion process are fulfilled in the PM reactor volume. The combustion in a porous reactor can be performed in the whole reactor volume, that is, local nonhomogeneity of the charge in the reactor or not simultaneous ignition of the charge in a particular pores do not necessarily negative influence the result of combustion, as it would be expected from free combustion process. As shown in Figures 57 and 58, lowand high-temperature oxidation processes (cool- and blueflames, thermal ignition, and heat release) as performed in a porous reactor have shorter ignition delay time and higher process dynamic [158]. This process acceleration is especially visible at lower temperatures. Owing to the heat accumulated in a porous reactor, a corresponding maximum combustion pressure is lower as that obtained under Diesel-engine like conditions (Figure 58).

A short comment is needed on cold start conditions. There is obvious that in order to properly operate a porous reactor as a combustion chamber in engine, the reactor must already be hot, that is enough energy must already be accumulated in the porous matrix. There are different possibilities to preheat the porous reactor under cold-start conditions. One of promising ways is a direct electric heating of the reactor $[104,105]$. Another possibility is to use compression energy to be accumulated in the porous reactor. After approximately 50 compression cycles (for a typical Diesel engine conditions), the porous reactors having a volume corresponding to a volume of the combustion chamber in piston bowl of Diesel engine may rich an ignition temperature. Depending on the realization of the engine with combustion in a porous reactor, it is also possible to start the engine with a "conventional" ignition and combustion and use the combustion energy to heat a cold reactor.

\section{Summary, Conclusions, Final Remarks, and Outlook}

This paper has described different possible applications of highly porous open cell structures to in-engine, especially to in-cylinder processes including the combustion process. This application means the utilization of unique features of porous media for supporting individual engine processes, especially fuel distribution, fuel vaporization, mixing, heat recuperation, ignition, and combustion (heat release). The last application allows the realization of a homogeneous flameless and very clean combustion process in the volume of the porous reactor as has been confirmed in [66]. Full applicability of this combustion technique to internal combustion engines concerning a clean combustion process and high cycle efficiency must still be experimentally verified. In particular, this applicability strongly depends on availability of suitable high-temperature materials and corresponding porous structures that have to be developed. There are still insufficient experimental data available on the physics of the engine processes realized in highly porous open cell structures. However, this technology as applied to the incylinder process has a great potential for improving engine cycle efficiency and significant reduction of combustion 


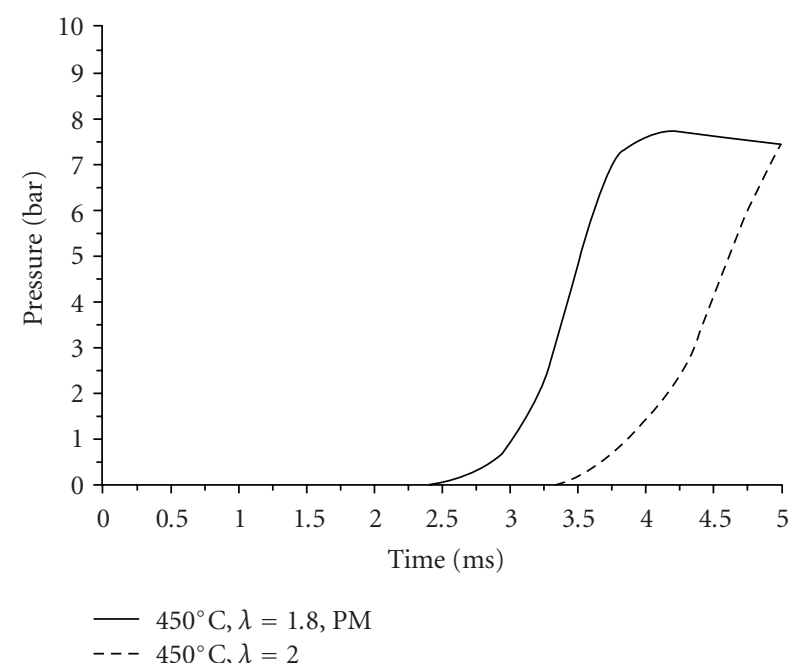

(a)

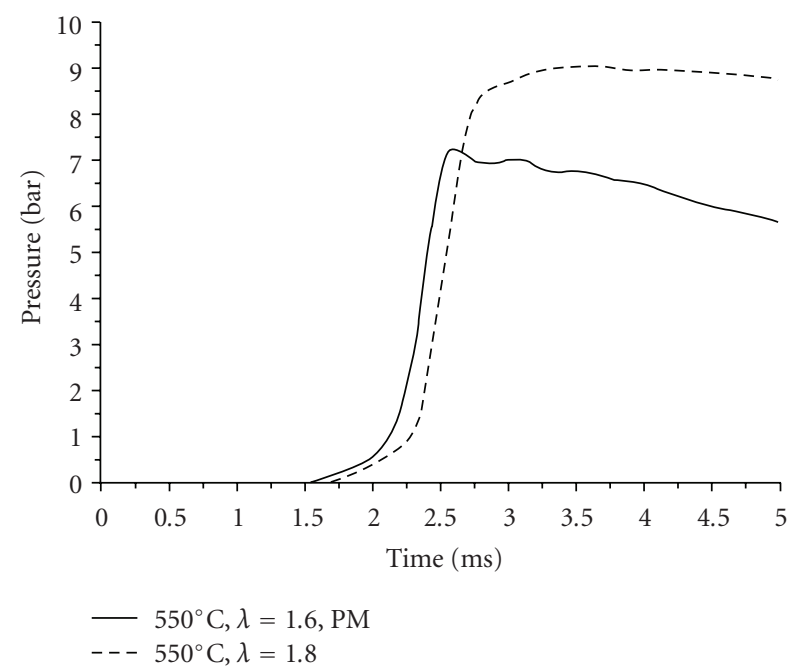

(c)

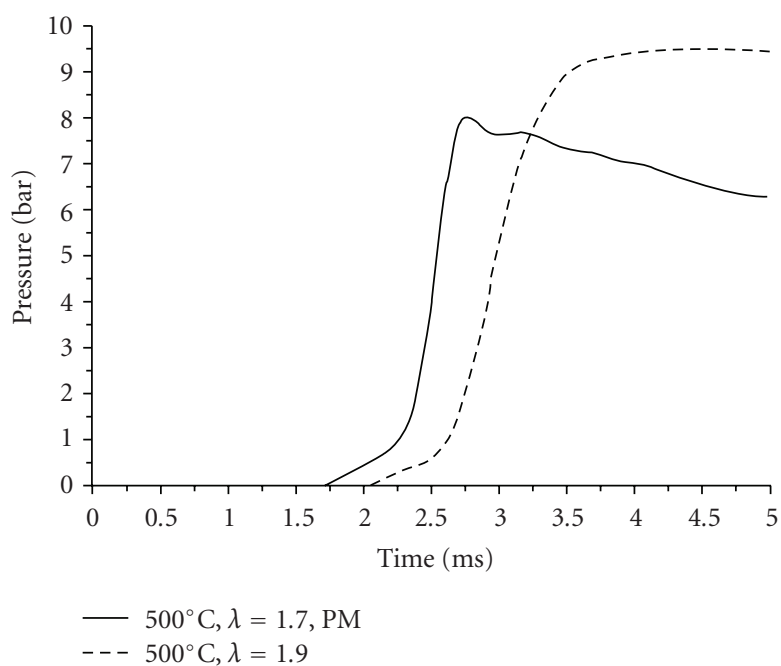

(b)

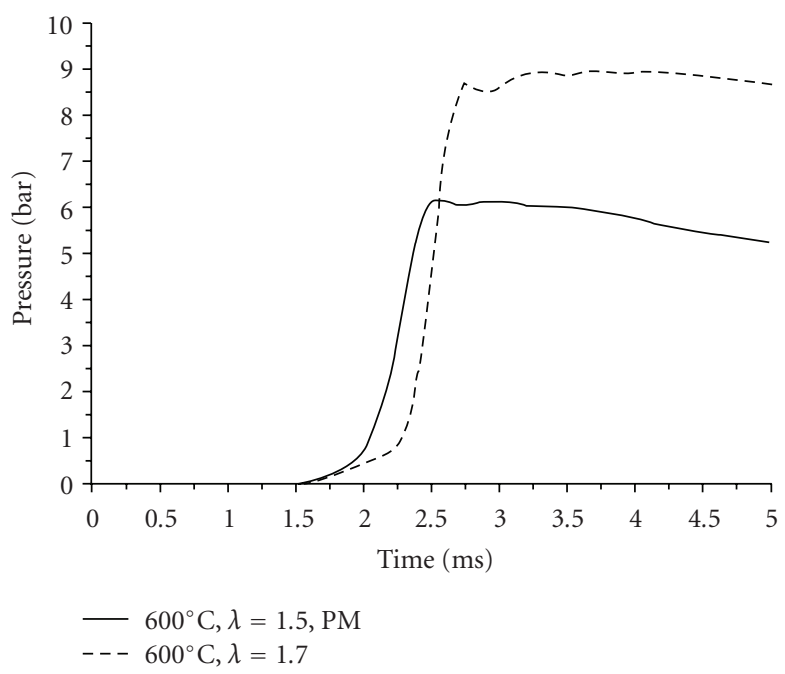

(d)

FIGURE 58: Comparison of pressure history after injection begin in a constant volume adiabatic combustion chamber for Diesel injection and $\mathrm{SiC}$ porous reactor (marked as PM) for different initial temperatures (time scale is reduced to the initial phase of the process, especially to premixed combustion).

emissions, and it is expected that more and more experimental and numerical investigations of particular engine processes in porous media will be reported in the nearest future. This is one of the most important intension of this paper to widely present potential of the combustion technology in porous media and to motivate researchers to deal with this topic. Parallel development of modern hightemperature materials and highly porous structures (not only foam structures) will help to apply this technology to engine processes. This aspect is of course critical for application of the porous media combustion technology to internal combustion engines, but is not a key topic of this paper. Actually, available structures and materials (especially $\mathrm{SiC}$ foam structures and high-temperature metal foams) are sufficient for practical demonstration of applicability of this technology to individual engine processes. As described in the paper, there are principally three different ways for application of porous-medium combustion technology to internal-combustion engines: support of individual processes, support of complex processes for the realization of a homogeneous combustion process and temperature control, as well as utilization of the porous structure as a heat capacitor for heat recuperation in the solid phase of the porous medium. In the first type of application, the porous structure may be utilized for fuel vaporization and improved fuel distribution in space making the mixture more homogeneous in the combustion chamber. Combination of this application with a direct high-pressure Diesel or gasoline injection offers a new possibility of realization of mixture formation in the engine, especially for mixture homogenization in the combustion chamber keeping the late-injection strategy (advantageous for controlling ignition timing). Extension of these processes for mixture formation and ignition in a porous-medium reactor volume allows realization of a homogeneous, flameless combustion (heat release) process characterized by a near-zero emissions level, 
homogeneous temperature field at reduced temperature level, as well as internal heat recuperating increasing the engine cycle efficiency. The last application, very often used in numerical thermodynamic calculations, is the application of a porous structure as a heat recuperator only. In a real engine, it would be very difficult to apply only the heat capacity function separately from other functions, for example, influence on mixture formation or ignition conditions.

The application of a highly porous open cells structure to in-cylinder engine processes may be one of the very promising ways for further engine developments, especially from the point of view of reduction of exhaust emissions under realization of a minimum of $\mathrm{CO}_{2}$ level (fuel consumption). There is a big field ahead of engine research to optimize engine cycles with heat recuperation in porous reactors. The cycle efficiency strongly depends on the assumptions and thermodynamic conditions used in the calculation. The engine concept with mixture formation and combustion in porous reactor is one of possible solution for the future. The thermodynamics of such engine cycle as well as pollution production cannot be described by existing models used for conventional engine analysis.

\section{Nomenclature}

ARC: Activated radical combustion

ATAC: Active thermo-atmosphere combustion

$d$ : $\quad$ Mean pore diameter $(\mathrm{mm})$

BDC: Bottom dead centre (piston location)

DI: Direct injection

DPF: Diesel particle filter

GDI: Gasoline direct injection

HCCI: Homogeneous charge compression ignition

I.C.: Internal combustion (engine)

ppi: $\quad$ Pores per linear inch (pore density)

PM: $\quad$ Porous medium (structure)

PAH: Polycyclic aromatic hydrocarbons

RC: Radical combustion

SCR: Selective catalytic reduction (lean $\mathrm{NO}_{\mathrm{x}}$-catalyst)

SSA: Specific surface area $\left(\mathrm{m}^{2} / \mathrm{m}^{3}\right)$

TDC: Top dead centre (piston location)

UHC: Unburned hydrocarbons

$P_{\text {inj: }}: \quad$ Injection pressure (rail pressure)

$X: \quad$ Distance between wall or porous structure and the injection nozzle outlet.

\section{Notations}

$\alpha$ : Crank angle

$\lambda$ : Air-to fuel ration (mixture composition)

Pe: Pecklet number

$S_{L}$ : Laminar flame velocity

$d_{p}$ : Equivalent pore diameter

$c_{p}$ : Specific heat of the gaseous mixture

$\rho_{g}$ : Density of the gaseous mixture

$\lambda_{g}$ : Heat conductivity of the gaseous mixture

$\varepsilon:$ Compression ratio

$\tau$ : Time after injection begin (trigger signal).

\section{References}

[1] A. Mayer, "Definition, measurement and filtration of ultrafine solid particles emitted by Diesel engines," in Proceedings of the 19th ATW-EMPA Symposium, April 2002.

[2] I. Gege, K. Ohno, S. Hong, and H. Sato, "Diesel particulate filter: filter material, innovation and design," in Proceedings of the FAD Conference, Dresden, Germany, 2003.

[3] M. Murtagh et al., "Development of a Diesel particulate filter composition and its effect on thermal durability and filtration performance," SAE Technical Paper 940235, 1994.

[4] G. A. Merkel, T. Tao, and W. A. Cutler, "New cordierite Diesel particulate filters for catalyzed and non-catalyzed applications," in Proceedings of the 6th International Congress on Catalysis and Automotive Pollution Control, 2003.

[5] G. A. Merkel, W. A. Cutler, and C. J. Warren, "Thermal durability of wall-flow ceramic Diesel particulate filters," SAE Technical Paper 2001-01-0190, 2001.

[6] A. Schäfer-Sindlinger, C. D. Vogt, S. Hashimoto, T. Hamanaka, and R. Matsubara, "New Materials for Particulate Filters in Passenger Cars, Auto Technology," no. 5, 2003.

[7] O. Savat, P. Marez, and G. Belot, "Passenger serial application of a particulate filter system on a common-rail directinjection Diesel engine," SAE Technical Paper 2000-01-0473, 2000.

[8] "Particulate traps for heavy duty vehicles," Environmental Documentation 130, Report of Swiss Agency for the Environment, Forests and Landscape (SAEFL), 2000.

[9] D. Turmel, F. Mao, Ch. Li, A. Prunier, and A. Pyzik, "Development of a new ceramic material for Diesel particulate emission control," in Proceedings of the Aachener Kolloquium Fahrzeug- und Motorentechnik, pp. 1087-1105, Aachen, Germany, 2004.

[10] "Emission control retrofit of Diesel-fuelled vehicles," Tech. Rep., Report of Manufacturers of Emission Controls Association, March 2000.

[11] P. Bovonsombat, B.-S. Kang, P. Spurk, H. Klein, and K. Ostgathe, "Development of current and future Diesel after treatment systems," in Proceedings of the MECA/AECC Meeting, Bangkok, Thailand, February 2001.

[12] A. Mayer et al., "Passive regeneration of catalyst coated Knitted fiber Diesel particulate traps," SAE Technical Paper 960138, 1996.

[13] A. Mayer, N. Heeb, J. Czerwinski, and M. Wyser, "Secondary emissions from catalytic active particle filter systems," Tech. Rep. 2003-01-0291, SAE Technical Paper, 2003.

[14] W. A. Cutler, P. Flörchinger, U. Zink, and D. Tomazic, "Regeneration-control-key to successful application of new DPF systems," in Proceedings of the Aachener Kolloquium Fahrzeug- und Motorentechnik, 2004.

[15] W. A. Cutler, "Overview of ceramic materials for Diesel particulate applications," in Proceedings of the 28th International Cocoa Beach Conference on Advanced Ceramics \& Composites, 2004.

[16] C. Arcoumanis and J. H. Whitelaw, "Fluid mechanics of internal combustion engines-a review," Proceedings of the Institution of Mechanical Engineers C, vol. 201, no. 1, pp. 5774, 1987.

[17] J. B. Heywood, Internal Combustion Engine Fundamentals, McGraw-Hill, New York, NY, USA, 1988.

[18] M. Weclas, A. Melling, and F. Durst, "Unsteady intake valve gap flows,” SAE Technical Paper 952477, 1995. 
[19] M. Weclas, "The influence of radial positioning accuracy on LDA velocity measurements in a valve gap," Measurement Science and Technology, vol. 7, no. 4, pp. 605-614, 1996.

[20] M. Weclas, A. Melling, and F. Durst, "Flow separation in the inlet valve gap of piston engines," Progress in Energy and Combustion Science, vol. 24, no. 3, pp. 165-195, 1998.

[21] I. Cosadia, J. Borée, G. Charnay, and P. Dumont, "Cyclic variations of the swirling flow in a Diesel transparent engine," Experiments in Fluids, vol. 41, no. 1, pp. 115-134, 2006.

[22] Ch. Bae, J. Yu, J. Kang, J. Kong, and K. O. Kyeong Ook Lee, "Effect of Nozzle geometry on the Common-Rail Diesel spray," SAE Technical Paper 2002-01-1625, 2002.

[23] M. S. Beckman and P. V. Farrell, "Simultaneous liquid and vapour Diesel fuel spray images from a HEUI injector," in Proceedings of the 14th Annual Conference on Liquid Atomization and Spray Systems (ILASS '01), Dearborn, Mich, USA, May 2001.

[24] G. Stiesch, Modeling Engine Spray and Combustion Process, Springer, New York, NY, USA, 2003.

[25] M. R. O. Panão and A. L. N. Moreira, "Experimental study of the flow regimes resulting from the impact of an intermittent gasoline spray," Experiments in Fluids, vol. 37, no. 6, pp. 834$855,2004$.

[26] M. F. Russell, G. Greeves, and N. Guerrassi, "More Torque, less emissions and less noise," SAE Technical Paper 2000-010942, 2000.

[27] Y. Ishibashi and M. Asai, "A low pressure pneumatic twostroke engine by activated radical combustion concept," SAE Technical Paper 980757, 1988.

[28] J. Lavy, J. C. Dabadie, P. Duret, C. Angelberger, J. F. Le Coz, and J. Cherel, "Controlled auto-ignition (CAI): a new highly efficient and near-zero $\mathrm{NO}_{\mathrm{x}}$ emission combustion process for gasoline engine application," in A New Generation of Engine Combustion Processes for the Future? P. Duret, Ed., IFP International Congress, pp. 101-114, TECHNIP, RueilMalmaison, France, 2001.

[29] Y. Ishibashi, K. Nishida, and M. Asai, "Activated radical combustion in a high-speed high-power pneumatic D.I. Twostroke engine," in A New Generation of Engine Combustion Processes for the Future? P. Duret, Ed., IFP International Congress, pp. 141-151, TECHNIP, Rueil-Malmaison, France, 2001.

[30] P. Wolters, W. Salber, and J. Dilthey, "Radical activated combustion. A new approach for gasoline engines," in A New Generation of Engine Combustion Processes for the Future? P. Duret, Ed., IFP International Congress, pp. 153-162, TECHNIP, Rueil-Malmaison, France, 2001.

[31] H. Zhao, J. Li, T. Ma, and N. Ladommatos, "Performance and analysis of a 4-stroke multi-cylinder gasoline engine with CAI combustion," SAE Technical Paper 2002-01-0420, 2002.

[32] W. Salber, P. Wolters, M. Duesmann, and J. Dilthey, "Controlled auto ignition combustion process with an electromechanical valve train," SAE Paper 2003-01-0032, 2003.

[33] A. Fuerhapter, W. F. Piock, and G. K. Fraidl, "CSI-controlled auto ignition-the best solution for the fuel consumptionversus emission trade-off," SAE World Congress SAE Technical Paper 2003-01-0754, 2003.

[34] J. Kusaka, T. Yamamato, and Y. Daisho, "Simulating the homogeneous charge compression ignition process using a detailed kinetic model for n-heptane mixtures," International Journal of Engine Research, vol. 1, no. 3, pp. 281-289, 2000.

[35] T. Urushihara, K. Hiraya, A. Kakuhou, and T. Itoh, "Parametric study of gasoline HCCI with various compression ratios, intake pressures and temperatures," in A New Generation of
Engine Combustion Processes for the Future? P. Duret, Ed., IFP International Congress, pp. 77-84, TECHNIP, RueilMalmaison, France, 2001.

[36] P. A. Caton, A. J. Simon, J. C. Gerdes, and C. F. Edwards, "Residual-effected homogeneous charge compression ignition at low compression ratio using exhaust reinduction," International Journal of Engine Research, vol. 4, no. 2, pp. 163177, 2003.

[37] G. Coma, P. Gastaldi, J. P. Hardy, and D. Maroteaux, "HCCI combustion: dream or reality?" in Proceedings of the 13th Aachen Colloquium on Vehicle and Engine Technology, pp. 513-524, 2004.

[38] Y. Ra and R. D. Reitz, "The role of vaporization and mixture preparation on HCCI engine combustion," in Proceedings of the Annual Conference on Liquid Atomization and Spray Systems (ILASS '04), Washington, DC, USA, May 2004.

[39] M. Canakci and R. D. Reitz, "Experimental optimization of a DI-HCCI-gasoline engine's performance and emissions using split injections with fully-automated micro-genetic algorithms," ASME Journal of Gas Turbines and Power, vol. 126, no. 1, pp. 167-177, 2004.

[40] P. A. Caton, H. H. Song, N. B. Kaahaaina, and C. F. Edwards, "Strategies for achieving residual effected homogeneous charge compression ignition using variable valve actuation," SAE Technical Paper 2005-01-0165, 2005.

[41] S. Lake, "Internal-Combustion Engine," US Patent no. 1,276,083, 1918.

[42] H. F. Leissner, "Internal-Combustion Engine," US Patent no. 1,260,408, 1918.

[43] D. Scherenberg, "Einrichtung zur Kraftstoffaufbereitung bei Fremdgezündeten Brennkraftmaschinen," German Patent Application no. DE 2306362, 1974.

[44] H. Schladitz and E. Hutzenlaub, "Verfahren und Vorrichtung zum Verdampfung von flüssigen Brennstoffen," German Patent Application no. DE 2343185, 1975.

[45] L. Schlier, W. Zhang, N. Travitzky, J. Cypris, M. Weclas, and P. Greil, "Macro-cellular silicon carbide reactors for a nonstationary combustion under piston engine-like conditions," International Journal of Applied Ceramic Technology. In press.

[46] G. Bernecker, "Carburetor," US Patent no. 4,089,314, 1978.

[47] H. Gladigow and W. Schaetzing, "Fuel atomization device," US Patent no. 5,609,297, 1997.

[48] M. Weclas, "Verfahren zur Erzeugung eines Flüssigbrennstoff-/Luftgemisches zum Betrieb einer Wärmekraftmaschine," German Patent Application no. DE 19813891, 1999.

[49] M. Scheffler and P. Colombo, Eds., Cellular Ceramics: Structure, Manufacturing, Propperties and Applications, WileyVCH, Cambridge, UK, 2005.

[50] A. P. Roberts and E. J. Garboczi, "Computation of the linear elastic properties of random porous materials with a wide variety of microstructure," Proceedings of the Royal Society of London, vol. 458, no. 2021, pp. 1033-1054, 2002.

[51] M. Weclas, "High velocity CR Diesel jet impingement on to porous structure and its utilization for mixture homogenization in I.C. engines," in Proceedings of the DITICE Workshop: Drop/Wall Interaction: Industrial Applications, Experiments and Modeling, Bergamo, Italy, May 2006.

[52] M. Weclas and R. Faltermeier, "Diesel jet impingement on small cylindrical obstacles for mixture homogenization by late injection strategy," International Journal of Engine Research, vol. 8, no. 5, pp. 399-413, 2007.

[53] M. Weclas, "Some fundamental observations on the Diesel jet destruction and spatial distribution in highly porous 
structures," Journal of Porous Media, vol. 11, no. 2, pp. 125144, 2008.

[54] M. Weclas, "Porous media in internal combustion engines," in Cellular Ceramics-Structure, Manufacturing, Properties and Applications, M. Scheffler and P. Colombo, Eds., Wiley-VCH, Cambridge, UK, 2005.

[55] W. Müller, "Kolben-Brennkraftmaschine," German Patent Application no. DE 2416804, 1975.

[56] W. C. Pfefferle, "Apparatus and method," US Patent no. 3,923,011, 1975.

[57] R. A. Haslett, “I.C. engine,” US Patent no. 4,092,967, 1978.

[58] R. M. Siewert, "Catalytic late direct injection spark ignition engine," US Patent no. 4,480,613, 1984.

[59] J. C. Firey, "Porous burner Diesel engine," US Patent no. 4,381,745, 1983.

[60] F. Durst and M. Weclas, "Verfahren und Vorrichtung zur Umwandlung von Wärme in Arbeit," German Patent no. 19753407, 1997.

[61] F. Durst and M. Weclas, "Method and device for converting heat into work," US Patent no. 6,125,815, 2000.

[62] E. Pott, "Verbrennungsmotor," German Patent Application no. DE 19857071, 2000.

[63] L. J. Gibson and M. F. Ashby, Cellular Solids, Structure \& Properties, Cambridge University Press, Cambridge, UK, 1999.

[64] K. Vafai and M. Sozen, "Analysis of energy and momentum transport for fluid flow through a porous bed," Journal of Heat Transfer, vol. 112, no. 3, pp. 690-699, 1990.

[65] G. Brenner, K. Pickenäcker, O. Pickenäcker, D. Trimis, K. Wawrzinek, and T. Weber, "Numerical and experimental investigation of matrix-stabilized methane/air combustion in porous inert media," Combustion and Flame, vol. 123, no. 12, pp. 201-213, 2000.

[66] F. Durst and M. Weclas, "A new type of internal combustion engine based on the porous-medium combustion technique," Journal of Automobile Engineering, vol. 215, no. 1, pp. 63-81, 2001.

[67] F. Durst and M. Weclas, "A new concept of IC engine with homogeneous combustion in porous medium (PM)," in Proceedings of the 5th International Symposium on Diagnostics and Modelling of Combustion in Internal Combustion Engines (COMODIA '01), Nagoya, Japan, July 2001.

[68] J. J. Hwang, G. J. Hwang, R. H. Yeh, and C. H. Chao, "Measurement of interstitial convective heat transfer and frictional drag for flow across metal foams," Journal of Heat Transfer, vol. 124, no. 1, pp. 120-129, 2002.

[69] Y. Ge, L. Chen, F. Sun, and C. Wu, "Thermodynamic simulation of performance of an Otto cycle with heat transfer and variable specific heats of working fluid," International Journal of Thermal Sciences, vol. 44, no. 5, pp. 506-511, 2005.

[70] P. Cheng and H. Zhu, "Effects of radial thermal dispersion on fully-developed forced convection in cylindrical packed tubes," International Journal of Heat and Mass Transfer, vol. 30, no. 11, pp. 2373-2383, 1987.

[71] A. B. Duncan, G. P. Peterson, and L. S. Fletcher, "Effective thermal conductivity within packed beds of spherical particles," Journal of Heat Transfer, vol. 111, pp. 831-836, 1989.

[72] S. B. Sathe, R. E. Peck, and T. W. Tong, "Flame stabilization and multimode heat transfer in porous radiant burners: a numerical study," Combustion Science and Technology, vol. 70, pp. 93-109, 1990.

[73] R. Echigo, "Radiation enhanced/controlled phenomena of heat and mass transfer in porous media," in Proceedings of the 3rd ASME/JSME Thermal Engineering Joint Conference, vol. 4, pp. 21-32, March 1991.

[74] R. Siegel and J. R. Howell, Thermal Radiation Heat Transfer, Hemisphere, Washington, DC, USA, 3rd edition, 1992.

[75] L. B. Younis and R. Viskanta, "Experimental determination of the volumetric heat transfer coefficient between stream of air and ceramic foam," International Journal of Heat and Mass Transfer, vol. 36, no. 6, pp. 1425-1434, 1993.

[76] A. A. Mohamad, S. Ramadhyani, and R. Viskanta, "Modelling of combustion and heat transfer in a packed bed with embedded coolant tubes," International Journal of Heat and Mass Transfer, vol. 37, no. 8, pp. 1181-1191, 1994.

[77] A. Amiri and K. Vafai, "Analysis of dispersion effects and non-thermal equilibrium, non-Darcian, variable porosity incompressible flow through porous media," International Journal of Heat and Mass Transfer, vol. 37, no. 6, pp. 939-954, 1994.

[78] G. J. Hwang and C. H. Chao, "Heat transfer measurement and analysis for sintered porous channels," Journal of Heat Transfer, vol. 116, no. 2, pp. 456-464, 1994.

[79] M. Varahasamy and R. M. Fand, "Heat transfer by forced convection in pipes packed with porous media whose matrices are composed of spheres," International Journal of Heat and Mass Transfer, vol. 39, no. 18, pp. 3931-3947, 1996.

[80] R. A. Wirtz, "A semi-empirical model for porous media heat exchanger design," in Proceedings of the American Society of Mechanical Engineers National Heat Transfer Conference, vol. 349, pp. 155-162, Baltimore, Md, USA, August 1997.

[81] M. Kaviany, Principles of Heat Transfer in Porous Media, Springer, New York, NY, USA, 2nd edition, 1999.

[82] V. V. Calmidi and R. L. Mahajan, "Forced convection in high porosity metal foams," Journal of Heat Transfer, vol. 122, no. 3, pp. 557-565, 2000.

[83] A. A. M. Oliveira and M. Kaviany, "Nonequilibrium in the transport of heat and reactants in combustion in porous media," Progress in Energy and Combustion Science, vol. 27, no. 5, pp. 523-545, 2001.

[84] J. J. Hwang, G. J. Hwang, R. H. Yeh, and C. H. Chao, "Measurement of interstitial convective heat transfer and frictional drag for flow across metal foams," Journal of Heat Transfer, vol. 124, no. 1, pp. 120-129, 2002.

[85] F. A. L. Dullien, Porous Media: Fluid Transport and Pore Structure, Academic Press, New York, NY, USA, 1979.

[86] D. P. Jones and H. Krier, "Gas flow resistance measurements through packed beds at high Reynolds number," Journal of Fluids Engineering, vol. 105, no. 2, pp. 168-173, 1983.

[87] C. Satik, M. Parlar, and Y. C. Yortsos, "A study of steady-state steam-water counterflow in porous media," International Journal of Heat and Mass Transfer, vol. 34, no. 7, pp. 17551771, 1991.

[88] P. M. Adler, Porous Media, Geometry and Transports, Butterworth-Heinemann, Boston, Mass, USA, 1992.

[89] M. J. Hall and J. P. Hiatt, "Exit flows from highly porous media," Physics of Fluids, vol. 6, no. 2, pp. 469-479, 1994.

[90] B. V. Antohe, J. L. Lage, D. C. Price, and R. M. Weber, "Experimental determination of permeability and inertia coefficients of mechanically compressed aluminum porous matrices," Journal of Fluids Engineering, vol. 119, no. 2, pp. 404-412, 1997.

[91] V. Starikovicius, "The multiphase flow and heat transfer in porous media," Report Fraunhofer-Institut für Techno- und Wirtschaftsmathematik ITWM 55, 2003.

[92] M. D. Innocentini, P. Sepulveda, and F. Santos Ortega, "Permeability," in Cellular Ceramics: Structure, Manufacturing, 
Properties and Applications, M. Scheffler and P. Colombo, Eds., Wiley-VCH, Cambridge, UK, 2005.

[93] A. A. Korzhavin, V. A. Bunev, R. KH. Abdullin, and V. S. Babkin, "Flame zone in gas combustion in an inert porous medium," Combustion, Explosion, and Shock Waves, vol. 18, no. 6, pp. 628-631, 1982.

[94] G. A. Lyamin and A. V. Pinaev, "Combustion regimes for gases in an inert porous material," Combustion, Explosion, and Shock Waves, vol. 22, no. 5, pp. 553-558, 1987, Translated from: Fizika Goreniya $i$ Vzryva, vol. 22, no. 5, pp. 64-70, 1986.

[95] P. F. Hsu, J. R. Howell, and R. D. Matthews, "Numerical investigation of premixed combustion within porous inert media," in Proceedings of the 3rd ASME/JSME Thermal Engineering Joint Conference, vol. 4, pp. 225-231, Reno, Nev, USA, March 1991.

[96] D. Trimis and F. Durst, "Combustion in a porous mediumadvances and applications," Combustion Science and Technology, vol. 121, no. 1-6, pp. 153-168, 1996.

[97] V. S. Babkin, A. A. Korzhavin, and V. A. Bunev, "Propagation of premixed gaseous explosion flames in porous media," Combustion and Flame, vol. 87, no. 2, pp. 182-190, 1991.

[98] D. Trimis, "Stabilized combustion in porous mediaapplications of the porous burner technology in energy- and heat-engineering," in Proceedings of the FLUIDS Conference and Exhibit, Denver, Colo, USA, 2000, AIAA-2000-2298.

[99] M. Weclas and J. Cypris, "Distribution-nozzle" concept: a method for Diesel spray distribution in space for charge homogenization by late injection strategy," in Proceedings of the 23rd Annual Conference on Liquid Atomization and Spray Systems (ILASS '10), Brno, Czech Republic, September 2010, Paper no. ID ILASS10-40.

[100] T. Fend, D. Trimis, R. Pitz-Paal, B. Hoffschmidt, and O. Reutter, "Thermal properties," in Cellular Ceramics: Structure, Manufacturing, Properties and Applications, M. Scheffler and P. Colombo, Eds., Wiley-VCH, Cambridge, UK, 2005.

[101] S. T. Gulati and A. Schneider, "Mechanical strength of cellular ceramic substrates," in Proceedings of the Ceramics for Environmental Protection, Cologne, Germany, December 1988.

[102] R. W. Rice, Porosity of Ceramics and Its Effects on Properties, Marcel Dekker, New York, NY, USA, 1998.

[103] R. W. Rice, "Mechanical properties," in Cellular Ceramics: Structure, Manufacturing, Properties and Applications, M. Scheffler and P. Colombo, Eds., Wiley-VCH, Cambridge, UK, 2005.

[104] H.-P. Martin and J. Adler, "Design of electrical and thermal properties for liquid phase sintered silicon carbide," in Proceedings of the Symposium K5 Multifunctional Ceramics, Materials Week, Munich, Germany, 2001.

[105] H.-P. Martin and J. Adler, "Electrical properties," in Cellular Ceramics: Structure, Manufacturing, Properties and Applications, M. Scheffler and P. Colombo, Eds., Wiley-VCH, Cambridge, UK, 2005.

[106] M. Weclas, "Verfahren zum Verbrennen von Brennstoff und Brennraum," German Patent Application no. DE 10135062, 2003.

[107] A. Basara and M. Weclas, "Structural analysis of burner combustion systems," in Proceedings of the Workshop on the Effective Methods of Energy Conversion and Relevant Measurement Techniques, Sarajevo, Bosnia, November 2002.

[108] A. Pereira and A. A. Oliveira, "Analysis and experiment of the combustion with excess enthalpy in porous media," in Proceedings of the European Combustion Meeting, 2003.
[109] S. B. Sathe, M. R. Kulkarni, R. E. Peck, and T. W. Tong, "An experimental and theoretical study of porous radiant burner performance," in Proceedings of the 23rd International Symposium on Combustion, pp. 1011-1018, The Combustion Institute, 1990.

[110] P.-F. Hsu, J. R. Howell, and R. D. Matthews, "Numerical investigation of premixed combustion within porous inert media," ASME Journal of Heat Transfer, vol. 115, pp. 744-750, 1993.

[111] F. Durst, M. Keppler, and M. Weclas, "Air-assisted nozzle applied to very compact, ultra-low emission porous medium oil-burner," in Proceedings of the 3rd Workshop on SPRAY, Lampoldshausen, Germany, 1997.

[112] V. V. Martynenko, R. Echigo, and H. Yoshida, "Mathematical model of self-sustaining combustion in inert porous medium with phase change under complex heat transfer," International Journal of Heat and Mass Transfer, vol. 41, no. 1, pp. 117-126, 1998.

[113] S. Mößbauer, O. Pickenäcker, K. Pickenäcker, and D. Trimis, "Application of the porous burner technology in energyand heat-engineering," in Proceedings of the 5th International Conference on Technologies and Combustion for a Clean Environment (Clean Air V), vol. 1, pp. 519-523, Lissabon, Portugal, July 1999, Paper 20.2 "Application of Porous Media to Combustion Processes I".

[114] I. Malico and J. C. F. Pereira, "Numerical predictions of porous burners with integrated heat exchanger for household applications," Journal of Porous Media, vol. 2, no. 2, pp. 153162, 1999.

[115] O. Pickenäcker, A. Kesting, and D. Trimis, "Novel low $\mathrm{NO}_{\mathbf{x}}$ burner design for boilers and furnaces by using staged combustion in inert porous media," in Proceedings of the 5th European Conference on Industrial Furnaces and Boilers (INFUB '00), Espinho-Porto, Portugal, April 2000.

[116] O. Pickenäcker and D. Trimis, "Experimental study of a staged methane/air burner based on combustion in a porous inert medium," Journal of Porous Media, vol. 4, no. 3, pp. 197213, 2001.

[117] M. Kaviany, "In cylinder-thermal regeneration: porous-foam engine regenerator," in Principles of Heat Transfer in Porous Media, Springer, New York, NY, USA, 1999.

[118] M. Weclas, Non-Stationary High Velocity Jet Impingement on Small Cylindrical Obstacles, Sonderdruck Schriftenreihe University of Applied Sciences in Nuernberg, 2008.

[119] H. L. MacLean and L. B. Lave, "Evaluating automobile fuel/propulsion system technologies," Progress in Energy and Combustion Science, vol. 29, no. 1, pp. 1-69, 2003.

[120] F. Zhao, M. C. Lai, and D. L. Harrington, "Automotive sparkignited direct-injection gasoline engines," Progress in Energy and Combustion Science, vol. 25, no. 5, pp. 437-562, 1999.

[121] R. Lindgren and I. Denbratt, "Modelling gasoline spraywall interaction-a review of current models," SAE Technical Paper 2000-01-2808, 2000.

[122] S. S. Sazhin, "Advanced models of fuel droplet heating and evaporation," Progress in Energy and Combustion Science, vol. 32, no. 2, pp. 162-214, 2006.

[123] F.-Q. Zhao and M.-C. Lai, “The spray characteristics of automotive port fuel injection-a critical review," SAE Technical Paper 950506, 1995.

[124] M. R. O. Panão and A. L. N. Moreira, "Flow characteristics of spray impingement in PFI injection systems," Experiments in Fluids, vol. 39, no. 2, pp. 364-374, 2005.

[125] M. Weclas, "Vorrichtung und Verfahren zur Homogenisierung des Gemisches bei der Verteilung von Flüssigkeiten 
insbesondere bei der Kraftstoffeinspritzung," German Patent Application no. DE 4,480,613, 2006.

[126] M. Weclas, "Homogenization of liquid distribution in space by Diesel jet interaction with porous structures and small obstacles," in Proceedings of the 22nd European Conference on Liquid Atomization and Spray Systems, Como, Italy, September 2008.

[127] F. Durst and M. Weclas, "Porous Medium (PM) combustion technology and its application to internal combustion engines: a new concept for a near-zero emission engine," in Applied Optical Measurements, M. Lehner and D. Mewes, Eds., Springer, New York, NY, USA, 1999.

[128] M. Weclas, "Potential of porous medium combustion technology as applied to internal combustion engines," Sonderdruck Schriftenreihe Fachhochschule Nürnberg, no. 32, 2005.

[129] M. Weclas, "New strategies for homogeneous combustion in I.C. engines based on the porous medium (PM)-technology," ILASS Europe, June 2001.

[130] M. Weclas, Strategy for Intelligent Internal Combustion Engine with Homogeneous Combustion in Cylinder, Sonderdruck Schriftenreihe University of Applied Sciences in Nuernberg, 2004.

[131] C. Chevalier, W. J. Pitz, J. Warnatz, C. K. Westbrook, and H. Melenk, "Hydrocarbon ignition: automatic generation of reaction mechanisms and applications to modelling of engine knock," Proceedings of the Combustion Institute, vol. 24, pp. 93-101, 1992.

[132] K. Lucka and H. Köhne, "Usage of cold flames for the evaporation of liquid fuels," in Proceedings of the 5th Conference on Technologies and Combustion for a Clean Enviroment, pp. 207-213, Lisbon, Portugal, July 1999.

[133] D. Grebner, J. Hein, W. Triebel, A. Burkert, J. König, and C. Eigenbrod, "2D-fast-scan cool-flame diagnostic using formaldehyde-LIF excited by XeF excimer laser radiation," in Proceedings of the Joint Meeting of Combustion Institute, pp. 485-487, Nancy, France, May 1999.

[134] A. Naidja, C. R. Krishna, T. Butcher, and D. Mahajan, "Cool flame partial oxidation and its role in combustion and reforming of fuels for fuel cell systems," Progress in Energy and Combustion Science, vol. 29, no. 2, pp. 155-191, 2003.

[135] N. Peters, G. Paczko, R. Seiser, and K. Seshadri, “Temperature crossover and non-thermal runaway at two-stage ignition of n-heptane," Combust Flame, vol. 128, pp. 38-59, 2003.

[136] D. M. Wang and A. P. Watkins, "Numerical modeling of Diesel spray wall impaction phenomena," International Journal of Heat and Fluid Flow, vol. 14, no. 3, pp. 301-312, 1993.

[137] J. Senda, M. Kobayashi, S. Iwashita, and H. Fujimoto, "Modeling of Diesel spray impingement on a flat plate," SAE Technical Paper 941894, 1994.

[138] J. Senda, H. Fujimoto, M. Kobayashi, K. Yamamoto, and Y. Enomoto, "Heat transfer characteristics of a Diesel spray impinging on a wall," Journal of the Marine Engineering Society in Japan, vol. 29, no. 10, 1995.

[139] C. Bai and A. D. Gosman, "Development of methodology for spray impingement simulation," SAE Technical Paper 950283, 1995.

[140] C. Mundo, M. Sommerfeld, and C. Tropea, "Droplet-wall collisions: experimental studies of the deformation and breakup process," International Journal of Multiphase Flow, vol. 21, no. 2, pp. 151-173, 1995.

[141] S. Lee and H. Ryou, "Modeling of spray-wall interactions considering liquid film formation," in Proceedings of the 8th
International Conference on Liquid Atomization and Spray Systems, pp. 586-593, Pasadena, Calif, USA, 2000.

[142] O. R. Grover Jr. and D. N. Assanis, "A spray wall impingement model based upon conservation principles," in Proceedings of the 5th International Symposium on Diagnostics and Modelling of Combustion in Internal Combustion Engines (COMODIA '01), Nagoya, Japan, July 2001.

[143] E. Berg, "DIME validation of spray-wall interaction models," in Proceedings of the DIME Workshop, Valencia, Spain, 2003.

[144] C. Arcoumanis, M. Gavaises, and B. French, "Effect of fuel injection process on the structure of Diesel sprays," SAE Technical Paper 970799, 1997.

[145] C. W. Park and M. Kaviany, "Evaporation-combustion affected by in-cylinder, reciprocating porous regenerator," Journal of Heat Transfer, vol. 124, no. 1, pp. 184-194, 2002.

[146] K. Hanamura, K. Bohda, Y. Miyairi, and R. Echigo, "Heat engine with reciprocating super-adiabatic combustion in porous media," in Proceedings of the International Congress \& Exposition, Detroit, Mich, USA, February 1997, SAE Techhnical Paper no. 970201.

[147] K. Hanamura and S. Nishio, "A feasibility study of reciprocating-flow super-adiabatic combustion engine," in Proceedings of the 6th ASME-JSME Thermal Engineering Joint Conference, 2003, Paper no. TED-AJ03-547.

[148] A. J. Ferrenberg, "Low heat rejection regenerated enginesa superior alternative to turbocompounding," SAE Technical Paper 940946, 1994.

[149] A. Ferrenberg and B. E. Williams, "Progress in the development of the regenerated Diesel engine," SAE Technical Paper 961677, 1996.

[150] A. J. Ferrenberg, "Regenerative internal combustion engine," US Patent no. 4,790,284, 1988.

[151] A. J. Ferrenberg, "The single cylinder regenerated internal combustion engine," SAE Technical Paper 900911, 1990.

[152] F. Ruiz, "Analysis of the 3rd generation IC-stirling engine," SAE Technical Paper 2005-01-3462, 2005.

[153] F. Ruiz, "A first look into the regenerative engine," SAE Technical Paper 890473, 1989.

[154] F. Ruiz, "Regenerative internal combustion engine. Part I. Theory," Journal of Propulsion and Power, vol. 6, no. 2, pp. 203-208, 1990.

[155] F. Ruiz, "Regenerative internal combustion engine. Part II. Practical configurations," Journal of Propulsion and Power, vol. 6, no. 2, pp. 209-213, 1990.

[156] S. Thyageswaran and F. Ruiz, "Time-dependent analysis of the regenerative engine cycle," SAE Technical Paper 900912, 1990.

[157] F. Durst, M. Weclas, and S. Mößbauer, "A new concept of porous medium combustion in I.C. engines," in Proceedings of the International Symposium on Recent Trends in Heat and Mass Transfer, Guwahati, India, 2002.

[158] M. Weclas, J. Cypris, and T. M. A. Maksoud, "Combustion of Diesel sprays under real-engine like conditions: analysis of low- and high-temperature processes," in Proceedings of the 23rd Annual Conference on Liquid Atomization and Spray Systems (ILASS '10), Brno, Czech Republic, September 2010, Paper no. ID ILASS10-39. 

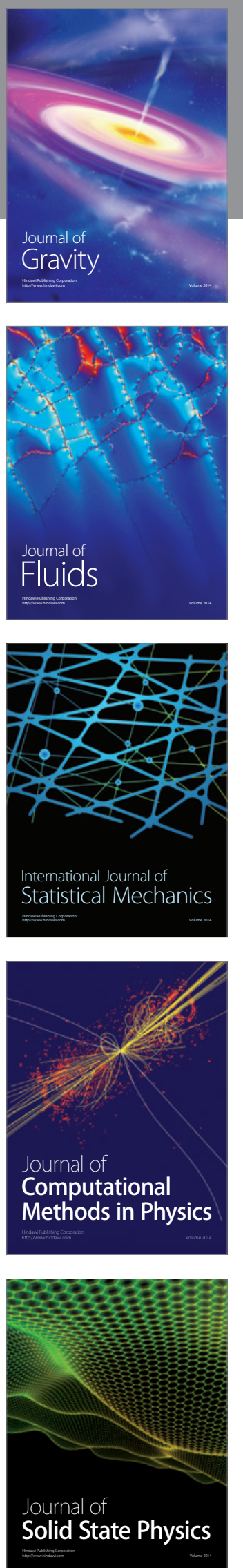

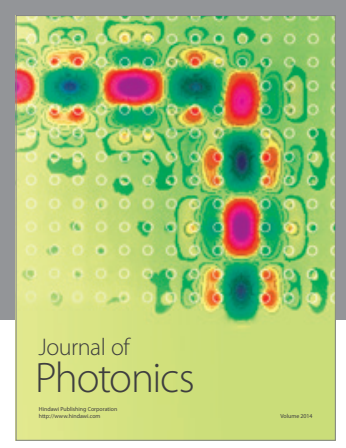

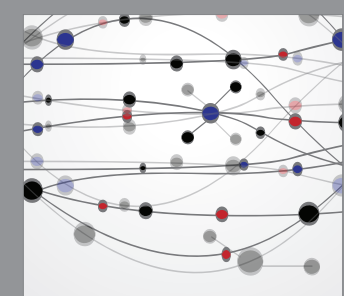

The Scientific World Journal
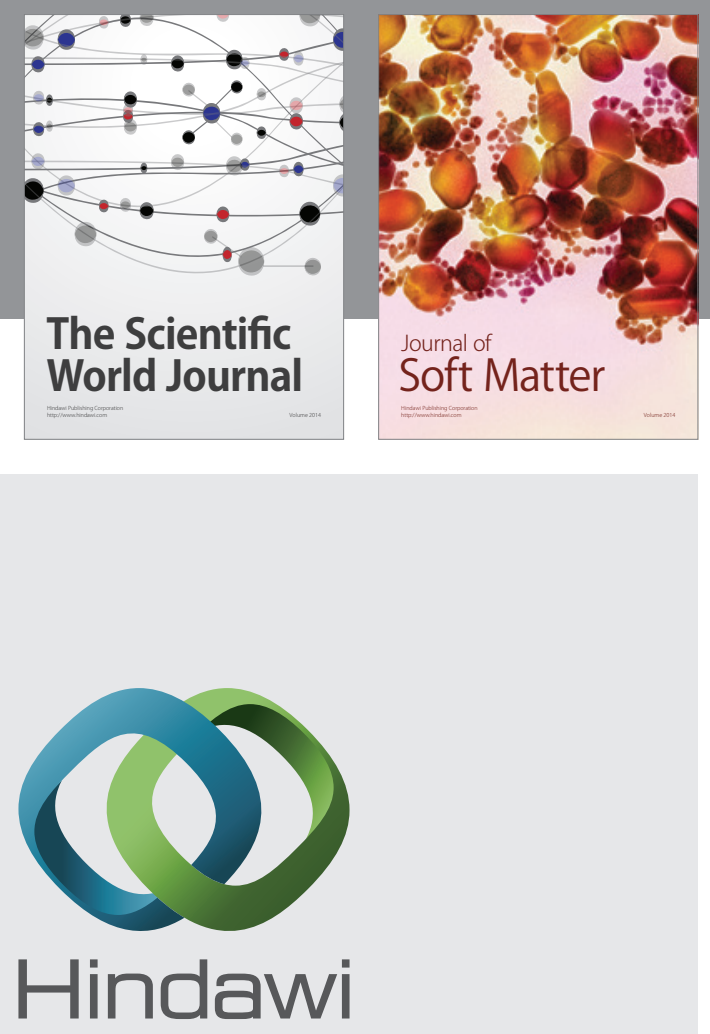

Submit your manuscripts at

http://www.hindawi.com
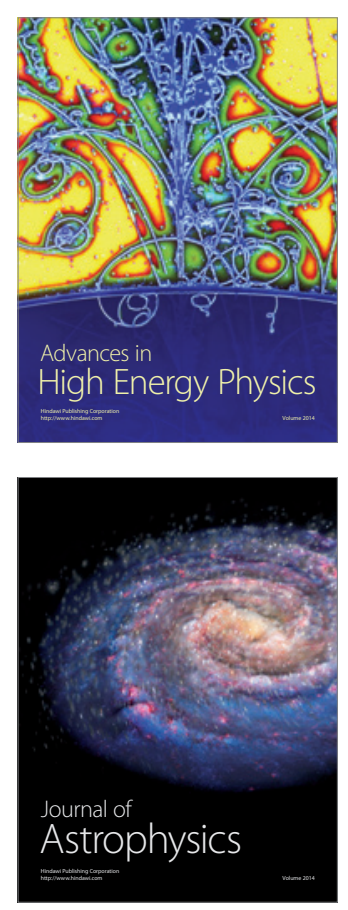
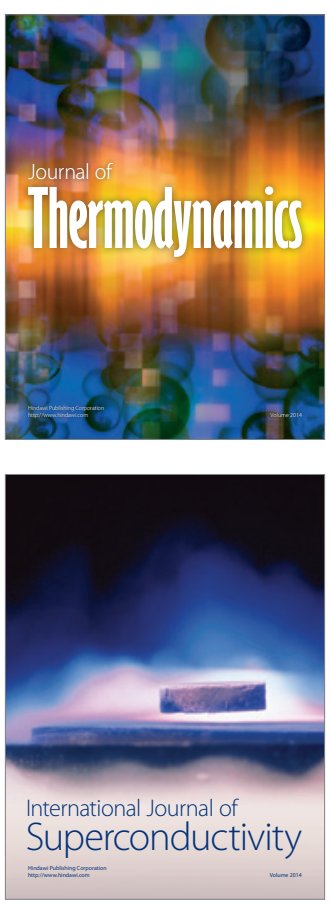
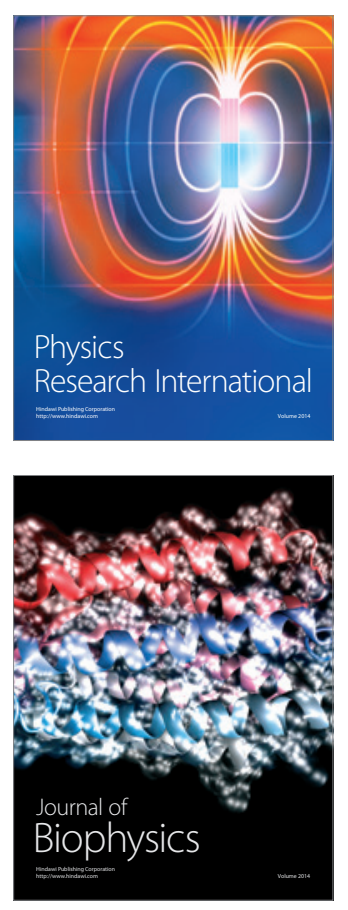
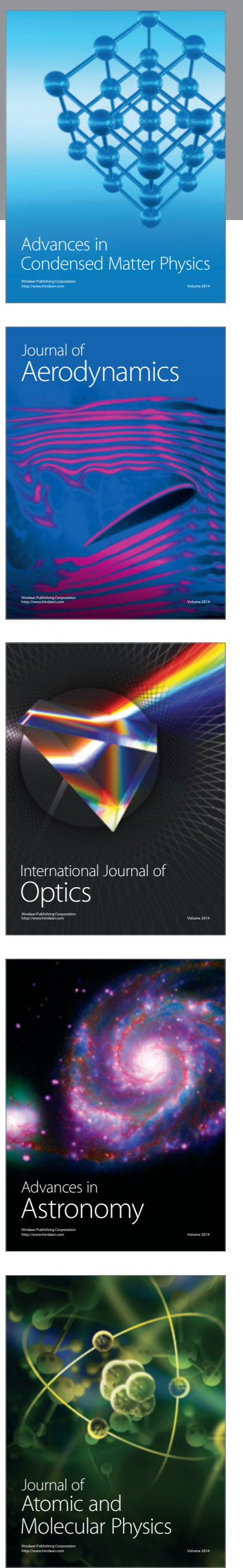